\title{
AZAR Y LIBERTAD
}

Tesis para optar al título de Magíster en Ciencias Sociales Presenta: Jennifer Ortiz Vanegas Director: Dr. Ariel Viguera
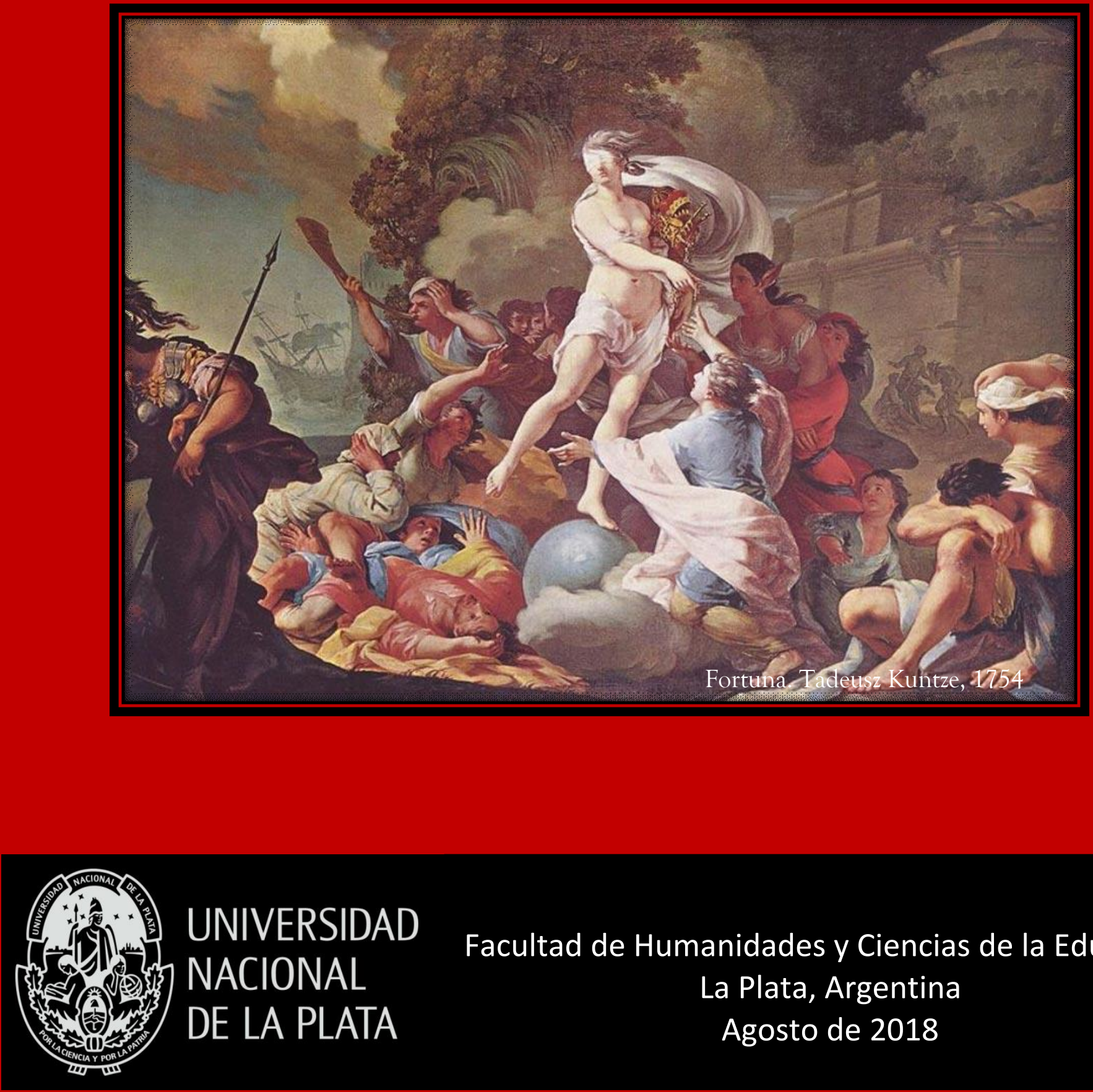

Facultad de Humanidades y Ciencias de la Educación La Plata, Argentina Agosto de 2018 


\title{
AZAR Y LIBERTAD
}

Tesis para optar al título de Magíster en Ciencias Sociales

\author{
Presenta \\ Jennifer Ortiz Vanegas \\ Psicóloga de la Universidad de Antioquia
}

\author{
Director \\ Doctor Ariel Viguera \\ Profesor Titular Ordinario de la Facultad de Psicología UNLP
}

Maestría en Ciencias Sociales

Facultad de Humanidades y Ciencias de la Educación

Universidad Nacional de La Plata

Agosto de 2018 
A mis padres

no sólo por la vida

por ser la inspiración para vivirla 


\section{Agradecimientos}

Al Ministerio de Educación de la República Argentina y al Consejo de Decanos de Facultades de Ciencias Sociales y Humanas por otorgarme la oportunidad de continuar mi formación profesional y personal en uno de sus claustros. A la Universidad Nacional de La Plata, especialmente al coordinador de la Maestría en Ciencias Sociales, el Dr. Martín Retamozo, y a las secretarias Catalina Curciarello y Marina Illanes, porque con su amabilidad y diligencia facilitaron y amenizaron mi experiencia en el posgrado. A los profesores de la maestría por ser los guías que me enseñaron algunos senderos por los cuales empezar a transitar ese basto terreno de las ciencias sociales.

A mi asesor, el Doctor Ariel Viguera, porque a pesar del tiempo y la distancia siempre me ofreció respuestas cálidas y atentas. Con solo dos encuentros personales me transmitió la confianza de encontrar en él un lector curioso e indogmático; cualidades de las más valiosas para mí. Tanto es así que quiero agradecer a Lucía Soria por su solidaridad, su escucha atenta de mi deseo, su atinada recomendación y por ser el puente que posibilitara ese encuentro afortunado con mi asesor.

Al Profesor Carlos Arturo Ramírez, mi maestro, el más especial de los agradecimientos; su presencia y su discurso los siento en mi ser como un maravilloso don divino. A los miembros del grupo de investigación El método analítico, ese, el amplio, por todos los espacios, siempre formativos, que he tenido el privilegio de compartir con ellos: los grupos y proyectos de investigación, la tertulia, los grupos clínicos, de estudio y de lectura, los encuentros bipersonales y los retiros espirituales. Reunidos por el discurso (Logos) hemos compartido la aventura de irlo viviendo juntos; ser todos Dios, aunque nos sabemos diablos cada uno.

A mis padres y a mi hermano por transmitirme con su compañía cotidiana la fortaleza y la sencillez que se requiere para disfrutar la vida y por hacer de nuestra familia su más grande apuesta; su firme deseo de seguir jugando juntos el juego de vivir hace que se fortalezca el mío. Y a mis perritas, mi compañía inseparable en este largo y solitario proceso de escritura. 
A Sebastián que a cada paso me acompaña y apuesta decidido por mí; con su fe me motiva a creer un poco más en mí. También a su familia que siento como mía, por quienes me siento acompañada en la vida. A Natalia (Areiza, Ruiz, Torrez y Valencia) por acompañarme a buscar el disfrute y el sentido de la vida en los momentos en que es más difícil hallarlos. A Juan Felipe por sus palabras siempre oportunas, cálidas y tan afines a mí. A Fanny Naranjo por su fe en mis proyectos.

A mis compañeros en Argentina a quienes recuerdo con especial cariño: Mairaya López, Julián Londoño, Juliana Díaz, Andrea Raina, Amado, Marly, Leandro, Calo, Johana Silva, César Camacho, Juan Pablo Bravo, Daniela Lizama, Mariana Ríos, Nacho Allevi, Paula Tagliabue. También a las amigas que llegué a sentir como mi familia en Argentina: Wanda, Ángela y Sara.

A Logos, a Caos, al Nosotros, al Tao, al I Ching, donde he hallado nuevamente una dimensión posible de lo sagrado. 


\section{Contenido}

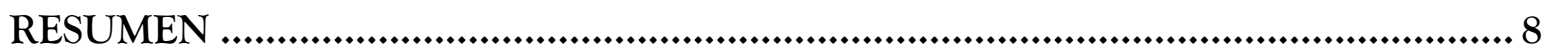

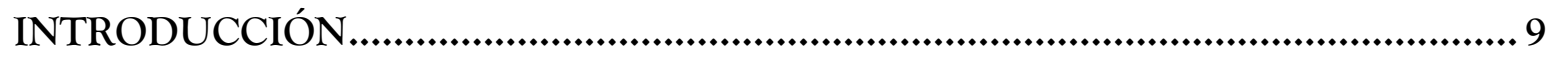

CAPÍTULO I

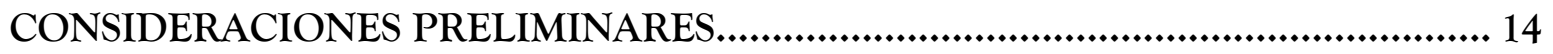

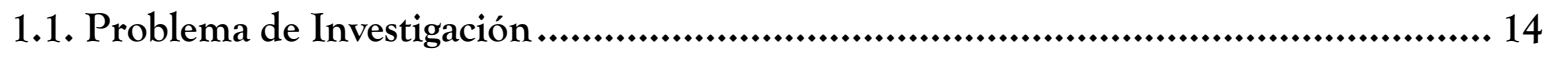

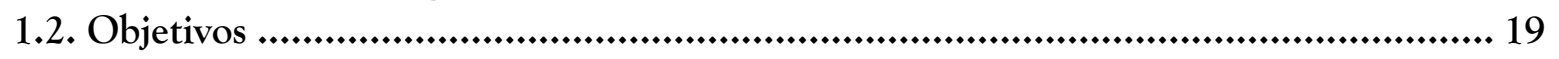

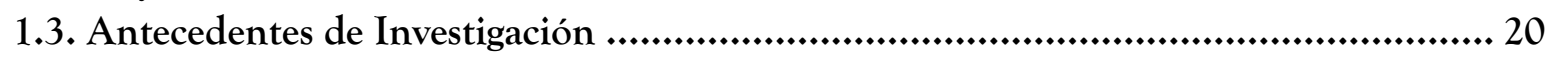

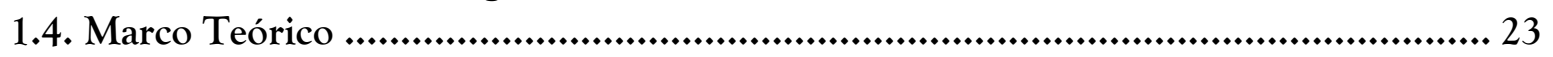

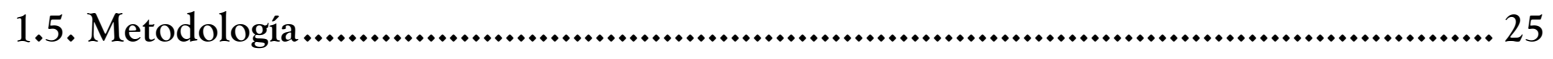

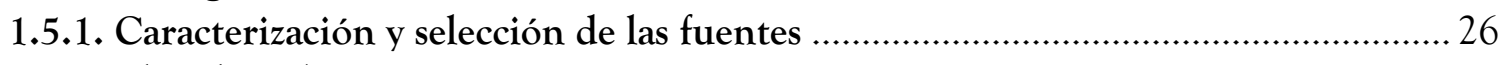

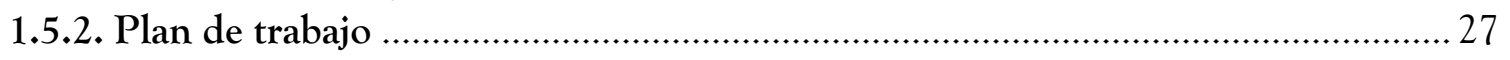

\section{CAPÍTULO II}

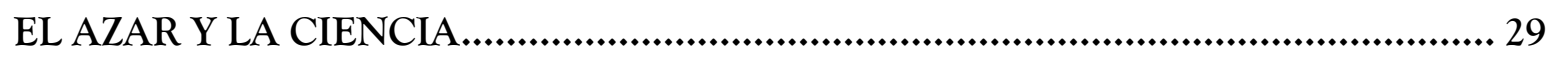

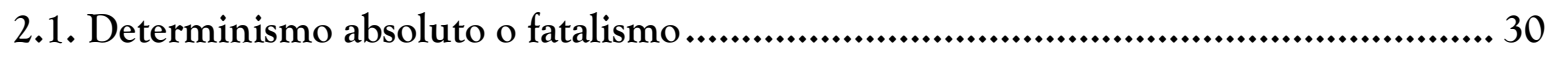

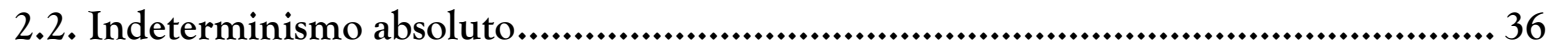

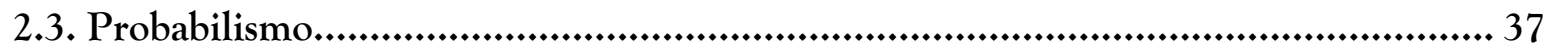

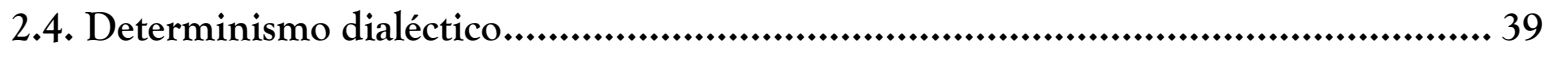

2.5. Sustentación del determinismo dialéctico: el azar en la ciencia contemporánea......... 41

2.6. Elección, emergencia y niveles de realidad ............................................................. 57

CAPÍTULO III

DETERMINISMO Y AZAR EN EL PROYECTO CIENTÍFICO DE FREUD .................6 65

3.1. El determinismo del proyecto científico freudiano......................................................6 65

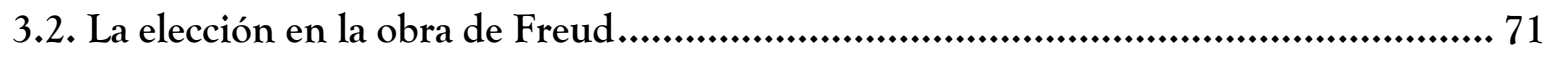

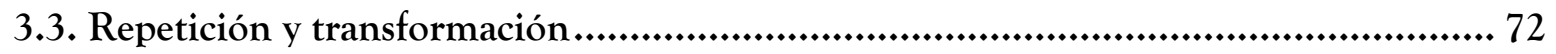

3.4. Azar como accidente y azar como ausencia de causas................................................. 79

3.5. El problema del determinismo psíquico y la libertad de volición. ................................ 83 


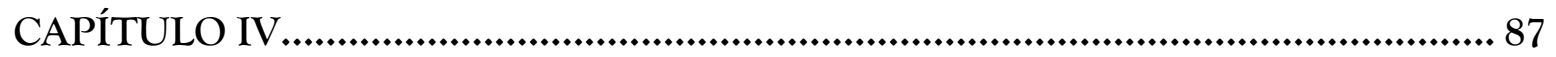

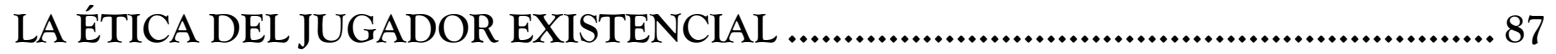

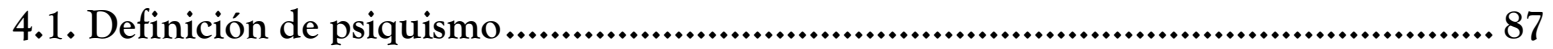

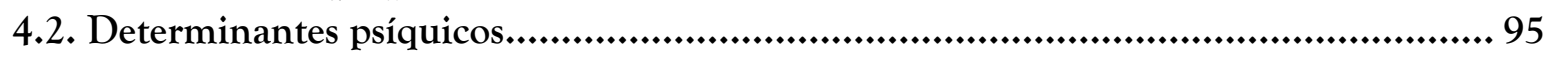

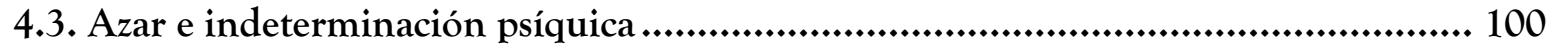

4.4. La elección en las grietas del determinismo...................................................... 112

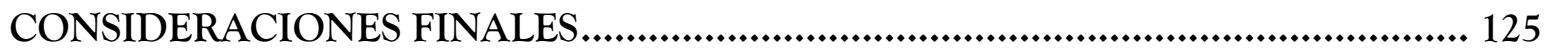

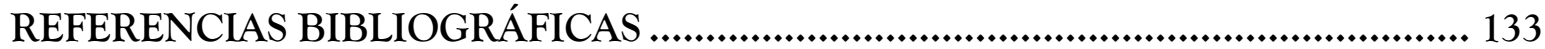




\section{Resumen}

Los conceptos de determinación y azar son retomados y problematizados en esta investigación, en la que se indaga la posibilidad y las implicaciones de contar con el azar y la elección subjetiva como factores causales de lo psíquico. Este problema de investigación es abordado desde la perspectiva del matemático y psicoanalista Carlos Arturo Ramírez, cuya obra sirve de marco para investigar cuestiones como: ¿qué noción de azar hay en su obra y qué fundamentos filosóficos, epistemológicos y científicos tiene?, ¿cómo se aborda desde su teoría la causalidad psíquica?, ¿en qué consiste su propuesta de la elección subjetiva, la responsabilización y la ética del jugador existencial?, ¿qué implicaciones tiene este planteamiento en la práctica de disciplinas como la psicología y el psicoanálisis?

El abordaje metodológico utilizado es cualitativo, específicamente la investigación documental con un enfoque hermenéutico. Puesto que la investigación documental presupone la revisión de los conceptos básicos que componen una idea o teoría, en este caso se revisan y fundamentan las nociones de azar, causalidad psíquica y elección en la obra de Ramírez. Además de los conceptos ya mencionados, se establecieron tres categorías de análisis: los fundamentos epistemológicos del azar, la cuestión del determinismo psíquico y la dimensión ética y existencial de la propuesta de Ramírez.

Palabras claves: determinismo, azar, libertad, elección.

\section{Abstract}

This paper addresses and problematizes the concepts of determinism and randomness to probe the possibility and implications of taking them and subjective choices into account as causal factors of the psyche. This research problem is dealt with from the mathematician and psychoanalyst Carlos A. Ramirez perspective, whose essays serve as the framework to inquire into issues, such as: the notion of randomness and the philosophical, epistemological, and scientific foundations are embedded in his work; the development of the psychic causality in his theory; how his proposals of subjective choice, responsabilization and the existential player ethics are elaborated and applied to the psychology and psychoanalysis fields.

The methodological approach is qualitative, more precisely a documentary research with a hermeneutical approach. Since documentary research requires a revision of the main concepts that constitute a theory, in this case refers to the notions of randomness, psychic causality and choice in Ramirez's work. Furthermore, 3 categories of analysis were developed: the epistemological foundations of randomness, the problem of the psychic determinism and the ethical and existential dimensions in Ramirez's work.

Keywords: determinism, randomness, freedom, choice. 


\section{Introducción}

Hay autores, muy pocos, que crean teorías y, con ellas, revoluciones científicas. Hay autores que van llenando los vacíos de las teorías de otros. Hay autores que comparan teorías. Hay autores que recolectan datos sobre las teorías y hay autores que son críticos, francotiradores de teorías. Todos estos lugares son importantes para hacer avanzar el conocimiento. Los enuncio para disculparme, de entrada, porque no hay en esta tesis una innovación científica; encuentro mi lugar entre quienes apenas alcanzan a comparar las teorías de los grandes autores y ponerlas a dialogar.

Tampoco soy escritora, simplemente tengo vocación de aprendiz y de docente: de acompañar a otros en su proceso de formación al mismo tiempo que avanzo en la mía. Y es esta vocación la que me ha llevado a plasmar las ideas de esta tesis, no con el propósito de construir una gran y suntuosa edificación teórica, sino de tender puentes que nos permitan transitar por el conocimiento que ha ido construyendo la humanidad.

Esta investigación no aspira ni alcanza a recoger todo lo dicho sobre el azar, un tema clásico de controversia que recorre todas las épocas de la humanidad: desde los filósofos antiguos pasa por los doctores de la iglesia en la Edad Media, llega a la ciencia moderna y se revoluciona en la contemporánea. Por eso el propósito de este trabajo es modesto: sistematizar los planteamientos de autores cercanos al pensamiento de Carlos Arturo Ramírez sobre el azar, que con sus obras han acompañado y fundamentado las discusiones y la tradición de nuestro grupo de investigación $E l$ método analítico, del cual este trabajo es fruto.

Es entonces un texto hecho para ser cuestionado y completado por los lectores que seguramente tendrán una posición personal sobre este tema y podrán confrontarla con las ideas que aquí se exponen, y que seguramente conocerán otros autores con otros argumentos sobre el tema. jAbierto queda siempre el debate!

El azar es un asunto existencialmente confrontador. Yo misma me vi continuamente confrontada por este insondable tema del que nada definitivo se puede concluir. De hecho, lo característico de esta tesis es que se retoman y relacionan un conjunto de conceptos que están en los límites de lo que nuestra razón puede concebir: el azar, la 
incertidumbre, la suerte, la fortuna, el destino, la casualidad y la causalidad, una noción que hemos construido, como dice Francis Halbwachs (1977), para intentar dar cuenta del misterio que entraña la producción de los fenómenos.

No es extraño que la representación más reconocida que tenemos de la Tyché (suerte, fortuna, azar) sea ciega. Asocio esta imagen, por supuesto, con la aleatoriedad de sus apariciones, que unas veces nos favorece y otras nos perjudica, pero también con la oscuridad del tema, lo difícil que es iluminarlo y la facilidad con que se cierra sobre sí mismo. La elaboración de esta tesis me producía con frecuencia una sensación de vértigo cuando intentaba pensar, entender, nombrar, explicar y argumentar justamente lo que por definición no podemos saber: el azar. Por eso disculpo y comprendo a los lectores, porque yo más que nadie reconozco lo abstruso del tema, el grado tan alto de dificultad que entraña y la disposición anímica que exige su abordaje.

Digo que el abordaje de este tema requiere una disposición anímica especial por lo siguiente: cuando leía los argumentos deterministas me llegaba a sentir persuadida, me sentía determinista; cuando leía los argumentos a favor del azar me sentía convencida de su existencia, y no hay ninguna prueba última para dirimir el debate. Por eso estar dispuestos a transitar los distintos lugares y mirar la realidad desde ellos es fundamental para formar un criterio y reducir el riesgo de rechazar un lugar $u$ otro por simple prejuicio, pues como dice Ramírez:

El azar es uno de los conceptos más difíciles de aceptar para el pensamiento racional: muchos son deterministas radicales aunque crean en el libre albedrío; prefieren profesar ideas tan absurdas como la de los dos mundos paralelos (sensible e inteligible) antes que aceptar cualquier grado de indeterminación. Pero es tal vez la angustia que genera la libertad la que nos incita a crear barreras que nos protejan de la responsabilidad, de la mayoría de edad (Ramírez, 2011a, sec. 305. Azar como subversión, p. 279).

Tuve entonces que hacer el ejercicio espiritual de abrirme para concebir en mí las diversas posiciones y sustentar finalmente una tesis, la del determinismo dialéctico, que implica asumir la existencia del azar, la libertad, la elección, la responsabilidad y la ética. Una tesis es justamente eso, una proposición que se sustenta con razonamientos.

Un eje transversal de esta investigación es la perspectiva evolucionista. Pensar este mundo como producto de la evolución hace que se desdibujen las divisiones del conocimiento en disciplinas, pues esta teoría evidencia cada vez más las estructuras que se repiten en la realidad física, orgánica y psíquica y los errores en los que se puede caer cuando se concibe la psicología independientemente de los eslabones previos de la evolución. Esta visión evolucionista, al mismo tiempo, nos ayuda a reconocer lo específico de cada nivel de la realidad. 
Tal como lo concibe Ramírez, el azar es transversal a todas las estructuras de la realidad, es decir, está presente desde el origen del Cosmos hasta su evolución en seres conscientes. Fundamenta esta hipótesis en los hallazgos de matemáticos, físicos, químicos, biólogos, neurólogos, psicólogos, psicoanalistas y filósofos contemporáneos, sin mencionar las elaboraciones clásicas, modernas y místicas que también han sido un importante referente para su obra.

Una tesis que se propone sistematizar los fundamentos de esta hipótesis implica entonces un recorrido por todas estas áreas del conocimiento. Debido a eso, lo que caracteriza este trabajo de investigación es el continuo diálogo que se establece entre los autores de las distintas disciplinas, es como un congreso en el que intervienen matemáticos, físicos, químicos, biólogos, neurólogos, psicólogos, psicoanalistas y filósofos, todos dejando oír su voz a propósito del azar.

De este modo se complejiza aún más la lectura de este trabajo, pues obliga a conversar en varios dialectos. Así sentí el proceso de investigación y de escritura, como un difícil reto de aprender varios idiomas a la vez y entender la manera en que cada autor hablaba del azar para captar cuándo había semejanzas y cuándo diferencias, para encontrar las relaciones, por ejemplo, entre la Tyché en Aristóteles y lo circunstancial en Freud; lo preindividual en Simondon y lo peculiar en Ramírez; la flexibilidad biológica en Elias y la indeterminación en Luria; los sistemas abiertos en Ilya Prigogine y en Bleichmar.

Quizá la forma de esta tesis, como diálogo transdisciplinario, exprese una tendencia del conocimiento en la actualidad, donde las fronteras se conciben porosas, borrosas o incluso ilusorias. Hay un interés cada vez más generalizado en los científicos por articular las ciencias naturales, no solo con las sociales y humanas, también con la mística y la espiritualidad, una separación que se efectuó tajantemente en la modernidad. Este propósito de articular distintas teorías sobre la realidad por supuesto que tiene riesgos: los sobrentendidos en la comunicación o los diálogos de sordos, y exige que los investigadores cultiven en sí mismos unas cualidades muy especiales: el escepticismo y al mismo tiempo la receptividad, el indogmatismo, el desprejuiciamiento, la docta ignorancia, la curiosidad, la ingenuidad y la capacidad de asombro. Es indudablemente un proyecto más complejo, pero si se confía en el largo plazo llegará a ser muy fructífero. Así expresa el psicólogo Sigmar Malvezzi en una entrevista esta tendencia al diálogo entre las ciencias: "No soy más psicólogo, soy multidisciplinario". Cada vez son menos los investigadores o docentes que se empeñan en mantenerse enclaustrados en su pequeña parcela de conocimiento y la protegen celosamente de la influencia de otros saberes, al presentir que tendrían que replantear sus anquilosadas teorías si conocieran otras ideas propuestas en esos saberes aparentemente lejanos al suyo. Aun así, poder elaborar y presentar las ideas controversiales de este trabajo me parece un gran avance en dirección al diálogo riguroso, una tendencia que deliberadamente quiero favorecer: 
Atreverse a hablar de imparcialidad, de teleonomía, ya es un avance grande; pero realizarlos, aplicarlos en la experiencia, es un proyecto ético. Retomar los conceptos de teleonomía, de espiritualidad, de alma, con las resonancias religiosas y dogmáticas que ensombrecieron el pensamiento filosófico durante milenios, es un acto de osadía, quizás inaudito, pero que abre esperanzas para los evolucionistas que no quieren dormir plácidamente en el dulce placer de la inercia tanática.

[...] A pesar de todo, es importante que ciertos conceptos, ideas nuevas (quizás ideologías) empiecen a aparecer en diversos ámbitos: eso muestra un cambio en el espíritu de la época. Cada vez son más los objetores del despotismo, y los que prefieren el indeterminismo y la incertidumbre de la libertad y el libre albedrío, a la cómoda modorra de la obediencia y la esclavitud. Esto se vuelve más importante cuando los tiranos se despersonalizan: ya no son reyes ni generales, son organizaciones y empresas transnacionales, de las cuales una máquina simbólica se ha apoderado, cuyos fines mercantiles y de competitividad subordinan cualquier interés humano. Es a esta máquina, que se ha constituido en un verdadero régimen que somete y esclaviza, al que hay que hacerle frente con la apuesta por una posibilidad de elección, de construcción de nuestro destino (Ramírez, 2011a, sec. 369. Constructivismo analítico, p. 311).

\section{El itinerario}

En el primer capítulo se presentan las consideraciones preliminares y formales de esta investigación. El problema de investigación, los objetivos propuestos, los antecedentes de la pregunta, el marco teórico que ha servido como punto de partida y la metodología que orientó la consulta y revisión de las fuentes.

En el segundo capítulo se presentan las distintas posiciones que frente a la cuestión del azar se pueden asumir, y en ese recorrido se muestra el devenir de este concepto desde la ciencia moderna a la contemporánea. Una de las posiciones frente al azar es el determinismo dialéctico, la hipótesis central y transversal a toda la tesis, y que en este capítulo es desarrollada y sustentada desde las ciencias naturales. Es quizás el capítulo más denso por su contenido epistemológico y los conceptos retomados de la matemática, la física, la química y la biología; por eso recurro, en ocasiones, a un tono jovial, intentando exponerlos de la manera más comprensible que me fue posible.

El problema del azar se traslada al ámbito psíquico en el tercer capítulo, en el cual se indaga el lugar que tiene en la obra de Freud, si aun contando con la compulsión a la repetición y las determinaciones inconscientes, que parecen conducir el destino del ser humano, es concebible la libertad, la elección y la transformación subjetiva. Estas indagaciones derivan en el clásico debate entre el determinismo y la libertad de volición, sobre el que se presentan algunas ideas.

El propósito del cuarto capítulo es presentar y sustentar las propuestas de Ramírez sobre el psiquismo y sus determinaciones. Concebir el azar y la elección como factores que determinan la configuración psíquica y el destino, da paso al desarrollo de la 
propuesta ética del jugador existencial, una propuesta que por su mismo contenido invita a un estilo más suelto, ligero e incluso literario.

Y para terminar, algunas consideraciones finales, mas no conclusiones, pues ya lo hemos dicho: nada conclusivo puede decirse sobre este nebuloso tema. Comencemos... 


\section{CAPÍTULO I \\ Consideraciones Preliminares}

...fue entonces cuando decidi buscar la ayuda de los pensadores del pasado. Después de todo, iacaso autores seguramente más inteligentes que yo, filósofos y políticos, sabios y escritores, no habrian debatido la misma cuestión, desde tiempos inmemoriales? Y, si analizaba su pensamiento, ino iba a poder aprovechar su inteligencia? Así fue como pasé del plano de los acontecimientos al de la reflexión (Nosotros y los otros, Todorov, 2009, p. 13)

\subsection{Problema de investigación}

El debate académico que da lugar a la pregunta de esta investigación puede presentarse desde dos ejes, uno teórico y otro práctico.

El eje teórico tiene que ver con los cambios que se han dado en la ciencia en el último siglo al cuestionar los presupuestos modernos y considerar la validez de conceptos como relatividad, complejidad, incertidumbre, caos, azar y fractalidad, debido a descubrimientos científicos en física, química, biología, genética, neurología... (Capra, 1998; Gell-Mann, 1995; Hofstadter, 1987; Kimura, 1986; Landsberg et al., 1986; Mandelbrot, 1996; Monod, 1993; Penrose, 2012, 1999, 2007, 2011; Prigogine \& Stengers, 1990; Wagensberg, 1994, 2007). Paradójicamente, con el propósito exacerbado de dominar, controlar, predecir y manipular la naturaleza, la vida y la sociedad la ciencia se ha topado con el azar, con lo indeterminado, con la incapacidad de prever los resultados y de remitirlos a causa alguna.

Estos avances suponen un cambio radical en los fundamentos de la ciencia y en la forma de ver el mundo, pues se ponen en cuestión los presupuestos objetivistas, positivistas y deterministas de la ciencia moderna, que ya habían sido cuestionados también por filósofos, epistemólogos y científicos sociales (Adorno et al., 1973; Balandier, 1998; Capra, 1992; Feyerabend, 1974; Gibbons et al., 1997; Habermas, 
1982, 1992, 2015; Hanson, 1997; Kuhn, 1992, 1982; Manrique, 2008; Morin, 2005; Penrose, 1999, 2007, 2011, 2012, Polanyi, 1962, 1967, Popper, 1972, 1973, 1974, 1985, 1997, 2003). Sin embargo, persiste la pregunta, quizá irresoluble, por la existencia de un azar ontológico o epistemológico. Estas cuestiones han dado lugar a varias y divergentes posturas filosóficas y epistemológicas: el indeterminismo, el determinismo absoluto (fatalismo), el probabilismo y el determinismo dialéctico (Ramírez, 2012).

La ciencia moderna parte del supuesto de un determinismo natural, ontológico, es decir, que a todos los fenómenos que se presentan en la naturaleza les subyace una causa. Según este modelo (causa-efecto) la labor de la ciencia consiste en develar las leyes (causas) que rigen la naturaleza y sus fenómenos (efectos). El determinismo supone que lo que establece el fin de un proceso es la totalidad de las causas eficientes y que el número de causas es finito y puede conocerse con exactitud, por eso cualquier tipo de proceso es, en teoría, predecible. Entonces, a partir del conocimiento de las causas se podría conocer también el estado pasado, presente y futuro de cualquier fenómeno. Lo interesante es que esta afirmación no es un hecho demostrado, sino una suposición filosófica. La base del determinismo es filosófica, no empírica (Duque Martínez, Lasso Toro, \& Orejuela Gómez, 2011, pág, 138).

La identificación de la mecánica con la física tiene como presupuesto la concepción de la naturaleza como máquina. Con la aplicación del modelo mecanicista de explicación a cuanta cosa hay, tanto a lo inorgánico como a lo orgánico, se impone una pretensión monopólica que convierte tal modelo mecanicista en el paradigma científico, el cual, desde el comienzo de la época moderna, determina el pensamiento occidental y se apodera cada vez más de otros dominios de la cultura. Precisamente por el hecho de que el paradigma mecanicista se ha elevado hasta convertirse en un modelo estructural universal, puede hablarse con todo derecho de una ideologización (Gloy, 1993).

Suponer que todo fenómeno tiene como antecedente una causa venía siendo una hipótesis fecunda para avanzar en el conocimiento de la realidad, que ya actualmente se reconoce compleja, no lineal, como un entramado de relaciones o interconexiones, más que como una máquina conformada por partes separadas o unidades aislables. La causalidad, la naturaleza determinada, las leyes universales, absolutas han caído como ideales de la ciencia moderna, "el mundo ordenado, progresivo, racionalmente controlable, ha caído con las ilusiones del siglo" (Bleichmar, 1994, pág. 11).

El paso de un modelo determinista a modelos complejos, sistémicos, abiertos, caóticos, azarosos, aleatorios... ha implicado que no sólo las ciencias naturales, sino también las ciencias sociales, interroguen y replanteen sus conceptos, su ontología, su metodología, su epistemología y sus paradigmas, de tal modo que sean acordes con los nuevos descubrimientos. En el caso del psicoanálisis, más específicamente, se trata de interrogar una teoría sobre el funcionamiento del psiquismo que surgió en medio de una concepción determinista del mundo y del ser humano. Entonces, a la luz de estos nuevos modelos, ¿cómo plantear las nociones de determinismo, azar y causalidad 
psíquica en la teoría psicoanalítica? La vigencia de esta pregunta fue lo que animó el coloquio realizado en 1994 Temporalidad, determinación y azar. Lo reversible y lo irreversible, y ha animado a muchos autores a pensar y proponer ideas al respecto. Tal como afirma Luis Hornstein, "a un siglo de la fundación del psicoanálisis, confrontarlo con nuevas formas de pensamiento no sólo es legítimo sino imprescindible" (1994, pág. 97).

Extrañamente, han sido los físicos, biólogos, neurólogos, matemáticos, científicos de la computación, más que los psicólogos, quienes han renovado el interés por el estudio de la consciencia desde una perspectiva compleja y transdisciplinaria, al considerarla un sistema con una estructura análoga a la de las partículas subatómicas, en el que tal vez se repliquen los fenómenos y procesos que se dan en ese nivel de la realidad, pues en el estudio del funcionamiento cerebral se formulan preguntas similares a las que surgen en el estudio del universo subatómico, entre ellas, la posibilidad o no de controlar, predecir y reproducir el funcionamiento de dichos sistemas, de conocer sus causas, las leyes bajo las cuales se rigen, si es que las tienen, y la dificultad de pensar en términos de cosas, partículas y aislar unidades allí donde sólo se ven relaciones (Damasio, 1994, 2010, Dennett, 1995, 2005; Duque Martínez et al., 2011; Llinás, 2003; Lopera, 2007; Penrose, 1999, 2011, 2012).

Las implicaciones de estos cambios teóricos y epistemológicos dan lugar al segundo eje en torno al cual se establece el problema de esta tesis, el eje práctico, pues los planteamientos teóricos sobre el determinismo y el azar actualizan perennes cuestiones filosóficas sobre la libertad y la responsabilidad del ser humano, sus posibilidades de elegir, de transformación en el ámbito personal (psicológico), social, económico y político (sociológico). Dicho así puede parecer una pregunta anacrónica, pero ha sido una inquietud vigente en grandes pensadores del último siglo, tales como Karl Popper, Jean Paul Sartre, Erich Fromm, Michel Foucault, Roger Penrose, Daniel Dennett, Hugo Zemelman entre muchos otros. Dice Compton:

La cuestión fundamental de la moralidad, que constituye no sólo un problema religioso vital, sino también un tema de activa investigación científica es: ¿Es el hombre un agente libre?

Si los átomos que componen nuestros cuerpos obedecen a leyes físicas tan inmutables como los movimientos de los planetas, ¿por qué esforzarse?, ¿qué puede importar la magnitud de nuestro esfuerzo, si nuestros actos ya están predeterminados por leyes matemáticas? (citado en Popper, 1974, pág. 203).

El planteamiento determinista excluye la posibilidad de eventos emergentes, sin causa, aleatorios o azarosos, llevando a una concepción fatalista del mundo, pues no hay nada que pueda emerger y cambiar el curso ya determinado de los acontecimientos. Si se aborda el estudio del hombre desde los mismos presupuestos de la ciencia moderna este carecería de libertad (posibilidad de elegir más allá de las determinaciones) y, en consecuencia, no sería responsable de sus acciones. Es lo que 
defienden autores como Watson y Skinner, quien no acepta la existencia del azar (véase Frager y Fadiman, 2010, p. 251). En su libro Más allá de la libertad y la dignidad (1987) Skinner presenta una propuesta para construir una sociedad mejor y más feliz basada en los principios de la ingeniería de la conducta, de la que podría ser un buen ejemplo la ficción Un mundo feliz de Aldous Huxley. Skinner niega la existencia de la dignidad humana porque implica una falsa noción de causalidad y de responsabilidad, ya que tener o no dignidad supone que la causa de la conducta es interna y que el hombre es responsable de su conducta, cuando en realidad, dice Skinner, está completamente determinada por el ambiente, por tanto, no habría razones para castigar o elogiar a alguien por sus conductas. Argumenta que la creencia en la autonomía y la libertad del hombre, es decir, creer en la existencia de acciones libres de algún tipo de control, obstaculiza el progreso de una tecnología eficaz de la conducta y el diseño de una cultura hecha a la medida del hombre y planeada por la ciencia.

Presuponer que el ser humano es libre de elegir cómo responder ante las situaciones que afronta y es, por tanto, responsable de sus elecciones es el fundamento de la práctica clínica y está en la base de conceptos como el de resiliencia: la capacidad que tiene el ser humano de superar las circunstancias traumáticas o adversas, salir de ellas fortalecido, sin resentimiento y de modificar aspectos de su vida que le causan sufrimiento en la relación con el mundo y con los otros. Una razón más para fundamentar la importancia y vigencia de esta pregunta de investigación.

Por otro lado, continúa vigente el debate sobre el determinismo en psicología, pues algunas corrientes psicológicas sobrevaloran los aspectos biológicos o socioculturales al momento de explicar el comportamiento, desconociendo otros factores que están en juego en la conducta humana. Se podría pensar que este es un debate cerrado, sin embargo, en el auge de la medicalización y sobrevaloración del determinismo biológico para explicar la psicopatología y el malestar contemporáneo, es importante resituar la pregunta por la elección subjetiva en la teoría y la práctica clínica, e indagar hasta qué punto es válido contar con ella como un factor influyente y determinante en el destino del ser humano.

Sin desconocer la incidencia de los factores biológicos y discursivos, Carlos Arturo Ramírez incluye el azar como otro de los factores determinantes de la realidad y, en particular, del psiquismo, lo que da lugar a otro factor determinante y transversal a todos los demás: la elección subjetiva (Ramírez, 2012; Lopera, Manrique, Zuluaga, \& Ortiz, 2010; Lopera, Ramírez, Zuluaga, \& Ortiz, 2010; Lopera, 2016; Manrique, Lopera, Pérez, Ramírez, \& Henao, 2016; Ramírez et al., 2014). La posibilidad y las implicaciones de contar con el azar y, por ende, con la elección subjetiva como factores causales de lo psíquico es la inquietud que anima esta investigación.

El factor ocasional singular, en su relación con lo contingente, lo fortuito y lo aleatorio, da cabida a la elección individual, y es el punto de partida del libre albedrío, esto es, de la 
libertad de escoger y de la responsabilidad. Es el resultado de la confluencia de todos los factores singulares en un deseo subjetivo. Si no se admite esta posibilidad se cae en el fatalismo, pero si se sobrevalora con respecto a los otros cinco factores, en el voluntarismo, ya mencionado, reflejado por el dicho popular "querer es poder", o por la omnipotencia del deseo, típica del pensamiento mágico (Ramírez, 2012, sec. 10. Etiología psíquica, pág. 36).

En las actuales condiciones sociales, políticas y económicas de globalización (que es el nombre dado a la expansión y exacerbación del capitalismo), libre mercado, desregularización de capitales, flexibilización laboral, crisis paradigmáticas... muchos pensadores y científicos sociales (Bauman, 1992; Bleichmar, 2011; Bleichmar et al., 1994; Han, 2012, 2014, Llamazares, 2011, 2013, Simondon, 2007, 2009, 2013; Zemelman, 2007; Zizek, 2005) han persistido en la pregunta por las posibilidades que tiene el ser humano de afrontar los retos de este nuevo mundo y de incidir en el rumbo de los acontecimientos en un entorno avasallador que parece escapar del dominio humano individual. En una época en la que se proclama el azar, la libertad, el individualismo, la autonomía, el empoderamiento del sujeto, la reivindicación de minorías... el ser humano parece más alienado, más sometido a mecanismos de control sutiles y sofisticados, y menos dueño de su destino. El neoliberalismo ha logrado explotar la idea de libertad haciendo un manejo instrumental de ella, sometiendo al ser humano "libre" a condiciones de incertidumbre y precariedad tales que la libertad es a la vez un ideal y una amenaza, logrando así condicionar su forma de vivir, de trabajar, de consumir, de distribuir el tiempo. Ni el psicologismo ni el sociologismo son suficientes para pensar las limitaciones, posibilidades, determinaciones y paradojas humanas, pues sustancializan, por un lado, una estructura psíquica y, por otro lado, las condiciones socio-culturales, tomando sólo su vertiente alienante, limitante y de control.

De este contexto teórico y práctico del último siglo se desprenden las preguntas que dan lugar a esta tesis de maestría: las posibilidades individuales y colectivas de ir más allá de las determinaciones, ¿cómo pensar el determinismo, la causalidad psíquica, la libertad, la elección y la responsabilidad en este nuevo marco epistemológico que aporta la ciencia contemporánea: azar, caos, complejidad y fractalidad? Más específicamente, se abordarán estas cuestiones en la obra de Carlos Arturo Ramírez, con la conjetura de que en su obra puede hallarse un marco teórico a partir del cual tender un puente entre los planteamientos de la filosofía, la ciencia, el psicoanálisis y la dimensión ética, política y existencial del ser humano.

Uno de los puntos de partida de la propuesta de Ramírez es cuestionar la idea de azar que plantea Aristóteles en el libro La física con los conceptos de Tyché y Autómaton. De este planteamiento aristotélico surge la idea de las series causales, que es retomada por Freud para referirse a la sobredeterminación de los fenómenos psíquicos, y por Lacan para introducir su noción de azar en el psicoanálisis como encuentro contingente con lo real. Muchos otros psicoanalistas adhieren a esta idea de la concurrencia de series causales para explicar el azar en el psicoanálisis (Bernardi, 
1994; Hornstein, 1994). Por ello, se propone indagar en esta tesis ¿qué noción de azar hay en la obra de Carlos Arturo Ramírez?, ¿cómo se aborda desde su teoría la causalidad psíquica?, ¿en qué consiste su propuesta de la elección subjetiva, la responsabilización y la ética del jugador existencial?, ¿cuáles son los fundamentos filosóficos, epistemológicos y psicoanalíticos de esta propuesta?, ¿qué implicaciones tiene este planteamiento en la práctica de disciplinas como la psicología y el psicoanálisis?

El alcance de esta investigación al abordar estas preguntas, y particularmente este autor, es poder desplazar el foco de análisis desde las determinaciones a las posibilidades, a las líneas de fuga, a los resquicios, las grietas que aparecen entre las determinaciones y los saberes (lo transdiciplinario), poder trascender la dicotomía del determinismo sociedad-individuo, tal como lo plantea Norbert Elias en su ensayo $L a$ sociedad de los individuos (1990), por no contar con marcos teóricos, formas de pensar, lenguajes y metáforas lo suficientemente dúctiles para representar de otra manera esta relación: ¿la sociedad está determinada por los individuos o el individuo está determinado por la sociedad? Al indagar conceptos como el de determinación y azar en la obra de Carlos Arturo Ramírez, quizá se abran nuevas vías para dar respuesta a estos interrogantes.

\subsection{Objetivos}

\subsubsection{Objetivo general}

- Analizar y fundamentar las nociones de azar, causalidad psíquica y elección en la teoría de Carlos Arturo Ramírez.

\subsubsection{Objetivos específicos}

- Dilucidar los fundamentos filosóficos, epistemológicos y conceptuales de la propuesta de Ramírez sobre el azar.

- Contrastar las nociones de azar, causalidad psíquica y elección subjetiva de Ramírez con la causalidad psíquica propuesta por Freud.

- Identificar las implicaciones éticas (prácticas, políticas, existenciales) de la noción de azar, causalidad psíquica y elección que hay en la obra de Ramírez. 


\subsection{Antecedentes de investigación}

El psicoanálisis, dicho a grandes rasgos, además de un método de investigación y un tratamiento para la neurosis, es una teoría metapsicológica que explica el funcionamiento del aparato psíquico determinado por lo inconsciente. Freud, por su formación como neurólogo, siempre vislumbró en el horizonte que las explicaciones psicológicas que estaba adelantando a comienzos del siglo XX, en algún momento podrían remitirse a sus causas biológicas cuando el avance de la ciencia así lo permitiera. Pero una de las limitaciones de esa expectativa es que las cadenas causales de los fenómenos psíquicos son múltiples: lo constitucional biológico, lo históricosocial y los encuentros contingentes, accidentales. Dadas las múltiples causas que se superponen, Freud plantea los hechos psíquicos como sobredeterminados, remisibles a más de un factor causal, a una confluencia de factores causales.

Hay algo en los fundamentos del psicoanálisis que lo acerca marcadamente al espinozismo: el concepto de sobredeterminación. Esta noción, de que todo se halla psíquicamente sobredeterminado, o tendría que estarlo a poco que investigáramos, es algo que se sale del concepto lógico habitual de determinación, rompe con una concatenación parcial y establece las bases de una interrelación multidireccional (Andreas Salomé, 1984, pág. 70).

Desde los planteamientos realizados por Freud sobre la causalidad psíquica (Freud, 1910b, 1912, 1913a, 1913b), muchas investigaciones han abordado esta cuestión (Aguilera, 2003; Bilbao, 2006; Degrande, 2014; Freud, 1910b, 1912, 1913a, 1913b; Guerrero, 2009; Hansberg \& Platts, 2002; López, 2006; Muñoz, 2012; Patarroyo Gutierrez, 2009; Porras, 2007; Zapata, 2010) y, a su vez, han planteado la importancia de articular los postulados psicoanalíticos con otros saberes, tal como lo expresan Héctor Blas Lahitte, Maximiliano Azcona y Vicente Ortiz Oria en su artículo sobre la noción de causalidad en Sigmund Freud:

[...] importantes preguntas permanecen abiertas: ¿Podría el psicoanálisis seguir creyendo en la coherencia de un modelo teórico que se basa en la importación de hipótesis descartadas en las ciencias que la han aportado?, ¿es posible sostener una teoría psicoanalítica manteniendo algunos de los supuestos freudianos pero soslayando y reemplazando otros?, ¿hay en el psicoanálisis freudiano elementos suficientes para elaborar una concepción distinta respecto de la causalidad? Posiblemente, un esbozo coherente de respuesta a estas preguntas no pueda provenir exclusivamente de la tradición freudiana. Así como Freud se apoyó en la ciencia y filosofía de su época para fundamentar su propuesta teórica, el psicoanálisis actual podría relacionarse con los dominios cognoscitivos lindantes en la búsqueda de un saber diagonal respecto de lo humano (Blas Lahitte, Azcona, \& Ortiz Oria, 2013, pág. 72).

En el coloquio Temporalidad, determinación y azar. Lo reversible y lo irreversible (Bleichmar et al., 1994) se presenta un estado de la cuestión sobre el problema de la determinación y el azar en psicoanálisis. Ricardo Bernardi (1994) en su artículo Sobre el determinismo psíquico muestra un panorama de los problemas que afronta el psicoanálisis en la actualidad, uno de ellos se refiere a los límites del modelo 
determinista en el que se funda el psicoanálisis y el paso a la hipótesis de la sobredeterminación psíquica, cómo esta yuxtaposición de factores causales y la inclusión de lo accidental, lo contingente, los encuentros inesperados, tiene como efecto el azar, pues "una de las maneras de entender el azar es precisamente como el entrecruzamiento de series determinísticas alejadas entre sí: el azar se produce cuando el trayecto del caminante se cruza con el funcionamiento digestivo de la paloma en vuelo" (Bernardi, 1994, pág. 16). Cada uno de los factores determinantes, al superponerse, aumentan la complejidad de los fenómenos, haciendo prácticamente imposible predecir los efectos de tal yuxtaposición. La sola inclusión de lo contingente como factor causal deja un amplio margen a la indeterminación y dificulta la aplicación de un modelo determinista en el psicoanálisis. Sin embargo, para Ramírez la idea de azar (tyché, suerte) que deriva de la sobreposición de series causales, retomada de Aristóteles, no es propiamente azar (aleatoriedad). En el desarrollo de esta investigación se mostrará en qué consiste la diferencia entre los dos autores.

La noción de azar que se deriva de las series concurrentes -a la que recurrió Freud para explicar la sobredeterminación de la neurosis, el inconsciente y los fenómenos psíquicos - es retomada de Aristóteles. En síntesis, para Aristóteles cuando algo ocurre por suerte quiere decir que tiene una causa accidental, no elegida para tal fin, pero no quiere decir con ello que no tiene causa (azar). Es por esto que la noción de azar en Aristóteles es un azar blando, en oposición al azar duro, ontológico. También para Lacan la traducción de tyché como azar es inadecuada, pues se trata de un encuentro (siempre desafortunado) con lo real, que parece ser accidental, pero no que no sea causado. En cambio, autores como Simondon, Morin, Popper, Prigogine y Mandelbrot, entre otros, plantean una noción de azar fuerte, coherente con la teoría de los sistemas abiertos y complejos y con la idea de azar que propone Ramírez basado en la ciencia contemporánea.

El encuentro de series causales puede ser contingente, pero no aleatorio o azaroso; conceptos que en la teoría de Ramírez son diferenciados. En Lacan, en cambio, lo contingente, lo fortuito, es homologado a lo aleatorio: aparece una serie causal que complementa unas predisposiciones y crea una impronta a partir de la cual se elige el objeto sexual. En este punto es importante mencionar también la distinción que hace Ramírez entre determinismo a priori y determinismo a posteriori, argumentando que no es lo mismo la predicción que la retrodicción (Ramírez, 2012, p. 285-286), conceptos que tendremos la oportunidad de desarrollar en el avance de esta investigación.

Silvia Bleichmar analiza la cuestión del determinismo y el azar en tres categorías extraídas de la metapsicología freudiana: en la fundación de lo inconsciente, en la teoría de la libido y en la teoría de la psicogénesis de las neurosis. Plantea la existencia de lo azaroso-acontencial en el mismo sentido de concurrencia accidental de series causales, pero dice que el inconsciente incide como factor determinante en el modo en que lo nuevo se va enlazando al entramado constituido, por lo que concibe el aparato 
psíquico como un sistema abierto que se va transformando, bien sea por el análisis (en la clínica) o por lo vivencial (Bleichmar, 1994, pp. 51-52). No obstante, también funciona como sistema cerrado en tanto lo inscrito en él tiende a repetirse como compulsión en un intento de evacuar lo que no tiene salida. En el estudio que Ariel Viguera realiza sobre el concepto signos de percepción y su papel en el origen del psiquismo, propone que lo que abre la vía a cierta indeterminación psíquica es la capacidad de transformar la articulación de las representaciones a partir de nuevos procesos histórico-vivenciales (Viguera, 2013).

Aquí aparece un punto en el que coinciden los planteamientos de Freud, Lacan, Bleichmar, Viguera, Zemelman y Ramírez, al concebir la conformación del psiquismo como una dialéctica entre las determinaciones y el azar. En palabras de Freud:

\begin{abstract}
Nos negamos a estatuir una oposición de principio entre las dos series de factores etiológicos; más bien, suponemos una regular acción conjugada de ambas para producir el efecto observado. Disposición y azar determinan el destino de un ser humano; rara vez, quizá nunca, lo hace uno sólo de esos poderes. La distribución de la eficiencia etiológica entre ellos sólo se podrá obtener individualmente y en cada caso. La serie dentro de la cual se ordenen las magnitudes cambiantes de ambos factores tendrá también, sin duda, sus casos extremos. Según sea el estado de nuestros conocimientos, apreciaremos de manera diversa la parte de la constitución o del vivenciar en el caso singular, y nos reservaremos el derecho de modificar nuestro juicio cuando nuestras intelecciones cambien. Por otro lado, uno podría atreverse a concebir la constitución misma como el precipitado de los efectos accidentales sufridos por la serie infinitamente grande de los antepasados (Freud, 1998c, p. 97, notal al pie № 2).
\end{abstract}

A pesar de estas dificultades para conceptualizar la causalidad psíquica, una pregunta ineludible para el psicoanalista es qué le ocurre al paciente, a qué se debe lo que le ocurre (la etiología) y cómo se cura. Tal como lo expresa Luis Hornstein "entre el determinismo duro, por lo cual todo lo que acontecerá en el futuro está escrito en alguna parte, y la reivindicación del azar, los psicoanalistas deberíamos debatir acerca de la libertad, la creatividad, la responsabilidad, y la ética, y preguntarnos qué significan, qué implican estos términos y qué consecuencias acarrean en nuestra práctica” (Hornstein, 1994, p. 104). Por eso, el propósito de esta tesis es fundamentar, desarrollar e indagar la propuesta de un autor que desde la ciencia, la matemática, el psicoanálisis, la filosofía y la mística ha abordado el tema del determinismo y el azar, particularmente el determinismo psíquico, asuntos que tienen como trasfondo y como horizonte el tema de la libertad, la elección, la responsabilidad y la ética.

También es importante enmarcar esta pregunta en la tradición investigativa del grupo El método analítico ${ }^{1}$, que desde los años 80 ha venido estudiando y gestado una

1 El método analítico y sus aplicaciones en las ciencias sociales y humanas es un grupo de investigación constituido oficialmente en el año 2004, avalado por dos universidades colombianas, la Universidad de Antioquia y la Universidad EAFIT, reconocido por COLCIENCIAS en categoría A1 del Sistema Nacional de Ciencia, Tecnología e Innovación (ScienTI). En el año 2010 funda el pregrado en Psicología de la Universidad 
formulación teórica en torno al problema del determinismo y el azar en la filosofía, la ciencia y el psicoanálisis, basada principalmente en las ideas de Carlos Arturo Ramírez. Es importante entonces emprender una investigación que permita formalizar, sistematizar, fundamentar y contrastar algunas de las ideas en torno a este tema de recurrente interés para los integrantes del grupo de investigación y que son la base de sus prácticas en el campo clínico, organizacional y de la docencia.

\subsection{Marco teórico}

Si bien uno de los objetivos de esta investigación consiste justamente en explicitar y sistematizar las teorías y conceptos que sirven de fundamento a la noción de azar en la obra de Carlos Arturo Ramírez, es posible tomar como referente y punto de partida algunos autores que desde la filosofía y la ciencia han planteado una noción de azar en correspondencia con la que plantea Ramírez: lo azaroso sería una variable de la que se desconocen sus causas, que hace imprevisible el comportamiento de ciertos eventos dada su falta de regularidad (Gil \& Manrique, 2013; Lopera, 2016; Ramírez, 2012b).

Ilya Prigogine ha sido uno de los autores más reconocidos que ha planteado la existencia del azar en la naturaleza, incluyendo este concepto en los postulados ontológicos de la ciencia contemporánea a partir de sus estudios sobre las estructuras disipativas, a diferencia de la ciencia moderna que concebía todos los fenómenos regulados por leyes naturales (Landsberg et al., 1986; Prigogine \& Stengers, 1990).

Karl Popper $(1974,1985,1997)$ también ha planteado en diversos momentos de su obra que todo cuanto existe en el mundo tiene factores determinados e indeterminados. Lo determinado sería como un reloj totalmente predecible, mientras que lo indeterminado sería como una nube, que tiende a comportarse azarosamente. Tanto los sistemas "relojes" como los sistemas "nubes" son naturales. Para Popper (1974) el ser humano funciona de forma intermedia entre las nubes y los relojes, queriendo decir con ello que posee unos elementos determinados y otros indeterminados. El determinismo dialéctico, según Ramírez, no es la ausencia de determinaciones, sino su interacción con factores indeterminados, azarosos.

Desde un campo distinto, la matemática, Benoît Mandelbrot denomina azar benigno al que se presenta en casos que admiten cierta regularidad a partir de la aplicación de dos teoremas: teorema ergódico, conocido como la ley de los grandes números, y el teorema central límite o clásico. Es un azar benigno porque las fluctuaciones que se dan en fenómenos aislados son impredecibles, pero cuando se tienen en cuenta a gran escala o en grandes números tienden a converger en una regularidad. En este tipo de

EAFIT y desde el año 2012 funda y dirige la colección académica en psicología de la Editorial San Pablo, con difusión en más de 10 países. 
azar la predicción es inexacta pero el grado de indeterminación es aceptable. El azar salvaje (o maligno) sería aquel que se comporta sin ninguna regularidad y es, por tanto, impredecible. Como ejemplo estarían las fluctuaciones de los precios en la bolsa y la amplitud de frecuencia en algunos ruidos eléctricos. Para ilustrar la relación que se da entre el azar benigno y el maligno (o salvaje) dice que la diferencia entre ellos es la misma que hay entre un gas y un sólido, por ello se refiere a los distintos estados del azar. Un tercer estado del azar es el lento, cuya característica es que los fenómenos se desarrollan tan lentamente que es prácticamente imposible evidenciar su regularidad y terminan siendo impredecibles, como en los casos de azar salvaje.

El filósofo francés Gilbert Simondon, también basado en los conceptos de la ciencia contemporánea, plantea lo preindividual como un campo activo de posibilidades, "energía potencial de un sistema" (Simondon, 2012, p. 36) que actúa en los procesos de individuación y da lugar a nuevas estructuras. El individuo es concebido por Simondon como un sistema energético que está en evolución gracias a la fuerza preindividual que porta, sus potencialidades, lo no regulado y por tanto creativo. No sería posible el proceso de individuación si no se acepta la existencia del azar, que aparece en su obra como realidad preindividual, ausencia de finalidad, ausencia de necesidad, imprevisibilidad, incertidumbre, multiplicidad de posibilidades (Morizot, 2012).

En la concepción que el físico Jorge Wagensberg tiene de la realidad no desconoce que la naturaleza está regulada: estas regularidades se expresan como leyes; sin embargo, define ley como una restricción y no como una obligación, lo que deja un margen para el azar (lo indeterminado) y la elección. Sin embargo, el azar tiene dos límites: la imposibilidad, cuando hay demasiadas restricciones y un objeto se queda sin el resquicio mínimo necesario para existir, y el comportamiento único, cuando las restricciones son tan fuertes que sólo dejan margen para una sola cosa, no deja lugar a la incertidumbre, no se puede elegir ni seleccionar, en este caso la restricción se convierte en obligación. Utiliza la imagen del juego de ajedrez para ilustrar esta idea, donde cada pieza tiene unas casillas prohibidas y otras permitidas, mientras que los movimientos obligatorios ocurren por acumulación de prohibiciones:

En general, el jugador tiene libertad para escoger qué pieza mover y adónde quiere llevarla. Esta libertad es la que nos permite hablar con cierto sentido de la táctica o estrategia del jugador, de su genio, de su talento agresivo, conservador o combinatorio, de su creatividad, de su conocimiento de las aperturas, de su habilidad en los finales, de sus errores... Si las reglas fueran todas de obligación se jugaría siempre la misma partida. Si no hubiera ninguna restricción, ganarían siempre las blancas en la primera jugada... (Wagensberg, 2005, p. 30).

El azar o la incertidumbre es el terreno que queda libre de prohibiciones, y por la existencia de este territorio es que tiene sentido hablar de selección (natural, artificial y cultural). Pensar la ley como una prohibición que deja margen a la elección, estimula y promueve la creatividad, mientras que un mundo de obligaciones, completamente 
determinado, deja a nuestro cerebro sin trabajo, nos obliga a una vida sin sentido, sin margen para la creación ni la responsabilidad. Al ser ambas posiciones igualmente probables o indemostrables, tomar partido por la hipótesis de la existencia del azar en la constitución de la realidad y defenderla es para Wagensberg un asunto de creencia, mientras que para Ramírez es una apuesta, una conjetura a la que se le apuesta después de haber examinado sus consecuencias, pues se considera más fecundo suponer que hay azar, libertad y elección. Esto es lo que Ramírez denomina el criterio pragmático (2012, p. 33).

Ramírez concibe la realidad como un producto de las formaciones de lo aleatorio, aludiendo al planteamiento de Freud según el cual los hechos psíquicos son formaciones de lo inconsciente. En ambos casos se enfatiza la confluencia de diversos factores que dan lugar a nuevas formaciones. Significa esto que el azar no se presenta puro, sino en una aleación con la repetición que se manifiesta como regularidad. La dialéctica entre ambos consiste en que se transforman mutuamente en la interacción: se modifica lo regulado y se reduce el dominio de lo azaroso. El efecto que produce el azar sobre lo organizado es la emergencia de nuevas estructuras. Es así como operaría también la consciencia (Penrose, 2011) y lo que daría lugar a la libertad, la elección y la creatividad (Lopera, 2007).

En cuanto a la noción de causalidad psíquica, se toman como referencia los planteamientos de Freud sobre el azar y la sobredeterminación (Freud, 1910b, 1912, 1913a, 1913b) tal como se presentó en los antecedentes y la relectura que se hace de ellos a la luz del coloquio Temporalidad, determinación y azar. Lo reversible y lo irreversible (Bleichmar et al., 1994). Son estos los principales autores de referencia, que marcan las coordenadas teóricas de esta investigación y desde los cuales se tienden puentes hacia la obra de Carlos Arturo Ramírez.

\subsection{Metodología}

Para el desarrollo de este proyecto se propuso una investigación documental enmarcada dentro de un diseño de investigación cualitativa. La investigación documental se basa en la revisión de los conceptos básicos que componen una idea o teoría (Galeano, 2011). Consuelo Hoyos (2000) afirma que la investigación documental apunta a impugnar o mejorar el estatus científico de una teoría haciendo una revisión de ella o de alguna de sus partes, lo que requiere una disposición crítica del investigador frente a la teoría. En el caso de esta investigación, la revisión y fundamentación de algunos conceptos básicos de la propuesta de Ramírez sobre el azar (causalidad, determinación, azar, emergencia, causalidad psíquica, libertad, elección y responsabilidad) constituyó el eje central del trabajo, cuyo objetivo, en correspondencia con la investigación documental, fue construir el fundamento epistemológico que sostiene su andamiaje teórico (Galeano, 2011, p. 26). 
En la investigación documental se procede identificando y definiendo los conceptos o palabras clave que orientarán la investigación, así como las principales categorías de análisis, aunque estas sean provisionales y puedan irse modificando según el avance de la investigación. Los conceptos clave de esta investigación fueron: determinismo, azar, causalidad psíquica, libertad, elección y responsabilidad. Y con estas categorías de análisis como punto de partida se procuró dar cuenta de los antecedentes y fundamentos de la propuesta de Ramírez sobre el azar, pasando por la cuestión de la causalidad psíquica hasta la relación de esta propuesta con la dimensión ética y existencial.

Se aplicaron los criterios de validez de la investigación documental: fidelidad al texto, completud del campo semántico, coherencia y consistencia. Estos criterios se establecen con el fin de no limitar la investigación a recoger y sistematizar conceptos, sino también a generar crítica desde los vacíos, contradicciones, inconsistencias o posibles límites de la teoría que den lugar a miradas alternas o a nuevas propuestas que complementen los referentes de base (Vargas, 1988). Esta mirada crítica y propositiva que trasciende la recolección de datos es transversal a todo el trabajo de investigación, pero se evidencia especialmente al cuestionar en el primer capítulo la obsolescencia de los presupuestos de la ciencia moderna; al evidenciar en el segundo capítulo la diferencia que hay entre la noción de azar que se encuentra en Aristóteles y la que propone Ramírez y al llevar al límite, en el tercer capítulo, la pregunta por la elección no sólo autónoma, sino libre.

El enfoque metodológico utilizado se inscribe, por supuesto, dentro de la investigación cualitativa y que tenía el propósito de ayudar a elegir las estrategias metodológicas (Galeano, 2011, p.31); se trata del enfoque hermenéutico, con el cual, a partir de la interpretación, se buscaba la comprensión de los conceptos dentro de un marco teórico y una época específicas, sus relaciones con otros autores e incluso las valoraciones que subyacen a las distintas propuestas y elaboraciones teóricas, es decir, la dimensión pragmática del discurso. Este enfoque atravesó de principio a fin el trabajo investigativo, ya que en un trabajo de corte documental el análisis de los textos escritos obliga a implementar dicho enfoque.

\subsubsection{Caracterización y selección de las fuentes}

Se utilizaron fuentes primarias de información, referidas a los textos de Carlos Arturo Ramírez (libros y artículos) en los que aborda el tema del determinismo, el azar, la causalidad psíquica, la libertad, la elección y la responsabilidad: Apuntes (2008), Divagaciones (2007), Transficciones (2008b), Cavilaciones (2009), Ocurrencias (2010), Fragmentos (2011), La vida como un juego existencial. Ensayitos (2012), Errancias (2012a), Escorzos (2014), Fabulaciones (1999), El método científico en el psicoanálisis (1991), El espíritu científico (1996), El psicoanálisis: una ética (1994), El 
deseo en Freud (1985) y El sentido de la vida. Una aproximación axiológica (Ramírez \& Saavedra, 1981).

Como fuentes secundarias se utilizaron textos basados en la obra del profesor Ramírez, en los que se analiza y también se discute la posición del autor frente al tema que ocupa esta investigación. Entre los que se incluyen libros, artículos y reseñas: Relaciones psicología-psicoanálisis (2014), El objeto de la psicología: el alma como cultura encarnada (Lopera, Manrique, et al., 2010), Ensayitos en debate: alcances y límites del método analítico (Ramírez \& Vargas, 2013), Sabiduría práctica y salud psíquica (Lopera, 2016). El trabajo como entorno de individuación psíquicatransindividual (Gil, 2015), La consciencia: ¿una realidad no algorítmica? (Lopera, 2007), Azar, libertad y responsabilidad: aportes para una práctica psicológica (Gil \& Manrique, 2013).

Finalmente, se utilizaron fuentes bibliográficas de referencia, y en esta categoría se incluyen aquellos textos o autores que son una referencia importante sobre el tema, pues debido a su trayectoria, experticia o pertinencia son una fuente obligada para fundamentar los conceptos: Aristóteles, Freud, Popper, Prigogine, Mandelbrot, Wagensberg, Simondon, Elias, Luria, Bleichmar, etc.

La selección de las fuentes se hizo con base en tres categorías de análisis:

- Fundamentos filosóficos, epistemológicos y conceptuales del determinismo, el azar y la causalidad.

- Determinación, azar y causalidad psíquica en psicoanálisis.

- Dimensión ética: implicaciones prácticas, políticas y existenciales del determinismo y el azar.

\subsubsection{Plan de trabajo}

Las actividades realizadas durante el trabajo investigativo fueron divididas por fases o procesos que, en algunos momentos, fueron llevados a cabo de manera simultánea, pues no eran necesariamente secuenciales (Hoyos, 2000):

Preparatoria: esta fase comenzó con una exploración sobre el problema de investigación. Con ese fin se rastreó y ubicó el material bibliográfico que era importante revisar de acuerdo con las categorías de análisis iniciales, lo que permitió organizar y depurar el material encontrado. Si bien este proceso se propone como un primer paso, las actividades descritas se realizaron continuamente a lo largo de la investigación a medida que iban apareciendo relaciones significativas entre autores y conceptos. 
Descriptiva: en esta fase ya había una mayor familiarización con el tema de investigación, lo que dio paso a un acercamiento más riguroso a los textos para afinar las categorías de análisis de acuerdo con la focalización de la información.

Interpretativa: en esta fase se llevó a cabo la labor hermenéutica propiamente dicha, fue el tiempo dispuesto para la búsqueda del sentido y la comprensión de los textos bajo estudio. Se trascendió la recopilación y categorización de los textos para llegar a la construcción teórica final. Fue la fase de mayor profundización, pues se fue definiendo el hilo argumental que daba cuenta de las relaciones encontradas y que permitieran encadenar las categorías de análisis de manera coherente, se compararon las construcciones teóricas de diversos autores con el fin de mostrar las diferencias y los puntos en común.

Construcción teórica global: fue el trabajo de escritura propiamente dicho en el que se formalizaron los resultados obtenidos en las fases previas, se expone entonces una construcción teórica, en coherencia con el problema de investigación y los objetivos propuestos, sobre las nociones de determinación, azar, causalidad psíquica y elección en la obra de Carlos Arturo Ramírez, en relación con la ciencia, el psicoanálisis y la psicología, que fueron los referentes teóricos propuestos.

Extensión y discusión de resultados: esta fase se realizó de manera gradual, ha sido un trabajo revisado por mi asesor, el doctor Ariel Viguera, por el profesor Matías Lucci, asesor metodológico de la Maestría en Ciencias Sociales de la Universidad Nacional de La Plata, por colegas con formación en los temas de esta investigación, quienes ayudaron con sus comentarios y recomendaciones bibliográficas a depurar los puntos que consideraban poco claros. También Carlos Arturo Ramírez hizo una lectura atenta y sus devoluciones (algunas sobre el contenido y otras sobre la forma) fueron cruciales para construir el hilo argumental de la tesis. Se espera que la discusión de este trabajo con los jurados evidencie líneas futuras de trabajo, puntos débiles y fortalezas para estimar la conveniencia o no de su publicación. 


\section{CAPÍTULO II El Azar y la Ciencia}

La noción de causalidad es una respuesta al problema planteado por el «misterio» de la producción de los fenómenos (Reflexiones sobre la causalidad física, Halbwachs, 1977, p. 29)

Para empezar a desarrollar este complejo tema - y ya veremos por qué es complejocomencemos por presentar la elaboración que hace Ramírez sobre el concepto de azar, para luego analizar estas ideas a la luz de los planteamientos que han realizado destacados científicos contemporáneos sobre este mismo concepto.

Ramírez entiende lo azaroso en el mismo sentido de aleatorio, esto es, un evento o un proceso del cual no se conocen las razones o determinaciones (Ramírez, 2012b, sec. 6. El azar, p. 26). Los sucesos aleatorios se caracterizan por ser irregulares, es decir que, al parecer, no obedecen a ninguna ley o regularidad que pueda ser enunciada, por lo tanto, no sabemos predecir cómo se van a desarrollar o cuál va a ser su resultado. Predecir es, justamente, afirmar cómo se desarrollará un suceso o cuál será su resultado antes de que ocurra. Una predicción se hace con base en unos criterios de confiabilidad, y se considera confiable cuando el margen de error es aceptable para los propósitos del que predice. Partiendo de estas aclaraciones que aporta el autor, se puede definir el azar como la ausencia o desconocimiento de regularidades, determinaciones, causas o leyes en un fenómeno.

Declarada esta definición, formulemos la pregunta que ha puesto a debatir a filósofos y científicos desde la antigüedad remota hasta la contemporaneidad: así entendido ¿el azar existe? El interminable debate que esta pregunta ha generado en la historia de la filosofía y la ciencia se debe a que cualquier respuesta que se dé debe resignarse a ser conjetural, pues hasta el momento cualquier posición al respecto es indemostrable, está en el límite de lo que podemos conocer. Por eso, en sus definiciones Ramírez introduce rigurosos matices y no afirma tajantemente que lo azaroso no tenga causas, sino que no se conocen; tampoco afirma que sea imposible predecir los sucesos 
azarosos, sino que no sabemos hacerlo, bien sea porque en las circunstancias dadas es incosteable investigarlo, no se han desarrollado los instrumentos o no hay la voluntad para hacerlo, o ya sea porque las determinaciones en efecto no existen. Miremos, ahora sí, las distintas formas en que se puede responder esta pregunta y las posiciones que de ahí se derivan.

- ¡No, el azar no existe! Ningún fenómeno puede ocurrir sin causa ni determinaciones, simplemente las desconocemos o no las podemos averiguar por las limitaciones de nuestro razonamiento y nuestros sentidos, o porque carecemos de los métodos, los recursos o la tecnología necesaria para conocerlas. Se trataría, a lo sumo, de un azar blando, epistemológico, aparente; concepción que también ha sido llamada subjetivista, porque solamente existe desde el punto de vista del sujeto limitado en sus posibilidades de conocer.

- ¡Sí, el azar sí existe! Hay en la realidad fenómenos que ocurren sin causa o determinación alguna, no todo lo que ocurre es necesario, tiene causa u obedece a una ley; y no se trata de una limitación de la inteligencia humana, de defectos en los instrumentos de medida o en los métodos de estudio, simplemente no existen esas determinaciones que puedan dar lugar a leyes. Este sería un azar duro, radical, extremo o también llamado ontológico.

Según la respuesta que se le dé a esta pregunta se asume también una posición frente al tema del azar. A continuación detallamos cada una de las distintas posiciones posibles.

\subsection{Determinismo absoluto o fatalismo}

Responder que el azar no existe da lugar a una posición que se conoce como determinismo absoluto o fatalismo. Esta doctrina filosófica afirma la universalidad del principio de causalidad al plantear que todos los acontecimientos del universo guardan entre sí una relación de causa y efecto, y que esa relación causal se puede formular como una ley natural, por tanto, todos los acontecimientos estarían sometidos a leyes naturales (Ferrater Mora, 1965, p. 431). El azar, es decir, cualquier fenómeno que no esté determinado y que no obedezca a ninguna ley estaría excluido de la cadena causal del universo. Sea esta la oportunidad para definir algunos de los conceptos que están en juego en el determinismo.

La relación de causalidad es la conexión que existe entre dos fenómenos, uno que sería la causa y otro que sería su efecto. La causa se puede definir entonces como el fenómeno que da origen $y$, por ello, precede en el tiempo a otro que sería su efecto. Asimismo, el efecto sería un fenómeno que sucede a otro y que es originado por él. Con estas definiciones queda más claro qué es lo que sostiene el determinismo 
absoluto cuando universaliza la relación de causalidad. Según eso, el universo estaría sometido a la ley de la causalidad, todo fenómeno sería un efecto de otro. El determinismo absoluto también implica que dadas unas causas necesarias y suficientes para que se produzca un efecto, este necesaria e inevitablemente ocurre. Y, finalmente, el determinismo implica que un determinado fenómeno causal conduce unívocamente a un determinado efecto. La univocidad también puede concebirse en plural: determinados fenómenos causales conducen unívocamente a determinados efectos. Se hace esta salvedad porque un fenómeno no tiene que tener una única causa, puede tener varias $y$, a la vez, un fenómeno causal puede generar, producir, originar, varios efectos.

En síntesis, tenemos que el determinismo absoluto defiende que hay una relación causal entre los fenómenos, relación que es universal, necesaria (inevitable) y unívoca. También es importante tener en cuenta que con la palabra fenómeno se incluye aquí todo, desde el más pequeño cambio en una partícula elemental, hasta un pensamiento.

Mientras algunos ven aquí una hipótesis metafísica, otros afirman que es científica, pero que no puede probarse debido a las limitaciones de la mente humana que no alcanza a tener en cuenta todos los factores o estados del universo. El pensador determinista de corazón, como Einstein, como Spinoza, prefiere pensar en una constitución de la realidad repleta de restricciones, sin el más tímido resquicio para el azar. En ella el ámbito de lo posible se reduce a una evolución única y prescrita. Cualquier duda es por torpeza o ignorancia del observador. En esta visión de la realidad, toda presunta incertidumbre es aparente, una ilusión, o una consecuencia de los límites de nuestra paciencia a la hora de observar el mundo (Wagensberg, 2007, p. 36).

Los deterministas radicales afirman que no sólo los fenómenos naturales están sometidos al determinismo, sino también las acciones humanas, que igualmente pueden ser explicadas como fenómenos naturales:

Priestley afirmaba resueltamente que los motivos influyen en la voluntad con la misma certidumbre y necesidad con que la fuerza de gravedad obra sobre una piedra y que aun cuando el hombre a menudo se reproche el no haber elegido de otra manera, el examen de su conducta demuestra que esto era imposible y que no habría podido obrar sino de tal modo (Abbagnano, 1974, p. 312).

Se ve claramente en esta cita de Priestley la relación necesaria y unívoca entre las causas y los efectos que es defendida por el determinismo absoluto. Es por esto que un auténtico determinismo es en realidad un predeterminismo (Abbagnano, 1974, p. 312), pues excluye la posibilidad de que ocurra (o de elegir) algo distinto de lo ya determinado. Esa ha sido una de las razones por las que más ha sido cuestionada esta posición, porque es fatalista, o sea que todo acontecimiento en el universo y toda acción humana tiene su causa o motivo en el tiempo que le antecede y no está en 
poder del hombre cambiar el curso cuando se efectúa la acción. Por tanto, los acontecimientos no se pueden evitar porque están sujetos a causas y determinaciones que los rigen. El futuro, al estar determinado, ya está escrito. Así lo expresa Marco Aurelio en sus meditaciones: "Te ocurra lo que te ocurra, ya estaba preparado de antemano para ti desde toda la eternidad, y el entrelazamiento de las causas ha trenzado conjuntamente desde siempre tu sustancia y el encuentro con este acontecimiento" (Marco Aurelio, 2001, p. 37).

Esta consecuencia tan radical del determinismo absoluto ha llevado a que algunos autores admitan el determinismo solamente en una parte de la realidad y afirmen que hay zonas, como las acciones y las decisiones humanas, que se sustraen al determinismo. Esta fue "la solución" que encontró Kant para este problema, él afirmaba el determinismo en relación con el mundo de los fenómenos, pero no en relación con el mundo nouménico de la libertad. En el tercer capítulo se presentan algunos cuestionamientos a esta propuesta.

El determinismo está vinculado con una visión mecanicista del universo que surge con la ciencia moderna; y el trasfondo de la ciencia moderna, a su vez, era la idea aristotélica, neoplatónica y medieval de un orden necesario en el mundo, según el cual todos los acontecimientos guardan entre sí una relación de causa y efecto (Abbagnano, 1974, p. 154). El éxito con el que la ciencia descubría las regularidades del universo afianzó el ideal de explicación causal absoluta del mundo, cuyo más célebre representante es el astrónomo Laplace, quien a comienzos del siglo XIX escribe en su Ensayo filosófico sobre las probabilidades:

Debemos considerar el estado presente del universo como el efecto de su estado anterior y causa del estado que seguirá. Una inteligencia que en un estado dado conociera todas las fuerzas de que está animada la naturaleza y la situación respectiva de los seres que la componen, en caso de ser tan vasta como para someter estos datos al cálculo, abrazaría en la misma fórmula los movimientos de los más grandes cuerpos del universo y los del más ligero átomo; de tal manera para ella nada sería incierto y el futuro, tanto como el pasado, estaría presente ante sus ojos (Laplace, 1985).

En esta formulación de Laplace la causalidad se pone en estrecha relación con la previsión infalible y con la deducción a priori. Es el ideal de un saber que puede prever todo acontecimiento futuro, por pequeño o grande que sea, deduciéndolo mediante leyes inmutables y necesarias. Esto es lo que hace la ciencia moderna: investiga las regularidades en la naturaleza y las formula como leyes. Estas leyes explican lo que ya ocurrió y permiten prever lo que va a ocurrir. El ejemplo típico es la regularidad que se descubrió en la trayectoria del cometa Halley alrededor del sol. Descubrir esa regularidad permite, a la vez, predecir cuándo volverá a ser visible desde la tierra. La capacidad de predicción de una ley se convierte en el criterio de validez y eficacia, por tanto la previsión de los fenómenos se vuelve el objetivo central de la ciencia y, sobre todo, de la tecnología, que nos permite contar con aparatos fiables, que sabemos cómo 
van a funcionar. El determinismo tendría entonces un aspecto positivo, que es la predictibilidad, y un aspecto negativo, que es el fatalismo.

Sin extendernos demasiado en los planteamientos de la mecánica cuántica y las diferentes interpretaciones que existen de ella, pues esto excede los propósitos y las posibilidades de esta investigación, es importante retomar brevemente el principio de incertidumbre que postula ${ }^{2}$, especialmente por las implicaciones tan profundas que ha tenido en el modo que los científicos ven la ciencia y el mundo, y por la controversia que se ha generado en torno a las consecuencias epistemológicas, filosóficas y existenciales que se pueden derivar de él. Es importante ser cuidadosos al momento de sacar conclusiones filosóficas y existenciales apresuradas a partir de estas teorías físicas, pues algunos han tomado estos planteamientos como una demostración de la existencia de la libertad humana o de la relatividad de todas las cosas. Al respecto, el científico Ilya Prigogine (1993, p. 27) dice que el principio de incertidumbre no implica que la física actual se convierta en una física subjetivista, que dependa de las preferencias o convicciones del científico, pero sí que es una física sujeta a restricciones intrínsecas y que ubica al científico como parte del mundo físico que describe, que presupone un observador situado en el mundo, es decir, que no puede alcanzar esa visión que está por fuera del mundo y conocer todas las variables y cambios presentes y futuros, tal como pretendía el determinismo absoluto. "Nuestro diálogo con la naturaleza solo logrará éxito si se prosigue desde dentro de la naturaleza" (Prigogine, 1993, p. 27).

Hecha esta salvedad, retomemos las implicaciones que tendría el principio de incertidumbre para el determinismo absoluto: según lo que plantea Stephen Hawking, este principio es un límite a ese ideal de previsión infalible: "El principio de

2 Hawking explica de forma sencilla para los legos en qué consiste este principio: el físico Max Planck para explicar por qué los cuerpos calientes, tales como las estrellas, emiten radiación, planteó en 1900 la hipótesis de que existen cuantos de energía que son emitidos por estos cuerpos. Esta hipótesis afirma también que la luz, los rayos $X$ y otros tipos de ondas no pueden ser emitidos en cantidades arbitrarias, sino en ciertos paquetes que él llamó cuantos. Pero aceptar esta hipótesis cuántica tenía una importante consecuencia, que apenas fue comprendida veintiséis años después con los estudios de Werner Heisenberg: para predecir la posición y la velocidad que una partícula tendrá en el futuro es necesario medir con precisión su posición y velocidad actuales. El modo de hacerlo es iluminando la partícula, porque las ondas luminosas son dispersadas por la partícula y eso permite conocer su posición. Para iluminarla es necesario utilizar luz de muy corta longitud de onda, es decir, que haya muy poca distancia entre una cresta de onda y la siguiente (como las crestas de onda que la caida de una piedra genera en el agua). Pero según la hipótesis de Planck no se puede usar una cantidad arbitrariamente pequeña de luz, se tiene que usar como mínimo un cuanto, y este cuanto de luz perturba la partícula y cambia su velocidad en una cantidad que no puede ser predicha. Según la hipótesis de Planck, mientras menor es la longitud de onda de la luz, mayor es la energía, lo que perturba aún más la velocidad de la partícula. De esto se deduce que mientras con mayor precisión se conoce la posición de la partícula, con menor exactitud se conoce su velocidad y viceversa. "Además, este límite no depende de la forma en que uno trata de medir la posición o la velocidad de la partícula, o del tipo de partícula: el principio de incertidumbre de Heisenberg es una propiedad fundamental, ineludible, del mundo" (Hawking, 2001, p. 83). 
incertidumbre marcó el final del sueño de Laplace de una teoría de la ciencia, un modelo del universo que sería totalmente determinista: ciertamente, ¡no se pueden predecir los acontecimientos futuros con exactitud si ni siquiera se puede medir el estado presente del universo de forma precisa!" (Hawking, 2001, p. 83), pues el postulado fundamental de este principio es que en un nivel cuántico es imposible para el ser humano observar el estado presente de un fenómeno sin perturbarlo. Hawking reformula entonces el objetivo que Laplace enunció para la ciencia: "nuestra intención es formular un conjunto de leyes que nos permitan predecir acontecimientos solo hasta el límite impuesto por el principio de incertidumbre" (Hawking, 2001, p. 215).

Según Ferrater Mora (1965, p. 432), además de la anterior, una de las principales dificultades de las doctrinas deterministas es que se basan en una definición excesivamente amplia y general del concepto, pues extienden a toda la realidad una estructura que es propia de la mecánica clásica, en la que si se conoce el estado mecánico inicial de un sistema, es decir, ciertos valores o magnitudes iniciales de ese sistema, estos varían en el tiempo de acuerdo con ciertas leyes, todo sucede con carácter de necesidad y es, por tanto, un sistema matemáticamente predecible. El determinismo cosmológico, ontológico, filosófico o precientífico extiende esta estructura del determinismo mecánico a todo lo que ocurre en el universo, incluyendo la realidad física, biológica y humana. Por esta misma vía va la objeción que plantea el filósofo de la ciencia Ernest Nagel, y es que el determinismo de la mecánica clásica se limita a las propiedades mecánicas de los sistemas físicos, pero para alcanzar el ideal de Laplace se tendrían que tener en cuenta, además, todas las propiedades de los cuerpos, no solo las mecánicas, sino también las ópticas, térmicas, electromagnéticas, químicas, biológicas, psíquicas y sociales.

Frente a esta objeción, algunos defensores del determinismo lo diferencian de la predictibilidad de los hechos, argumentando que la determinación implica exclusivamente la ausencia de azar en la cadena causal que da lugar a un suceso concreto, mientras que la predictibilidad exige además que se conozcan todas las condiciones iniciales de la cadena causal, y reconocen que en la práctica existen muchas dificultades para lograr ese conocimiento. Esto implica que un sistema puede estar completamente determinado, pero aun así no es posible predecir su desarrollo, se trata de una impredictibilidad práctica debida exclusivamente a las limitaciones humanas para conocer todas las variables en juego.

Otros autores cuestionan que el determinismo esté en la realidad y argumentan que son las teorías y las descripciones científicas las que son deterministas, ya que el determinismo requiere dos condiciones que, en rigor, no se dan nunca en la práctica: los sistemas tienen que ser suficientemente sencillos y aislados, pero la simplificación de los sistemas y su aislamiento es siempre una idealización y una estrategia de investigación. "Entonces, cuando se pretende tener en cuenta la complejidad de los sistemas, es decir, cuando se quiere que la descripción sea más compleja, es necesario 
introducir, precisamente, elementos estocásticos ${ }^{3}$. Y, con ello, la teoría determinista ha pasado a ser indeterminista. En pocas palabras, la física clásica también es indeterminista cuando conviene" (Landsberg et al., 1986, p. 84).

Otra observación que puede hacerse a la posición determinista es que la relación de causalidad es sólo una de las diferentes formas de dependencia, relación o interacción que puede haber entre los fenómenos. También puede haber una relación de concomitancia, correlación o sincronicidad; esta última es propuesta por el psicoanalista Carl Gustav Jung y uno de los fundadores de la mecánica cuántica, el físico Wolfgang Ernst Pauli.

En esta exposición que se ha hecho del determinismo es importante hacer una salvedad sobre las dificultades para darle una definición satisfactoria, pues es un concepto que ha sido tan debatido y problematizado en la filosofía y la ciencia, que se encuentran muchas diferencias y sutilezas en su definición o en sus implicaciones. Sólo por mencionar, hay autores que diferencian el causalismo del determinismo, es decir, que es posible afirmar que todo tiene una causa sin adherir por ello al determinismo; según esto, causalismo y determinismo no coincidirían (Ferrater Mora, 1965, p. 432), por ejemplo: tropezar con una piedra es un hecho que tiene causas, pero esto no sería equivalente a decir que estaba determinado o, más aún, predeterminado, como si hubiera en él un carácter de necesidad e inevitabilidad.

Por ahora baste con mencionar que el desarrollo de la teoría cinética de gases, los avances de la matemática con la teoría de la probabilidad y los procesos estocásticos, las teorías de la mecánica cuántica y el desarrollo de las teorías del caos y de las catástrofes, todos estos estudios en conjunto fueron generando un cambio en la ciencia: se ha ido reemplazando el concepto de causalidad por otros como condición, relación o función, y el de determinación por el de posibilidad, probabilidad y previsión probable. Estos cambios se fundan en el reconocimiento de que en los acontecimientos hay muchas posibilidades, aunque no todas tienen la misma probabilidad de ocurrir. "Por lo tanto, la palabra determinismo, más que ser abandonada, ha sufrido en el lenguaje científico y filosófico contemporáneo una transformación radical. No designa ya el ideal de la causalidad necesaria y de la previsión infalible, sino el método de la relación condicional y de la previsión probable" (Abbagnano, 1974, p. 314), tal como veremos más adelante en el probabilismo.

3 En los sistemas o modelos deterministas todos los datos se conocen con certeza, lo que implica que al analizar el modelo en cualquier momento se tiene disponible toda la información necesaria para anticipar el estado del sistema en el futuro. Mientras que un sistema o modelo estocástico es el que tiene un comportamiento no determinista, en la medida que el siguiente estado del sistema está determinado tanto por las acciones de elementos predecibles del proceso como por elementos aleatorios, es decir, que su valor no se puede conocer con anticipación, tienen una variación en el tiempo que es impredecible. En otras palabras, son procesos en los que existe una secuencia cambiante de eventos a medida que pasa el tiempo, haciendo necesario especificar las variables aleatorias para cada instante. 


\subsection{Indeterminismo absoluto}

Es el máximo grado de incidencia del azar, pues según esta posición nada está determinado, todo ocurre al azar. Un ejemplo de esta posición se encuentra en el kalam, la teología islámica medieval. Los mutacálimes, eruditos y teólogos del islam, profesaban la doctrina del libre albedrío y adoptaron una posición contraria a la del fatalismo que defendía la ortodoxia islámica. Sostenían que Dios crea el universo a cada instante (Grabmann, 1928), así que no habría una relación causal entre el estado anterior del universo y el estado actual, ni el estado actual determinaría cómo van a ser las cosas en el futuro. Ramírez cuestiona esta posición argumentando que si fuera así, no deja de ser inquietante que sea una creación tan monótona, regular y predecible, pues cada instante creado es muy parecido al anterior (Ramírez, 2012b, p. 28).

El indeterminismo, en general, suele negar que los acontecimientos estén determinados, ya sea por una ley divina, un principio, un fin o una cadena causal estricta. La experiencia inmediata y la eficacia de las leyes científicas contradicen tan contundentemente el indeterminismo absoluto que esta posición ha sido virtualmente descartada en la literatura científica y filosófica. "Suponer que no hay regularidades en el universo va tan en contra del sentido común, que se vuelve inaceptable: nadie niega que al golpearse con un martillo en un dedo sentiría dolor; al contrario, si no siente nada, investiga asombrado la causa de esta irregularidad" (Ramírez, 2012b, sec. 6. El azar, p. 29).

El astrofísico Evry Schatzman sostiene y argumenta que las leyes que se han encontrado en la naturaleza no son una simple especulación teórica; la afirmación de la universalidad de las leyes naturales se sostiene en una gran cantidad de datos observables que dan cuenta de constantes que se cumplen en todo el universo que conocemos. El ejemplo típico y más contundente es el de la ley de la gravitación. "Esta primera ley implica ya una validez que va más allá de la experiencia humana sobre la tierra. Gobierna tanto el movimiento de la luna alrededor de la tierra como el de los planetas alrededor del sol. La observación revela que en el cielo hay miles y millones de sistemas binarios en los que cada una de las estrellas, siguiendo la ley del movimiento de Kepler, se mueve alrededor de una elipse con foco en el centro de gravedad" (Landsberg et al., 1986, p. 102). Otro ejemplo es el espectro de luz que producen los elementos químicos: la presencia de los mismos elementos químicos en todas partes también es una manifestación de la universalidad de las leyes de la naturaleza: "En la producción de rayas espectrales están implicadas numerosas leyes que conciernen, a su vez, a varias constantes microscópicas: la carga eléctrica, las masas del electrón y del protón y la constante de Planck, que aparece en todos los fenómenos cuánticos. La presencia de las mismas rayas espectrales, incluso en los 
objetos más remotos, muestra pues que estas constantes tienen el mismo valor en cualquier lugar del universo. Los mismos procesos físicos generan, en todas partes, los mismos espectros. Podemos decir que la prueba cuantitativa de la universalidad de las leyes de la naturaleza alcanza el horizonte del universo observable" (Landsberg et al., 1986, p. 104). Son entonces demasiadas y muy contundentes las regularidades que se han encontrado en la naturaleza como para que sea plausible un indeterminismo absoluto.

\subsection{Probabilismo}

Al seguir el hilo del desarrollo de la ciencia - la física como paradigma - se puede observar una transición importante: la ciencia se ha ido moviendo de ese ideal de explicación causal absoluta (determinismo absoluto) para aproximarse a otras nociones, tales como condición, relación y función, hasta llegar finalmente a la propuesta de abandonar los conceptos de determinación y causalidad por otros como el de probabilidad. Esta es la dirección que ha tomado la ciencia contemporánea, que reconoce el carácter de probabilidad a un número extenso de acontecimientos o a todos (Abbagnano, 1974, p. 953).

Volker Gadenne (2006) muestra de la siguiente manera la transición que ha hecho la ciencia desde el determinismo al probabilismo. Una ley determinista tiene la siguiente estructura: un fenómeno A conduce a un fenómeno B. De este modo explica y también permite predecir el mundo, pues saber que el fenómeno A trae siempre el fenómeno $\mathrm{B}$, hace posible predecir cuándo va a darse $\mathrm{B}$; y en los casos en los que puede provocarse o impedirse A también puede controlarse la aparición de B. Un ejemplo típico es la bola de billar en movimiento (fenómeno A) que golpea a otra y causa su desplazamiento (fenómeno B). En general, las leyes de la mecánica clásica de Newton tienen esta estructura. Las leyes probabilistas o estadísticas, en cambio, postulan que si se da un fenómeno A éste conduce a un fenómeno $\mathrm{B}$ con una probabilidad X (Gadenne, 2006, p. 148). Lo que antes se consideraba determinado (necesaria y unívocamente) se empieza a considerar probable 4 .

Se considera probable un acontecimiento con un suficiente grado comparativo de confirmación o de verosimilitud. En otras palabras, la probabilidad es el grado o la

\footnotetext{
4 En la actualidad, especialmente en psicología, es frecuente que las leyes se formulen con el agregado ceteris paribus (siendo todo lo demás constante o permaneciendo igual); una reserva que se ha ido introduciendo en las leyes científicas y que hace referencia al grado de probabilidad e indeterminación de una ley, pues se entiende que una ley se cumple siempre y cuando otros factores no intervengan o se mantengan aproximadamente constantes. Se consideran entonces leyes imperfectas porque están afectadas por aspectos indeterminados, son leyes que permiten excepciones y de ese modo se reduce el grado de determinación de la proposición: "con la reserva ceteris paribus la proposición recoge, es verdad, todos los factores causales globalmente, pero de una manera indeterminada" (Gadenne, 2006, p. 156).
} 
medida de la posibilidad de un acontecimiento, esto supone entonces la elección o preferencia por una de las alternativas posibles (Abbagnano, 1974, p. 949), como cuando se dice "probablemente mañana lloverá", queda aún la posibilidad de que no llueva, pero es una opción que se considera menos probable.

Según Carnap y Russell se pueden diferenciar dos concepciones de probabilidad: la primera es llamada por Carnap probabilidad inductiva o grado de confirmación, y Russell la denomina grado de credibilidad. Por la función que este tipo de probabilidad cumple, también es llamada probabilidad singular, pues se caracteriza por mirar el grado de posibilidad de un acontecimiento singular, y por eso se expresa mediante proposiciones tales como "probablemente mañana lloverá". En el caso del lanzamiento de un dado, por ejemplo, se considera que cada una de sus caras tiene la misma probabilidad de aparecer, es decir, cada una tiene una probabilidad de un sexto. Autores como Keynes, Ramsey y Jeffreys han definido este tipo de probabilidad como "grado de creencia racional".

La segunda concepción de probabilidad es llamada por Carnap probabilidad estadística o frecuencia relativa, y Russell la llama probabilidad matemática. Por la función que cumple puede denominarse probabilidad colectiva, ya que lo característico de este tipo de probabilidad es que no mira la probabilidad de un acontecimiento particular, sino de clases, especie o cualidad de acontecimientos, entonces se considera probable lo que se sabe que ocurre en la mayoría de los casos. Por ejemplo, al realizar muchas y rigurosas observaciones de la mortalidad en una comunidad a lo largo de varios siglos, se puede calcular la frecuencia relativa y la frecuencia límite de mortalidad. Pero el cálculo obtenido no es la probabilidad de un evento singular, sino de una clase de acontecimiento, por eso este cálculo no sirve para predecir si un individuo va a morir en el presente año, sino la frecuencia de mortalidad en el grupo al que pertenece. Asimismo, se puede calcular que en un millón de lanzamientos de una moneda la frecuencia relativa de aparición de cada lado es de 500 mil, pero este cálculo no sirve para predecir qué lado va a salir en el próximo lanzamiento, sino la frecuencia de un resultado en muchos lanzamientos. Esta probabilidad estadística no opera a priori, es decir, antes de poder afirmar algo sobre una clase de hechos, se requiere haber determinado previamente la frecuencia del hecho mismo y, por lo tanto, su grado de probabilidad solo se puede determinar $a$ posteriori.

Ramírez plantea que el probabilismo parte de un nivel aleatorio, es decir, un nivel en el que los elementos que conforman una estructura tendrían un comportamiento caótico, irregular, no sujeto a leyes, pero debido a la ley de los grandes números, eso que en principio es azaroso se reuniría luego en un determinismo según leyes que también tendrían un grado de probabilidad. Lo que estamos diciendo es que elementos caóticos, al combinarse o articularse, paradójicamente, producen singularidades organizadas y sujetas a leyes; es lo que se observa, por ejemplo, en las partículas elementales que conforman un gas: a un nivel microscópico el 
comportamiento de las partículas es caótico, aunque a un nivel macroscópico las propiedades del gas y su interacción con otros elementos del entorno sean regulares y predecibles. Algo similar ocurre con las hormigas que conforman colonias, los individuos que conforman sociedades... Todas estas son singularidades (partículas, hormigas, personas) con un comportamiento que de base es caótico, pero que pueden articularse y producir eventos regulares, determinados, sujetos a leyes (Johnson, 2004; Ramírez, 2012b; Solé, Bascompte, Delgado, Luque, \& Manrubia, 1996).

La ley de los grandes números siempre será misteriosa: ¿por qué una serie de sucesos supuestamente aleatorios cumple una ley? Si se lanza un dado puede salir cualquiera de los seis números. Pero si se lanza seis millones de veces cada número aparecería aproximadamente un millón de veces (Ramírez, 2012b, sec. 6. El azar, p. 28).

Esta ley es enunciada por el matemático ruso Andrei Kolmogoroff, quien con sus contribuciones a la teoría de la probabilidad la hizo definitivamente aceptable para los matemáticos; al respecto declara: "todo el valor epistemológico de la teoría de las probabilidades se basa en esto: los fenómenos aleatorios, considerados en su acción colectiva a gran escala, crean una regularidad no aleatoria" (como se cita en Mandelbrot, 1996, p. 14).

La ciencia, en general, es determinista, pues en este campo es fecundo partir del supuesto de que los fenómenos tienen causas y regularidades, iy buscarlas! Ese supuesto ha llevado a grandes descubrimientos y avances científicos. "El método científico es determinista. El científico es, de oficio, determinista" afirma Jorge Wagensberg (Landsberg et al., 1986, p. 93): Sin embargo, la teoría de la probabilidad implica concebir dentro de la ciencia cierto grado de indeterminación, pues se admite la imposibilidad de establecer y definir el estado inicial de un fenómeno por no contener en sí todas las variables que realmente toman parte en él, a menos que se trate de sistemas excesivamente simplificados y en condiciones controladas de experimentación. Este indeterminismo científico niega que haya una necesidad absoluta en el desarrollo de los procesos físicos y biológicos, es decir, que los acontecimientos no se desarrollan como un proceso causal lineal o, como decíamos anteriormente, unívoco (determinadas causas conducen unívoca e indefectiblemente a unos determinados efectos), sino que se trata de procesos no lineales que introducen un grado de indeterminación en los acontecimientos, lo que da lugar al azar.

La idea de azar en Ramírez, veremos a continuación, incluye el azar que está en juego en la ley de grandes números, en el cálculo de probabilidades y la teoría del caos, pero va más lejos, y de la mano de científicos como Benoît Mandelbrot veremos la sustentación de un azar más "salvaje" que este.

\subsection{Determinismo dialéctico}


Esta es la posición que propone Ramírez frente al azar. Si bien es una forma de probabilismo, porque acepta las bases del probabilismo científico anteriormente expuestas, con este nombre, determinismo dialéctico, se quiere expresar que la realidad se conforma en un diálogo entre lo determinado y lo indeterminado, de esta dialéctica emergen singularidades, eventos, sucesos, procesos o fenómenos que son en parte determinados, es decir, regulares y sujetos a leyes, y en parte indeterminados, caóticos, azarosos (Ramírez, 2012b, sec. 6. El azar, p. 29). Desde esta perspectiva no se niega el determinismo, como pretenden hacerlo quienes argumentan que son las teorías y las descripciones de los científicos las que son deterministas; se reconocen las constantes, las regularidades y determinaciones que hay en la naturaleza, pero también las indeterminaciones.

Plantea Ramírez que lo organizado (lo que tiene, por lo tanto, leyes que lo ordenan) se adapta a los eventos azarosos, los tamiza y conforma con ellos estructuras. Lo organizado filtra y así logra mitigar y suavizar la intensidad de los efectos que puede producir lo azaroso en la realidad. Lo contrario también ocurre, el azar disminuye la fuerza de las determinaciones. Las estructuras que surgen de este acoplamiento de lo ordenado con lo caótico son llamadas por Ramírez formaciones de lo aleatorio (Ramírez, 2012b, p. 244), un concepto fundamental en su obra, pues toda la realidad, en todos sus niveles (físico, biológico, psíquico y social) estaría conformada por estas estructuras, dicho de otra manera, todas las estructuras que encontramos en la naturaleza, ya sean átomos, moléculas, células, organismos, situaciones, etc., serían un producto de este acoplamiento de lo caótico con lo regulado. Con la expresión formaciones de lo aleatorio Ramírez está haciendo una alusión a Freud, quien llamó "formaciones del inconsciente" a lo que resultaba del encuentro del deseo inconsciente con la censura del yo. El encuentro de estas dos tendencias contrapuestas es lo que produce lapsus, sueños, recuerdos encubridores, chistes, síntomas... En todos estos fenómenos estudiados por el psicoanálisis hay una aleación de lo inconsciente y la represión, serían formaciones de compromiso entre estas dos tendencias, como una especie de acuerdo al que llegan, aunque en ocasiones sea un acuerdo que resulta displacentero para el sujeto.

Esta forma en la que parece evolucionar la realidad implica que muchos eventos no puedan determinarse solamente desde las leyes generales del universo, sino que se deben tener en cuenta también las leyes y acciones particulares de los medios cercanos y las singularidades. Así que, los fenómenos, además de estar sujetos a leyes generales, podrían tener leyes singulares y también irregularidades y aspectos caóticos ${ }^{5}$.

¿Pero qué asidero tiene esta forma de concebir la realidad?, ¿hay en la ciencia contemporánea descubrimientos y argumentos con los que se pueda sustentar el azar

5 En el cuarto capítulo de esta investigación se amplía el concepto singularidad, tal como es concebido por Ramírez. 
en la realidad?, ¿todo lo que existe son formaciones de lo aleatorio?, ¿tanto lo determinado como lo caótico están en todos los niveles de la realidad? Recordemos que estas ideas eran prácticamente excluidas y proscritas en la ciencia moderna en pro del determinismo y la búsqueda de leyes generales.

\subsection{Sustentación del determinismo dialéctico: el azar en la ciencia contemporánea}

Una de las mentes más brillantes del siglo XIX, Charles Sanders Peirce, hace una defensa categórica del azar al oponerse a la idea de la necesidad, de que todo suceso está determinado por una ley; se refiere al azar como "esa diversidad del universo a la que las leyes dejan espacio" (Peirce, 1893, p. 409). Retomaremos en sus palabras su defensa del determinismo dialéctico: "Eso significaba realmente creer que el azar no era un azar absoluto. Significaba reconocer que el azar desempeña una parte en el mundo real independientemente de lo que podamos saber o ignorar de él" (Peirce, 1893, p. 409).

En el pensamiento de Peirce el mundo no se construyó por leyes necesarias, sino por probabilidades que se realizaron. Negaba la universalidad de la doctrina del determinismo y la necesidad tomando como referentes las doctrinas de Epicuro y Lucrecio que hablaban de un azar espontáneo. Concibe pues que en el mundo hay espontaneidad, "de la cual nuestro sentido de la libre elección es un elemento menor" (Hacking, 1995, p. 289). Consideraba, visionariamente, que la hipótesis de la espontaneidad del azar y sus consecuencias podían ser objeto de la matemática y trazarse con detallada precisión, y aunque por el momento no se estudiara el azar, consideraba este tema una mina de oro para los futuros matemáticos. No se equivocó.

Un primer punto de referencia para sustentar la propuesta de Ramírez puede hallarse en la física cuántica. El cálculo de probabilidades no es exclusivo de la teoría cuántica, se suele utilizar, como vimos, en numerosas situaciones, desde las más cotidianas, como el lanzamiento de un dado, la predicción del tiempo, las apuestas en las carreras de caballos, hasta la termodinámica y la ingeniería. Sin embargo, en situaciones macrofísicas un escéptico podría atribuir el uso de las probabilidades a la falta de conocimiento del sistema en cuestión y no a un azar intrínseco al sistema. Pero las probabilidades en teoría cuántica no son una cuestión de desconocimiento del sistema, son algo fundamental.

Esta pérdida de capacidad de predicción era lo que incomodaba a Einstein y a muchos de sus colegas. [...] Pero en aquel entonces era perfectamente posible creer que la teoría cuántica era incompleta, en algún sentido, y que las probabilidades aparecían, como sucede en termodinámica o cuando lanzamos una moneda, porque nos falta alguna información sobre las partículas. Hoy en día esta idea tiene poca aceptación, ya que los avances teóricos y experimentales indican que la naturaleza realmente utiliza números 
aleatorios, y que la pérdida de certeza a la hora de predecir las posiciones de las partículas es una propiedad intrínseca del mundo físico: las probabilidades son lo máximo a lo que podemos aspirar (Cox \& Forshaw, 2015, p. 59).

Otra referencia del azar en la ciencia la encontramos en la teoría del caos. Con este nombre se denomina el estudio que la matemática junto con otras ciencias y áreas del conocimiento (física, química, biología, informática, meteorología) realizan de fenómenos o sistemas complejos, tales como el clima, los terremotos, los ecosistemas, la consciencia, las sociedades, las ciudades. También podríamos decir que no sólo es una teoría, sino una perspectiva de la ciencia actual. Esto es lo que señala Ilya Prigogine: la tendencia en la ciencia contemporánea es a estudiar los fenómenos como sistemas dinámicos, inestables, aleatorios, que evolucionan, cambian con el tiempo; a diferencia de la ciencia clásica de Galileo, Kepler y Newton que se ocupaba de los fenómenos desde una perspectiva estable, atemporal.

Lo que nos interesa destacar son las características de esos fenómenos complejos. Una primera es que son considerados sistemas porque emergen de las interacciones entre sus elementos componentes; y las propiedades que aparecen en el sistema, como resultado de esa interacción, no pueden explicarse a partir de las propiedades de los elementos componentes, porque el sistema completo posee más información que cada una de las partes tomadas de forma independiente. "Una colonia de hormigas, por ejemplo, es capaz de llevar a cabo tareas de gran complejidad, como explorar su entorno, construir galerías o decidir la fuente de alimento entre dos posibles a escoger. Pero consideradas una por una, ninguna puede acometer, por sí sola, semejantes tareas. Decimos que el comportamiento social del hormiguero no es deducible de las propiedades de un individuo de la colonia" (Solé et al., 1996, pp. 1415).

La segunda característica es que los sistemas complejos aparecen a medio camino entre el orden y el desorden. Por un lado, el orden les permite almacenar información y mantener la estabilidad de las estructuras. Pero, al mismo tiempo, la información debe ser manipulable, debe circular, y para ello se precisa flexibilidad, cierto grado de desorden (Solé et al., 1996, p. 15 y 19).

La tercera característica es que en todos los fenómenos complejos los elementos en interacción poseen la capacidad de amplificar perturbaciones fortuitas: estas pueden ser, por ejemplo, pequeñas tensiones en las placas tectónicas que dan lugar a sismos, la caída de un grano de arena sobre el montón que da lugar a un deslizamiento, o una mutación genética que amplificada favorece la aparición de una nueva especie (Solé et al., 1996, p. 16). Esto es lo que se conoce popularmente como el efecto mariposa.

La primera característica se refiere entonces a las conexiones, la interdependencia que se presenta en estos sistemas, mientras que en la segunda y la tercera característica aparece el papel tan importante que juega el azar, a tal punto que el 
surgimiento e incluso la permanencia de estos fenómenos depende de eventos fortuitos y de cierto grado de desorden (indeterminación) en sus estructuras.

Los científicos se han preguntado cuál es el origen de la complejidad, cómo surgen los fenómenos complejos de esta realidad, y como respuesta han propuesto la hipótesis de la frontera del caos, según la cual los sistemas complejos serían el resultado de una evolución del sistema hacia puntos críticos (Solé et al., 1996, p. 15) que dan lugar a transiciones de fase, es decir, cuando un sistema evoluciona hasta el filo del desorden, cuando está en un punto crítico, cercano a la disolución, la desintegración o la extinción, hace una transición a un nuevo orden global, emerge un nuevo orden, en otras palabras, en lugar de aniquilarse se hace más complejo. Estos puntos críticos son llamados por Prigogine puntos de bifurcación, porque en este punto el sistema toma una nueva trayectoria y emerge un cambio cualitativo irreversible en el comportamiento del sistema. Es significativo que en el estudio de estos sistemas no es posible predecir la llegada de un punto de bifurcación, pues las mismas condiciones observadas en el momento de una bifurcación pudieron haberse dado antes en el entorno sin tener repercusiones en el sistema. La evolución del sistema es impredecible.

Veamos estos conceptos ilustrados en un ejemplo: al estudiar el desarrollo de las selvas tropicales, los investigadores han concluido que su orden y diversidad se debe al desorden (perturbación) producido por la caída de árboles, pero estamos hablando de árboles de 60 metros que en su trayectoria tumban otros y llegan a abrir claros de luz de cientos de metros cuadrados. Las caídas de estos árboles en varios puntos de la selva llevan al ecosistema a un punto crítico porque modifican bruscamente las condiciones de temperatura y humedad. Sin embargo, al estudiar la dinámica de esta perturbación, analizando los mapas de los claros en toda la selva y realizando modelos computacionales, lo que se encuentra es que esas caídas, en principio aleatorias, a gran escala forman un patrón fractal y, además, las semillas que antes dormitaban empiezan una carrera por ocupar el espacio que se acaba de abrir, lo que contribuye significativamente al mantenimiento de la diversidad (Solé et al., 1996). Se observa en el ejemplo que el sistema (la selva) va evolucionando hacia un punto crítico (la sequía, la erosión, la extinción de especies que puede generar la caída de los árboles) gracias al cual se da una transición de fase (la diversidad, la repoblación, el crecimiento de jóvenes y fuertes árboles que de otro modo no podrían germinar). Fue lo que ocurrió también con la extinción de los dinosaurios, que en lugar de desequilibrar el ecosistema terrestre al punto de que se extinguiera la vida, dio paso a una nueva fase: el predominio de los mamíferos.

La clave de los puntos críticos (cuando el sistema está en el punto máximo de fluctuación) es que en ellos se alcanza un máximo de transmisión de información. La computación (entendida como la capacidad de un sistema complejo para captar y procesar información) podría aparecer en la naturaleza en esos puntos críticos, en la frontera del caos (Solé et al., 1996, p. 19). En las colonias de hormigas y la actividad 
neuronal, se ha observado que a baja densidad las interacciones y los cambios en el sistema son muy irregulares, es decir, los individuos (hormigas, neuronas) aunque se activan no pueden propagar sus cambios. Mientras que a grandes densidades las fluctuaciones del sistema se tornan periódicas, de modo que los cambios en un elemento se propagan en forma de onda coherente a través de todo el sistema. Cuando hay una densidad crítica (que está entre el orden y el desorden) se produce una transición de fase. Cerca de esos puntos críticos el cerebro poseería la capacidad óptima de manejar y procesar información. De ser así, tal vez el sistema más complejo que conocemos se encuentre también en la frontera del caos (Solé et al., 1996, p. 21).

Es interesante mencionar que en esta idea, según la cual el orden de los sistemas surge a partir del caos, se ha fundamentado la terapia electroconvulsiva (TEC), pues se supone que al generar caos en el cerebro con descargas eléctricas que alteran las conexiones neuronales, la tendencia del sistema será a reorganizarse, a generar una reestructuración más ordenada de la actividad eléctrica del cerebro.

El físico Peter Landsberg se pregunta isi se lograran desarrollar mejores modelos teóricos y se utilizaran ordenadores más potentes, podría alcanzarse mayor precisión y grado de certeza en la predicción del comportamiento y desarrollo de estos sistemas caóticos? "De nuevo quedamos defraudados. —es lo que responde-Siempre hay un error del ordenador. Un pequeño error inicial puede hacerse más y más grande conforme se realiza el cálculo y finalmente no puede decirse nada con precisión. La probabilidad y la incertidumbre entran tanto en el cálculo como en la observación sencillamente porque la precisión infinita es imposible". También dice que la situación para los científicos se complica más cuando estos sistemas, cuyas ecuaciones son perfectamente deterministas, terminan desarrollando un comportamiento errático: "Esto se llama caos. [...] La idea clave es que estos sistemas son extraordinariamente sensibles a las condiciones iniciales de las que arrancaron. Por ejemplo, en un modelo matemático, cada salida (output) puede emplearse para generar una nueva entrada (input) y, al cabo de una serie de interacciones, puede generarse un conjunto aparentemente aleatorio de salidas" (Landsberg et al., 1986, p. 22).

Una tercera referencia al determinismo dialéctico la encontramos en las ideas del físico Francis Halbwachs (1977, p. 42). Cuando habla de la causalidad en la física dice que hay un aspecto aleatorio de los fenómenos que se incluye en el concepto más bien vago de azar. En las distribuciones estadísticas, a primera vista, pareciera haber una legalidad particular, que no está ligada a una causalidad sino a una ausencia o una laguna de la causalidad, es decir, casos en los que "la ausencia de disimetría [de un factor que intervenga y obligue una trayectoria] excluye una determinación causal estricta de los fenómenos". Esto es lo que ocurre cuando se tira un dado un número de veces suficientemente grande, por ejemplo seis millones de veces; es probable que cada cara salga aproximadamente un millón de veces, porque ningún factor, ninguna causa viene a favorecer que salga tal o cual número. Este sería un ejemplo de un fenómeno simple que no comporta disimetría causal, es decir, hay allí una ausencia de 
causalidad. Dice Halbwachs que estos casos no son los de más interés ni los que reportan mayores problemas para el físico, como sí lo son los casos en los que hay una “combinación de una ley causal y de una ley aleatoria” (Halbwachs, 1977, p. 43).

Para ilustrar estos casos pone como ejemplo los disparos sucesivos de un arma automática en una situación experimental, protegida, en lo posible, de la influencia de variables que afecten las condiciones iniciales y el desarrollo de la situación. Así, para que las condiciones de cada disparo sean las mismas se fija rígidamente el arma a un afuste, se usan balas idénticas con cargas idénticas. En estas condiciones todas las balas deberían impactar el objetivo en el mismo punto, ya que según el principio de causalidad las mismas causas producen los mismos efectos. Pero lo que ocurre en realidad es que nunca hay un punto único de impacto, sino que hay una distribución de los impactos en torno a ese punto ideal que se fijó en el cálculo. Es otra manera de ilustrar la afirmación de Landsberg y el hallazgo del principio de incertidumbre: ¡La precisión infinita es imposible! Siempre queda un resto de indeterminación, de aleatoriedad.

Esa distribución o desviación de los impactos puede, no obstante, ser también calculada de antemano con lo que Halbwachs llama "las leyes del azar", que entendemos como los cálculos probabilísticos. Los factores que perturban este sistema, que en principio es determinista, son: los ligeros movimientos del afuste en cada disparo, las fluctuaciones del aire y las irregularidades de la máquina que ha fabricado las balas y los cartuchos. Lo característico de estos factores que perturban el sistema es que son causados, a su vez, por factores externos al sistema y actúan de manera incoherente respecto a la ley causal, y como no pueden ser conocidos individualmente, solo pueden entrar en el cálculo de forma aleatoria.

Esta situación evidencia la diferencia entre la ciencia física y la realidad física. Lo que hace la física es describir situaciones ideales, "pero la descripción exacta de un fenómeno físico será siempre el resultado de la combinación de una ley causal y una ley aleatoria, contrapartida de los niveles de la naturaleza" (Halbwachs, 1977, p. 45).

Esta forma del azar que desarrolla Halbwachs es el azar del que se ocupa el cálculo de probabilidades y la ley de grandes números, que calcula las posibilidades de que un evento ocurra según la descripción matemática de la varianza y la frecuencia de ese fenómeno teniendo en cuenta algunas variables desconocidas (Landsberg et al., 1986, p. 45), pero habíamos anunciado un autor que ha planteado la existencia de un azar que va más allá, porque ni siquiera se somete a estas "leyes de lo aleatorio".

Se trata del matemático Benoît Mandelbrot (1996), quien realizó una importante contribución a la ciencia, no sólo con su conceptualización sobre los fractales, tema por el que es mundialmente conocido, sino también con lo que él denominó "diversos estados del azar" y desde ya los enunciamos: el azar en su estado "benigno" y el azar en su estado "salvaje". La distinción de estos estados del azar fue un aporte tal a las 
matemáticas que modificó el modo de interpretar los fenómenos de los que se ocupa (Mandelbrot, 1996, p. 18).

Mandelbrot utiliza ejemplos de la vida cotidiana para ilustrar esos estados del azar. Tomemos el ejemplo del filo de una navaja bien afilada. A simple vista el filo de la navaja parece tener una dirección perfectamente recta, uniforme, pero a escala microscópica tiene un aspecto extremadamente irregular, es este un buen ejemplo de lo que afirmaba Ramírez: que los elementos que conforman la estructura (el filo) son irregulares, aleatorios, pero agrupados y a gran escala conforman una regularidad. Esta forma del azar es la que Mandelbrot ha denominado "azar benigno" en el sentido médico del término, justamente porque los científicos le han encontrado tratamiento, es una especie de problema tratable. Gracias a la ley de grandes números y el cálculo de probabilidades este es un azar manejable, hasta el punto que los físicos han tenido la impresión de haberlo domeñado:

Las fluctuaciones benignas han sido descritas por los matemáticos; muchas han sido explicadas por los científicos; los ingenieros han aprendido a manejarlas para volverlas más tolerables. Estos últimos podrían evaluar la probabilidad de un acontecimiento futuro basándose en medidas, calculadas sobre un número suficientemente grande de acontecimientos pasados (Mandelbrot, 1996, p. 18).

Por eso cualquier ciencia que se ocupe del azar benigno puede convertirse todavía en una ciencia exacta (Mandelbrot, 1996, p. 16). Pero las investigaciones llevaron a Mandelbrot a distinguir otra forma del azar:

Llegué a la conclusión de que el azar benigno de la mecánica estadística no había supuesto más que un primer estadio del indeterminismo en las ciencias. Era, en consecuencia, indispensable ir más allá del caso benigno (sin modificar el cálculo de probabilidades), pasar a un "segundo estadio" del azar, al que ahora me refiero con otro término pintoresco y vigoroso: azar "salvaje" o brutal. Poco a poco me vi llevado a considerar estos dos azares, no ya como dos estadios sucesivos de un proceso histórico, sino como dos "estados" de características intrínsecamente diferentes (Mandelbrot, 1996, p. 16).

Este azar salvaje puede tener dos causas: en primer lugar, que las magnitudes importantes de un fenómeno experimenten fluctuaciones que no son benignas, es decir, que no verifiquen la regularidad de Gnedenko y Kolmogoroff, la ley de los grandes números. La segunda causa es que las fluctuaciones de las magnitudes puede que sí converjan hacia la regularidad, pero de una forma extraordinariamente lenta, de modo que los datos obtenidos no dicen mucho sobre lo que puede pasar a un nivel colectivo o macro, y tal como decía el economista Keynes, al burlarse del afecto que sentían sus colegas por el largo plazo: "a largo plazo, todos muertos". Por estas características, en el estudio del azar salvaje los métodos del azar benigno fracasan. Y por esta razón Mandelbrot estuvo tentado a llamarlo "azar maligno" también en un sentido médico, que sugiere problemas muy difíciles "y para los cuales la noción de tratamiento o de cura no tenía la misma significación que en los casos benignos" (Mandelbrot, 1996, p. 20). 
La idea del azar salvaje rondaba en el campo de las matemáticas desde 1853, pero en ese entonces la existencia de un fenómeno con esas características se consideraba patológica y nadie esperaba encontrárselos en la realidad. Sin embargo, Mandelbrot aporta varios ejemplos de fenómenos en los que se encuentra el azar en su estado salvaje. Retomemos dos de ellos:

$\sim$ El aspecto de la costa de Gran Bretaña: a diferencia de lo que ocurre con el filo de la navaja, sus irregularidades no convergen finalmente en una tendencia general rectilínea, más bien aparece más irregular a medida que se pasa del nivel local, al comarcal y al provincial.

Las fluctuaciones de las crecidas anuales del Nilo: basándose en el estudio de las fluctuaciones del azar benigno se podría asumir equivocadamente que si se registran las fluctuaciones del Nilo en períodos más bien largos y sucesivos estas deberían ser, a grandes rasgos, idénticas, sin embargo, los datos registrados indican que las medidas tienden a ser muy diferentes.

La ciencia moderna, y su fe puesta en el determinismo, hacía que la idea del azar salvaje pareciera absurda y quedara excluida. Sin embargo, los trabajos de Mandelbrot mostraron su importancia y recurrencia en la naturaleza. Si los científicos no se esperaban el azar salvaje y lo habían mantenido al margen de las investigaciones era porque los estudios de la probabilidad habían camuflado semejante salvajismo, unas veces exagerándolo, al tildarlo de excepcional o patológico, y otras veces minimizándolo en pro de la generalización que caracterizaba a todas las ciencias hace 30 años, pero "el azar salvaje merece considerarse objeto de estudio por derecho propio" (Mandelbrot, 1996, p. 19), y para ello se requieren "unas leyes más sofisticadas, de orden superior; como las ecuaciones diferenciales que describirían el comportamiento del caos, según la teoría de las catástrofes" (Ramírez, 2012b, sec. 138. Formaciones de lo aleatorio, p. 244).

Sin embargo, sobre el estudio del azar Ramírez hace una precisión: afirma que el azar como tal no se estudia, ya que esto implicaría simbolizarlo, regularizarlo; lo que entraría en contradicción con lo que su nombre pretende designar: lo informe, lo no regularizable. Lo que sí puede estudiarse son los efectos del azar sobre lo determinado:

[...] si queremos estudiar el azar, lo aleatorio, hemos de investigar su dialéctica con lo determinado. Pero no partiendo del supuesto de que el azar también lo está, aunque con leyes más complejas, como hacen los partidarios del azar blando o benigno, sino aceptando su indeterminación en toda su significación; sin rechazar siquiera las connotaciones demoníacas que sugiere la palabra maligno, que Mandelbrot alude y que Einstein descarta cuando dice: "Dios no juega a los dados". Pues a esta afirmación responderíamos: "Si no hay azar, ¿cómo podría Dios jugar?" (Ramírez, 2012b, sec. 138. Formaciones de lo aleatorio, p. 244). 
Finalmente, Mandelbrot destaca lo significativo que ha sido el estudio del azar salvaje o puro en su trabajo sobre los fractales, "el azar puro puede tener un aspecto que no podemos negarnos a calificar de creativo" (Mandelbrot, 1996, p. 20), y que esa creatividad le proporcionó, diez años más tarde, los pseudo-relieves terrestres fractales. Más adelante veremos con detalle la relación que establece Ramírez justamente entre el azar y la creación.

Veamos a continuación cómo ha sido planteado el azar en el nivel biológico de la realidad, su esencial función que, junto con la necesidad (las determinaciones), ha dado lugar a todo lo que existe.

A esta conclusión llegó Jacques Monod con sus estudios en biología molecular, quien fue galardonado con el premio nobel de medicina por sus investigaciones en ese campo: el desarrollo de los seres vivos ocurre por una mezcla de azar y necesidad (determinaciones). Allí muestra la aparición del orden (leyes, regularidades, invariancias, determinaciones) a partir de un azar absoluto inicial. Estructuras complejas de nuestra conformación biológica (mitocondrias o membranas), que tienen propiedades funcionales específicas, determinadas, son construidas por el ensamblaje espontáneo de las proteínas que las constituyen. "Hay aparición de orden, diferenciación estructural, adquisición de funciones a partir de una mezcla desordenada de moléculas individualmente desprovistas de toda actividad, de toda propiedad funcional intrínseca que no sea reconocer los compañeros con los que van a construir la estructura" (Monod, 1993, p. 100). La esencia de estos procesos consiste en que la organización de un edificio multimolecular complejo está contenida, en potencia, en la estructura de sus constituyentes, pero sólo se revela y deviene actual por el ensamblaje con otros.

Además de esto, al estudiar la estructura de una proteína, es decir, la secuencia de aminoácidos que la compone y determina sus propiedades electivas, no se encuentra ninguna regularidad, ninguna singularidad, ninguna restricción:

Se conocen hoy en día centenares de secuencias, correspondientes a distintas proteínas, extraídas de los organismos más diversos. De estas secuencias, y de su comparación sistemática ayudada por los modernos medios de análisis y cálculo, se puede hoy deducir la ley general: la del azar. Para ser más precisos: estas estructuras están «al azar» en el sentido que, conociendo exactamente el orden de 199 residuos de una proteína que comprende 200, es imposible formular ninguna regla, teórica o empírica, que permita prever la naturaleza del único residuo no identificado aún por el análisis (Monod, 1993, p. 109).

Pero al mismo tiempo hay que reconocer una paradoja, y es que la misma secuencia de aminoácidos que aparece como el producto de una elección al azar, está reproducida en todas las moléculas de la proteína considerada, es decir, la secuencia al azar de cada proteína está reproducida millones de veces en cada célula por un 
mecanismo de alta fidelidad que asegura la invariancia de las estructuras. "El azar es captado, conservado, reproducido por la máquina de invariancia y casi convertido en orden, regla, necesidad", y "De un juego totalmente ciego, todo, por definición, puede salir, incluida la misma visión" (Monod, 1993, p. 110).

Lo que hace la ciencia es buscar invariantes, regularidades, leyes. El descubrimiento de la célula y la teoría celular en el campo de la biología aportó la unidad que hay detrás de toda la diversidad: "Se sabe hoy en día que, desde la bacteria al hombre, la maquinaria química es esencialmente la misma, tanto por sus estructuras como por su funcionamiento" (Monod, 1993, p. 116). Surgen entonces dos preguntas: si químicamente los constituyentes son los mismos en todos los seres vivos ¿cómo explicar la diversidad morfológica y fisiológica?, y ¿cómo es que cada especie conserva sin variaciones a través de las generaciones la estructura que la caracteriza y la diferencia de cualquier otra?

Monod responde estas cuestiones planteando que los seres vivos, efectivamente, están formados por secuencias metabólicas que son universales (nucleótidos y aminoácidos), pero estas secuencias se pueden usar para muchas funciones, entonces en cada organismo hay una adaptación funcional de secuencias metabólicas universales (Monod, 1993, p. 116). Los constituyentes universales (nucleótidos y aminoácidos) funcionan como un alfabeto con el que puede escribirse toda la diversidad de las estructuras y las funciones de la biósfera, mientras que lo que asegura la invariancia es la reproducción sin variaciones en cada generación celular del texto escrito en el ADN como secuencias de nucleótidos.

Los aminoácidos de la proteína hacen la labor de traducir la información del ADN, y este mecanismo de traducción es unidireccional, la información va del ADN a la proteína, pero nunca a la inversa. Por eso el único mecanismo posible de modificación es que haya una alteración en las instrucciones representadas en la secuencia del ADN. Parece entonces un sistema cerrado, conservador, "podría pues parecer que por su misma estructura, este sistema deba oponerse a todo cambio, a toda evolución" (Monod, 1993, p. 124).

Sin embargo, que siempre se reproduzca la secuencia de nucleótidos del ADN sin ninguna variación es imposible, la física demuestra que reducir a cero las perturbaciones (el azar) es un límite imposible y que toda entidad microscópica puede sufrir perturbaciones de orden cuántico, y la acumulación de esas perturbaciones altera la estructura del sistema macroscópico de forma gradual (Monod, 1993, p. 124). El mecanismo de invariancia de los seres vivos, a pesar de su perfección, no escapa a esta ley, y ocurren errores de transcripción que, en lugar de ser corregidos, son automáticamente transcritos debido a la fidelidad ciega del mecanismo de transcripción. Estos errores, al alterar la secuencia de nucleótidos del ADN, terminan teniendo efectos funcionales en la proteína. 
Decimos que estas alteraciones son accidentales, que tienen lugar al azar. Y ya que constituyen la única fuente posible de mutaciones del texto genético, único depositario, a su vez, de las estructuras hereditarias del organismo, se deduce necesariamente que sólo el azar está en el origen de toda novedad, de toda creación en la biósfera. El puro azar, el único azar, libertad absoluta pero ciega, en la raíz misma del prodigioso edificio de la evolución (Monod, 1993, pp. 125-126).

La evolución no es una propiedad de los seres vivos, sino que, por el contrario, tiene su raíz en las imperfecciones del mecanismo de reproducción altamente conservador que constituye a los seres vivos y que es su más grande privilegio. Lo que ocurre es que esa fuente de perturbaciones que, en un sistema no vivo, es decir, no replicativo, destruiría poco a poco su estructura, en el caso de los seres vivos es el origen de su evolución. Es así como ocurren las formaciones de lo aleatorio en la biología: el azar muestra su libertad creadora gracias a la estructura replicativa del ADN, que opera como un conservatorio del azar:

\begin{abstract}
Los acontecimientos elementales iniciales que abren la vía de la evolución a esos sistemas intensamente conservadores que son los seres vivos, son microscópicos, fortuitos y sin ninguna relación con los efectos que puedan entrañar en el funcionamiento teleonómico.
\end{abstract}

Pero una vez inscrito en la estructura del ADN, el accidente singular, y como tal esencialmente imprevisible, va a ser mecánica y fielmente replicado y traducido, es decir a la vez multiplicado y transpuesto a millones o a miles de millones de ejemplares. Sacado del reino del puro azar, entra en el de la necesidad, de las certidumbres más implacables (Monod, 1993, p. 133).

La selección ocurre al nivel del organismo, ya que las novedades, que se presentan como alteraciones de la estructura de una proteína, podrán ser aceptadas o no "en función de su compatibilidad con el conjunto de un sistema ya ligado por innumerables sujeciones que deciden la ejecución del proyecto del organismo. Las únicas mutaciones aceptables son pues las que, por lo menos, no reducen la coherencia del aparato teleonómico, sino más bien lo confirman en la orientación ya adoptada o, sin duda más raramente, lo enriquecen de nuevas posibilidades" (Monod, 1993, p. 134).

Otro autor fundamental en esta sustentación del azar en la ciencia es el físico Jorge Wagensberg. Él desarrolla una concepción de la realidad que incluye tanto aspectos determinados como indeterminados, y plantea como hipótesis de trabajo de la ciencia contemporánea la existencia ontológica del azar; en sus palabras: "el derecho de la naturaleza a una dosis de azar" (Wagensberg, 2007, p. 26). Veamos entonces cómo Wagensberg sustenta la idea del determinismo dialéctico.

Si en la naturaleza no hubiera ni una sola ley todo sería posible, todos los objetos del mundo serían igualmente frecuentes y todos los sucesos igualmente probables, un objeto cualquiera podría sufrir un cambio cualquiera. Para Ramírez esto sería el Caos 
con mayúscula ${ }^{6}$, un estado en el que no hay ninguna ley y, por tanto, nada permanece, todo se crea y se destruye al instante (Ramírez, 2012b). Esta es la posición que previamente desarrollamos como indeterminismo, y que ha sido descartada por la ciencia, pues la experiencia más inmediata y cotidiana permite constatar que la realidad en la que vivimos no se comporta así, no todo vale, no todo es posible, por ejemplo no es posible un sol cúbico o que un planeta espontáneamente invierta el sentido de su rotación. Ya es tarde para aferrarse a esta idea, la ciencia ya ha descubierto muchas dependencias, regularidades y restricciones. Estas regularidades de la naturaleza permiten deducir que en el universo hay (conocidas o desconocidas) leyes fundamentales, muchas de ellas ya han probado su eficacia para hacer predicciones y anticipar lo incierto. Wagensberg va a llamar a este conjunto de leyes fundamentales del universo "La Constitución de la Realidad", con el propósito de aludir juguetonamente a "La Constitución Política" de los estados, donde están contenidas las leyes fundamentales que conforman el sistema jurídico y regulan la vida de los ciudadanos.

Hacer esta analogía de las leyes fundamentales de la naturaleza con las leyes fundamentales de un estado, le permite a Wagensberg ilustrar lo que para él es una ley. Una ley, más que una obligación, es una restricción o una prohibición, como las que el sistema penal de un estado establece para los ciudadanos, que no obligan a vivir de una única manera, sino que limitan las posibilidades de cómo vivir para no ser penalizado. Aunque la ley prohíbe ciertos comportamientos, aún quedan muchos otros comportamientos legales posibles y el ciudadano tiene la opción de actuar legal o ilegalmente. De la misma manera, las leyes fundamentales de la naturaleza son un conjunto de restricciones que dejan, sin embargo, un amplio margen de elección.

Esta diferencia entre concebir la ley como obligación o como restricción no es menor: definir las leyes como obligaciones implica que no hay posibilidad ni margen para elegir, sólo hay un camino, el que ordena la ley. Mientras que definir la ley como una prohibición o una restricción, deja abierto el camino de todas las demás posibilidades que no están prohibidas por la ley. Dicho de otro modo, la ley como obligación implica una visión determinista del mundo, mientras que la ley como prohibición da lugar a lo indeterminado, al azar, a un territorio libre en el que las cosas ocurren por elección, no por obligación, donde lo que ocurre no lo determina o lo decide la ley, sino que ocurre con el permiso de la ley. Justamente esta es la tesis que defiende Jacques Monod. Este autor afirma que la biósfera, el desarrollo de seres vivos, es un acontecimiento compatible con las leyes fundamentales, pero no deducible de ellas, por lo tanto es un acontecimiento esencialmente imprevisible. Lo que esto significa es que la existencia de un objeto como un átomo, una piedra o un ser vivo, debe ser compatible con los principios de una teoría, pero que no se le exige a la teoría prever la existencia de esa configuración particular del átomo, de la piedra o de un

6 Una ampliación de este concepto se presenta en el cuarto capítulo de esta investigación. 
organismo, "este objeto no tiene, según la teoría, el deber de existir, mas tiene el derecho" (Monod, 1993, p. 53-54).

En defensa de la ley como restricción, Wagensberg recurre a una lúcida metáfora del físico Richard Feyman, según la cual la realidad funcionaría como una partida de ajedrez y las reglas de este juego operarían como las leyes de la naturaleza. Veamos: en el ajedrez las reglas operan como prohibiciones, pues, dada una posición, cada pieza tiene unas casillas permitidas y otras prohibidas, pero el jugador tiene la libertad de escoger qué pieza mover y hacia qué dirección. Esa libertad es la que nos permite apreciar la táctica, las habilidades del jugador, su creatividad, su talento, hablar de un estilo de juego agresivo o conservador y también de sus errores. Con base en esta posibilidad de elección es que se organiza un torneo de ajedrez, que no tendría sentido si estuviera escrito de antemano quién va a ganar. Cada movimiento hace que la partida tome un nuevo rumbo, abre posibilidades que antes no existían y, a la vez, elimina otras. Nada de esto sería posible si las reglas del juego operaran como obligación, pues de ese modo siempre se jugaría la misma partida. En cambio, el número de partidas posibles que se pueden jugar es, en la práctica, infinito: "un uno seguido de ciento veinte ceros, mucho más que el número de átomos que constituyen la materia del universo entero (ya de por sí escalofriante, un uno seguido de ochenta ceros)" (Wagensberg, 2007, p. 30).

Así como el juego de ajedrez, la realidad es una trama de alternativas, de caminos posibles, está plagada de bifurcaciones (un concepto central en la teoría del científico Ilya Prigogine), la realidad tendría la forma de una nervura, es decir, como una estructura con forma ramificada, que recuerda la estructura del sistema nervioso. "Cuando un fenómeno se nos antoja impuesto por una ley determinista, como el tiro parabólico de un artillero, es porque estamos ante un caso de rarísima simplicidad. En general, la realidad es una trama de evoluciones posibles" (Wagensberg, 2007, p. 31).

Los movimientos obligatorios, la situación de "jugada forzada" o de "elección obligada" existen en ajedrez, pero es un caso límite que se presenta por acumulación de prohibiciones, como es el caso del jaque: las prohibiciones o restricciones son tantas que obligan un movimiento, y en el jaque mate las restricciones son tales que todos los movimientos están prohibidos, hacer un movimiento es sencilla y completamente imposible, "se comprende que los jugadores de ajedrez acostumbren a abandonar el juego y reconocer su derrota antes de verse en la humillante situación de mover piezas forzadamente, una situación en la que su cerebro ya no tiene trabajo que hacer, nada que seleccionar" (Wagensberg, 2007, p. 35). Extrapolando esta situación del juego a la naturaleza, diríamos que en ella podrían presentarse obligaciones, pero para que eso ocurra se necesitan infinitas prohibiciones. Es una manera de mostrar la elección que se esconde detrás de una obligación.

Según el determinismo sólo un único comportamiento es posible, la opción existe, pero es única, es obligatoria, las restricciones serían tan fuertes que habría margen 
para una sola cosa, no habría margen para elegir nada, no hay espacio para que el azar influya en la evolución de las cosas. Esta ha sido la situación soñada por Laplace, leyes capaces de predecir la evolución del mundo. Las leyes de este tipo, que operan como una determinación perfecta, han sido de mucho prestigio en la física; las más importantes leyes de la física son expresadas como ecuaciones diferenciales, es decir, muestra las n variables de un fenómeno en su estado inicial y sus variaciones en el tiempo y el espacio. Algunos de los más importantes y famosos ejemplos de estas leyes son: la segunda ley de Newton en la mecánica clásica, las ecuaciones del electromagnetismo creadas por Maxwell, la ecuación de Einstein para la teoría general de la relatividad y la ecuación de Schrödinger para la física cuántica. Estas leyes, expresadas como ecuaciones, son leyes de obligación o deterministas, porque una vez que en el sistema se fija un estado cualquiera (esto se hace tomando el valor de las condiciones iniciales o en cierto tiempo y espacio) todo queda perfectamente fijado para cualquier otro tiempo y espacio, es decir, la evolución del sistema se puede predecir. Con esta escudería de leyes fundamentales es comprensible la tendencia a pensar que las leyes son obligaciones que no dejan ninguna posibilidad para algo como una elección que pueda intervenir y modificar el destino del mundo (Wagensberg, 2007, p. 32).

Sin embargo, para desmontar esta visión, Wagensberg recuerda que siempre existe un margen para la elección; de hecho, la fijación de las condiciones iniciales de un sistema en el tiempo y el espacio, que son las que determinan la trayectoria que va a ocurrir o acceder a la realidad, consiste en la selección de unos valores concretos, y es aquí donde radica la elección y la libertad del sistema (su impredecibilidad): en ese margen de las condiciones iniciales. Muchas situaciones son tan inestables que una fluctuación infinitesimal de las condiciones iniciales decide el futuro del sistema. Es así como la teoría del caos define un sistema caótico: aquel que es altamente sensible a las condiciones iniciales. Por eso, "en la práctica, hacer una predicción de la obligación dictada por una ley determinista requiere siempre una selección" (Wagensberg, 2007, p. 33). Es pertinente agregar que la inestabilidad e impredecibilidad del sistema no está dada sólo por los cambios en las condiciones iniciales, sino en toda la evolución del sistema; en otras palabras, no sólo hay incidencia del azar en las condiciones iniciales, sino en cualquier momento del proceso.

Lo que Wagensberg muestra es que incluso las leyes fundamentales más deterministas pueden describirse como una prohibición y no como obligación, por ejemplo el principio de conservación de la física, según el cual magnitudes como la masa (cantidad de materia) o la energía siempre se conservan durante un proceso real. Esta ley es muy fuerte y muy útil para predecir lo que puede pasar en una reacción química o una colisión de partículas, ya que por muchas cosas que pasen durante el proceso se puede afirmar que antes y después de él estas magnitudes serán las mismas, no se viola el principio de conservación de la materia o la energía, un proceso que viole este principio sencillamente no puede acceder a esta realidad, no se puede construir un motor que dé más energía de la que consume. De ahí la ley como 
prohibición: "tal proceso no puede ocurrir". El grado de determinismo de una ley científica está dado por su capacidad para prohibir. Otros ejemplos de leyes que operan como prohibición son: la velocidad de cualquier objeto real no puede ser mayor que la velocidad de la luz (300.000 kilómetros por segundo), superar esta velocidad está prohibido en este mundo. Así mismo, la temperatura de un objeto no puede ser igual o menor a $0^{\circ}$ Kelvin, estas temperaturas están prohibidas para cualquier objeto de este mundo. Estas son algunas de las reglas de juego de la naturaleza, pero La Constitución de la Realidad selecciona lo que existe combinando estas leyes que prohíben ciertos movimientos con el azar (Wagensberg, 2007, p. 85), un diálogo entre lo determinado y lo indeterminado.

Miremos en otro nivel de la realidad, ya no el físico sino el biológico, un ejemplo de ese diálogo entre lo determinado y las elecciones posibilitadas por lo indeterminado, el azar. Para un animal que está a punto de ser cazado por un depredador hambriento las restricciones de la constitución de la realidad pueden ser muchas, pero el dominio de lo no regulado puede ser todavía muy grande. Supongamos que una cebra descubre a una leona al acecho. Las restricciones de la realidad hacen que la cebra no pueda volar, ni trepar a un árbol, ni enterrarse, pero puede elegir entre muchos otros comportamientos que sí estarían permitidos por la constitución de su realidad: puede correr en infinitas direcciones, puede correr en zigzag para aumentar las posibilidades de que su depredador falle en su último salto, puede elegir separarse de su manada y confiar en que la leona seguirá al grupo y se olvidará de ella, puede elegir perderse dentro de la manada y confiar en que así otra cebra puede ser cazada... "De las infinitas alternativas, ocurrirá lo que ocurrirá según la decisión que tome el animal. Acceder y permanecer en la realidad requiere la idea de selección" (Wagensberg, 2007, p. 39). Se comienzan a perfilar aquí las profundas implicaciones del azar y la elección en el destino personal, pero de este tema nos ocuparemos en los siguientes capítulos.

El paisaje de la realidad sería como un territorio enmarañado de caminos que se entrecruzan, algunos de ellos con señales de prohibido el paso, pero no hay señales de dirección obligatoria, una dirección obligatoria sería el resultado de que todas las demás direcciones estén prohibidas. En la realidad habría entonces caminos prohibidos, caminos permitidos y territorios sin ley. Ese territorio que las prohibiciones han dejado libre se ha denominado azar o incertidumbre (Wagensberg, 2007, p. 36). Esta visión del mundo es compatible con la idea de novedad, con la idea de una evolución no escrita, no predeterminada. Y entre la ocurrencia y no ocurrencia de un suceso hay una selección.

Sin embargo, al avanzar con esta idea surgen nuevas preguntas. En el ajedrez es claro que quien elige, quien decide o selecciona entre opciones es el jugador, pero ¿quién o qué elige, decide o selecciona en la naturaleza? En el ajedrez el criterio para seleccionar es ganar, hay un objetivo que orienta la selección del jugador, pero en la naturaleza ¿hay criterios para seleccionar?, ¿hay objetivos?, ¿se trata de ganarle a un 
adversario? La respuesta de Wagensberg es que sólo se puede hablar de objetivos cuando interviene el cerebro, es decir, sólo los seres con cerebro pueden trazarse objetivos, pero en el resto de procesos de la naturaleza pareciera haber dos principios que orientan la selección: la tendencia a seguir existiendo (tener la posibilidad de perseverar y permanecer en la realidad) y minimizar la energía, lo que implica seguir una trayectoria óptima (realizar la mejor opción teniendo en cuenta las condiciones), pues así como el jugador intenta ganar en el menor número de jugadas (si puede ganar con dos jugadas no lo hace con tres), así mismo los fenómenos de la realidad tienden a minimizar la energía.

Esta tendencia a seguir existiendo y el principio de mínima acción podrían parecer teleológicos, es decir, dan la impresión de que las cosas suceden con la intención de alcanzar un objetivo predeterminado, un propósito. En general, las ideas teleológicas tienen bastante mala reputación en la ciencia, porque implican defender la existencia de un ser que ha diseñado el mundo. Esta apariencia teleológica la advierte Jacques Monod, por eso en su ensayo El azar y la necesidad se pregunta cómo explicar la evolución de los organismos vivos, que pareciera desarrollarse con la intencionalidad de ejecutar un proyecto, de lograr un propósito, pero, a la vez, respetando el mandato de objetividad de la ciencia, esto implica aportar una explicación que no recurra a seres metafísicos, al animismo, que no proyecte sobre la naturaleza la actividad del ser humano y suponga un ser con intenciones que dirige la evolución, porque, aunque sea un axioma, "la ciencia moderna sigue siendo alérgica a aceptar un Espíritu o Dios creador, organizador" (Ramírez, 2012b, sec. 145. Teleonomía y nostridad, p. 252).

Ramírez considera que matemáticamente es posible mostrar que los procesos naturales se desarrollan de una manera óptima, minimizando la energía como dice Wagensberg, sin que sea necesario apelar a una intención o proyecto que los dirige. Esto se puede ilustrar con la imagen de un arroyo descendiendo de una montaña: de todas las trayectorias posibles el agua sigue, indefectiblemente, la más rápida, la más sencilla, dadas las condiciones de la montaña (su inclinación y sus accidentes), y no porque el agua "busque" esa trayectoria o tenga una intención o propósito que realizar al descender de la montaña, sino por el principio de mínima acción.

Con los conceptos de teleonomía y optimización, tomados de Monod, de las matemáticas y la ingeniería, Ramírez responde las preguntas que formula Wagensberg: la teleonomía descarta el concepto de finalidad (objetivo, propósito), pero no el de forma final, pues parece haber una tendencia en la naturaleza a la optimización de los procesos, lo que va generando formas óptimas, "mejores", en tanto serían más estables debido a su eficacia ecológica, lo que los griegos llamaban una forma armónica con el entorno, con el cosmos (Ramírez, 2012b, sec. 145. Teleonomía y nostridad, p. 252); ese sería el criterio de selección de la naturaleza. En el caso de los seres vivos el proyecto primitivo único es la conservación y la multiplicación de la especie, en los términos de la biología, el proyecto esencial de los seres vivos es la 
invariancia, esto es el poder de reproducir y transmitir sin variaciones la información correspondiente a su propia estructura.

Otro ejemplo de optimización es el que muestra Monod en la conformación de una proteína, ya que de todas las estructuras a las que se puede acceder, se realiza la más compacta posible, y esta se realiza porque, al favorecer la expulsión de un máximo de moléculas de agua, es la más estable, la que perdura, se conserva y, por eso, tiene la posibilidad de replicarse: "estas formas plegadas de la proteína son termodinámicamente más estables que las formas desplegadas" (Monod, 1993, p. 106), lo que muestra también esa tendencia de las formas, de las estructuras, a preservarse, a seguir existiendo.

Monod compara las estructuras que componen una cámara fotográfica y el ojo de un vertebrado para mostrar que la adaptación funcional de los seres vivos hace que sea "estéril y arbitrario querer negar que el órgano natural, el ojo, representa el término de un «proyecto» (el de captar imágenes) tan claro como el que llevó a la consecución de la cámara fotográfica" (Monod, 1993, p. 20); esto lo lleva a concluir que una de las propiedades fundamentales que caracteriza sin excepción a todos los seres vivos es que son objetos teleonómicos (dotados de un proyecto).

Quizá sea un simple asunto de uso del lenguaje, pero decir que los seres vivos son objetos dotados de un proyecto, tal como lo hace Monod, no parece exorcizar completamente los espíritus de la subjetividad y el antropocentrismo. Ramírez conserva una actitud escéptica al reconocer que hasta ahora es indemostrable tanto la existencia como la inexistencia de un Dios o un telos que dirige la evolución del universo. Como plantea Barthelemy, la objetividad no es excluir o asentar las causas finales, simplemente es la fidelidad a lo real, sea el indeterminismo o sea la finalidad lo que esté inscrito en el mundo objetivo (Barthelemy, 1974, p. 58). Sin embargo, la teoría de la evolución ofrece una explicación más sencilla de la aparición de criaturas complejas sin recurrir a la existencia de alguien que las hubiera diseñado y, además, tiene la virtud de coincidir perfectamente con los datos disponibles:

No hay un componente teleológico en la teoría de Darwin: mutaciones aleatorias producen variaciones en los organismos, y las presiones externas debidas al entorno y a otros seres vivos determinan cuáles de esas variaciones se transmiten a la siguiente generación. Basta con este proceso para dar cuenta de la complejidad que observamos actualmente en la vida sobre la Tierra. Dicho de otro modo, no es necesario un gran designio ni la ascensión gradual de la vida hacia algún tipo de perfección, sino que la evolución de la vida es una caminata aleatoria, generada por la copia imperfecta de genes en un entorno externo en constante cambio (Cox \& Forshaw, 2015, pp. 67-68, el resaltado es nuestro).

Tanto en la partida de ajedrez como en la evolución de la realidad, cada suceso redefine una trama de distintas alternativas, se trata de procesos históricos llenos de bifurcaciones que avanzan hacia el futuro. Así como en el ajedrez, ocurre en la 
naturaleza, en el derecho penal, en el tráfico: existe la posibilidad de selección, y gracias a ella podemos hablar de la creación de nuevos seres, de la creatividad de un jugador de ajedrez, de la creatividad deplorada de un delincuente y de la creatividad celebrada de un artista, de libertad, de responsabilidad y de ética. Es de esta manera como Wagensberg plantea entonces el determinismo dialéctico:

\begin{abstract}
En pocas palabras, el conjunto de las leyes fundamentales de la naturaleza está en algún punto a medio camino entre los dos extremos: el «nada vale» y el «todo vale». Los dos extremos son dos casos únicos con infinitos intermedios. Un extremo corresponde a la creencia determinista, el azar es el producto de nuestra ignorancia. El otro extremo es sencillamente falso. Optar por el azar como un derecho intrínseco de la naturaleza es, pues, infinitamente más sensato. Hemos revoloteado en torno a esta pregunta: «¿Es el azar un producto de nuestra ignorancia o un derecho intrínseco de la naturaleza?»... y ya nos hemos posado sobre una de las respuestas. No se trata de creer o no en ella. Digamos que la aceptamos como hipótesis de trabajo para lo que queda de este ensayo. Las hipótesis de trabajo no son verdaderas o falsas, son sensatas o insensatas, funcionan o no funcionan
\end{abstract} (Wagensberg, 2007, p. 40).

Aparecen fundamentadas en este físico contemporáneo muchas de las ideas esenciales que Ramírez ha planteado: fundamenta la hipótesis del azar como ese resquicio de indeterminación que da lugar a la elección, y no solo al nivel de la realidad humana, como inventó Kant, sino en toda la naturaleza: la elección que tiene lugar en todos los niveles de la realidad física, química, biológica, psíquica, social.

\title{
2.6. Elección, emergencia y niveles de realidad
}

Desde la perspectiva del determinismo absoluto todo lo que ocurre ya estaba determinado por un estado anterior del universo, es decir, en el estado presente ya está escrito lo que ocurrirá y cómo. Mientras que desde la perspectiva de estos científicos contemporáneos que en sus investigaciones han concebido el azar, los fenómenos se van desarrollando por elecciones en medio de bifurcaciones, y es eso lo que los hace, hasta cierto punto, impredecibles, indeterminados, pues en cada instante se está eligiendo el devenir del siguiente.

Si las leyes de la realidad delimitan lo posible, pero queda todo un terreno libre donde más de una ruta es posible y una de esas opciones es la que tiene lugar y se realiza, eso indica que hay una selección, es más, que todo lo que existe es el resultado de una selección. Se podría decir que la naturaleza selecciona al azar o que el azar selecciona, pero esta selección no se lleva a cabo de manera homogénea o indiferenciadamente, el azar selecciona según la probabilidad que tenga cada alternativa. Conocer este modus operandi, esta forma de seleccionar, es el propósito con el que surge la teoría matemática de la probabilidad. Hacer apuestas sobre la selección más probable admite un tratamiento matemático. La selección es un artefacto que rompe las equiprobabilidades y muestra que no todo es igualmente probable (Wagensberg, 
2007, p. 63). Donde no hay determinaciones las singularidades "eligen" entre varias opciones, es este el principio de la creación, de la evolución del universo, es decir, de la emergencia de nuevas singularidades.

Es importante explicitar el encadenamiento que se está proponiendo entre el azar, la elección y la emergencia - definida por Monod como la propiedad de reproducir y multiplicar estructuras de complejidad creciente (como se cita en Barthelemy, 1974, p. 63) - . La existencia del azar, entendiendo por ello lo indeterminado, lo no regulado, lo caótico, lo aleatorio, hace que sea posible elegir, más aún, que sea necesario hacerlo cuando no hay una ley, una causa o una razón que determine el camino a seguir. Y esta forma de proceder de la naturaleza, a partir de elecciones, es lo que va dando lugar a la emergencia o creación de nuevos seres.

Las entidades libres son las que dan dinamismo al universo, es decir, las que no están articuladas a ningún sistema de nivel superior y por tanto no están reguladas por él. Tenemos así átomos libres (cuando no forman moléculas), moléculas libres, células libres... Al no estar instaladas en un lugar fijo dentro de un sistema, están disponibles para una nueva articulación, con lo que se posibilita la aparición de nuevos tipos de sistemas (Wells, 1973). Es esto lo que el filósofo Gilbert Simondon denomina la dimensión preindividual de la realidad, tal como veremos en el último capítulo de esta investigación.

Las singularidades o seres emergentes tendrían propiedades distintas de las que tienen sus elementos constituyentes; es lo que afirma la conocida frase: el todo (en este caso lo que emerge) es más que la suma de sus partes (los elementos constituyentes). Consideremos, por ejemplo, un gas o una sustancia. En el micronivel tenemos partículas y leyes mecánicas con variables tales como posiciones, velocidades, funciones de onda, etc. Mientras que en el macronivel tenemos un gas y leyes termodinámicas, con variables como la densidad, el volumen, la temperatura, la entropía, el color... propiedades que ni siquiera están definidas para una partícula. El nuevo nivel de realidad tiene nuevas propiedades, nuevas magnitudes y sigue nuevas leyes, tenemos entonces dos visiones diferentes de una misma realidad.

El emergentismo plantea que una combinación dada de fuerzas puede producir nuevas propiedades, nuevas relaciones en el universo (sinergia) o, incluso, nuevas fuerzas, y esto es lo que da lugar a nuevos entes que, a su vez, se van articulando. Serían creaciones que no requieren un creador (Ramírez, 2012b, sec. 142. El devenir de Logos, p. 248). "Crear algo es precisamente eso: establecer una nueva configuración, un nuevo ser que interactuará con el medio y originará una nueva dinámica" (Ramírez, 2012b, sec. 7. Creación, p. 30). La creatividad sería la tendencia a forjar nuevas articulaciones, a construir; mientras que la destructividad es la tendencia a destruir las construcciones que ya existen. 
Explicar el universo y todo lo que existe a partir del emergentismo es coherente con las teorías actuales de la física sobre la materia, pues ésta se considera justamente una articulación de fuerzas, una concentración de energía; y es también coherente con la teoría de la evolución en biología: la evolución implica la aparición de características nuevas, cualitativamente diferentes, esto es lo que se denomina emergencia. Todas estas teorías científicas sobre el origen del universo, de la materia y de la vida en la tierra, han dado lugar a una visión de la realidad que ha evolucionado por niveles:

\begin{abstract}
La articulación no es sólo agregación. Ciertas formas combinatorias permiten que emerjan propiedades distintas: crean algo nuevo. Es el principio de la creación. La combinación de partículas elementales puede llegar a producir (articular) átomos, la combinación de átomos producir moléculas y la asociación de estas, minerales. En ciertas combinaciones minerales emerge una nueva propiedad: la reproducción, como en los cristales. Son estos quizá, con los virus, los rudimentos de la vida, que empezará propiamente con las células. De allí sólo hay un paso a las plantas. Las más complejas de ellas pueden realizar movimientos rápidos (atrapadoras de insectos, adormidera). Todas ellas se mueven lentamente respondiendo a estímulos. Se discute si las más complejas pueden llegar a sentir. La sensación especifica al animal. Inicialmente serían sólo sensaciones de placerdisplacer [...] Sin embargo, al aparecer la consciencia, que está sostenida en la sensación, el propio placer se vuelve un objetivo en sí mismo. Es el principio del placer de Freud. [...] Muchos animales pueden tener consciencia, pero sólo el hombre posee un Yo, que surge como consecuencia del lenguaje y del vínculo social que este crea. Emerge así la autoconsciencia, el saber que se sabe, la reflexión (Ramírez, 2012b, sec. 48. Lo emergente, p. 113).
\end{abstract}

Un nivel de observación se define porque se constituye de objetos tales que ellos mismos se bastan para nombrar y conocer una parte de la realidad: partícula, átomo, molécula, célula, organismo... estas son unidades relevantes con interacciones mutuas relevantes, es decir, individuos. Podemos definir entonces un individuo como un objeto que se caracteriza por tener una independencia respecto del entorno y una estabilidad suficientes para interactuar de manera relevante con él, y que su consideración aporte conocimiento de la realidad a la que pertenece (Wagensberg, 2007). Las partículas son individualidades que al interactuar crean una nueva realidad llamada átomo, con nuevas propiedades. Los átomos al interactuar crean moléculas. Las células al interactuar dan lugar a un nuevo nivel de realidad constituido por organismos, los organismos, al interactuar conforman nuevas individualidades, como colonias, manadas, familias, sociedades.

Al observar o estudiar la realidad se puede elegir un nivel de observación, esto equivale a elegir una realidad, puesto que cada nivel puede diferenciarse como tal porque está regulado por leyes diferentes, sus leyes constitucionales o su constitución es diferente, por eso la ciencia ha desarrollado diferentes disciplinas para estas clases de realidad: la física para la materia inerte, la biología para la materia viva, la psicología para la materia consciente y la sociología, la economía para los grupos de seres conscientes. Las leyes del nivel microscópico pueden ser inaplicables en el macroscópico, por eso cada nivel tiene leyes que se ajusten a lo que se observa en él. 
En el primer nivel de realidad el objeto típico de estudio es una partícula y sus propiedades, en el siguiente nivel una célula y las leyes del comportamiento celular; en otro nivel el objeto de estudio típico puede ser un jugador de bolsa y las leyes que regulan el alza en las acciones.

Entre estos niveles de realidad y disciplinas que los estudian se encuentran puntos de superposición, en los cuales surgen otras áreas de conocimiento como la matemática, la economía, la medicina, la administración, la neuropsicología, ecología, geografía, historia, psicoanálisis, humanidades, arte, religión, entre otras (Manrique \& De Castro, 2016, p. 67).

Cada nivel emergente contiene al anterior, como un juego de matrioshkas. Diferenciar los niveles de realidad le permite al científico considerar cuándo interviene más de un nivel en los fenómenos que le interesa investigar y cuándo es un fenómeno que puede abordarse con independencia de los niveles anteriores. Por ejemplo, para estudiar una afasia es importante conocer no sólo las manifestaciones comportamentales y lo que ocurre a nivel psicológico, sino también a nivel neuronal. Pero para un sociólogo interesado en conocer las razones de una migración humana es irrelevante conocer el metabolismo de las células eucariotas, aunque todas las personas estén constituidas por ellas. "Las leyes que regulan la vida de un árbol o de un pájaro serán muy difícilmente deducibles de las leyes del mundo de las células eucariotas, aunque éstas sean los auténticos ladrillos de la estructura de árboles y pájaros..." (Wagensberg, 2007, p. 50). Hacer esta consideración evita caer en reduccionismos o desconocer factores causales relevantes para la explicación de un fenómeno:

El reduccionismo es la descripción, explicación o predicción de un fenómeno ubicado en un nivel de realidad a partir de las reglas que rigen en un nivel inferior de la realidad (Polanyi, 1968). Por ejemplo, el fisicalismo es la explicación de lo biológico exclusivamente a partir de las leyes físicas, el fisiologismo es la explicación de lo psíquico a partir de reglas biológicas, el psicologismo es la explicación de lo social a partir de reglas psicológicas (Manrique \& De Castro, 2016, p. 68)

Las consecuencias del reduccionismo son fundamentales para la psicología, pues en esta disciplina hay una tendencia a reducir los fenómenos psicológicos, por un lado, al nivel biológico de la realidad, lo que deriva en propuestas de tratamiento que tienen en cuenta solamente la medicación y la biología del ser humano (previamente mencionamos la terapia electroconvulsiva (TEC), que se basa en una explicación reduccionista del comportamiento humano, aunque se considera un procedimiento mayor y de último recurso). Por otro lado, se tiende a reducir la explicación de los fenómenos a un solo modelo: las pulsiones, los neurotransmisores, los esquemas de pensamiento, los refuerzos del ambiente... sin que haya un diálogo entre los distintos modelos de explicación y se reconozcan las distintas influencias que pueden determinar el comportamiento. Este tema será profundizado en el cuarto capítulo, cuando se aborde con detalle la causalidad en el nivel psíquico. 
Llegados al nivel de realidad de los organismos, aquellos que tienen cerebro son capaces de hacer algo especial en la naturaleza: anticiparse a la incertidumbre, y es así como Wagensberg define la inteligencia (Wagensberg, 2007, p. 59). Este es uno de los logros más importantes de la materia, poder anticipar la incertidumbre, una de las estrategias evolutivas más eficaces si de lo que se trata en la naturaleza es de elegir. Esta ramificación de la realidad da lugar a las creaciones, ya no de la naturaleza ciega, sino de la creatividad humana, creaciones con un propósito, dirigidas a objetivos. La constitución de la realidad de un organismo vivo y con cerebro sin duda impone muchas restricciones para él, que le vetan muchas posibilidades de existir, pero al mismo tiempo deja un enorme terreno de opciones; de hecho, se abren posibilidades que para una partícula son imposibles. La nervura de la realidad de un organismo humano no es de unas pocas ramas, sino de una frondosidad enorme (Wagensberg, 2007, p. 58).

Solo se puede permanecer en la realidad si primero se emerge, y para emerger en la realidad tiene que haber una compatibilidad de la singularidad que emerge con la constitución de la realidad. En el nivel más elemental de la realidad, el de la materia inerte, para permanecer en la realidad se requiere ser un elemento estable, tener estabilidad (Wagensberg, 2007, p. 61), eso es lo que hace un átomo, una molécula, un cristal, una piedra o una estrella ante los cambios de su entorno, ante la incertidumbre: persevera, continúa siendo. Estos objetos existen porque emergen de la combinación de lo que ya está ahí, y su permanencia en la realidad depende de su estabilidad. Ante los cambios del entorno, ante la incertidumbre, la única rebelión posible para un objeto inerte es ser estable, ese es el primer criterio de selección en el nivel más elemental de la realidad: la estabilidad. Resistir, ser un sistema con estabilidad es una propiedad que la naturaleza selecciona, favorece o, si se quiere, bendice. La resistencia, la estabilidad es la primera forma de rebelión contra la incertidumbre (Wagensberg, 2007, p. 63).

Pero la materia ha encontrado otras maneras más sofisticadas de permanecer en la realidad: es la materia que cobra vida. En este nivel de la realidad la naturaleza selecciona lo que sirve para seguir estando vivo. La materia viva no solo resiste los cambios caprichosos del entorno, sino que cuenta además con otra estrategia, otra posibilidad: modificarlo. Por ejemplo, ante una variación muy drástica de la temperatura del entorno, demasiado fría o demasiado caliente, un organismo vivo no sólo resiste conservando su identidad ante esos cambios, sino que al intercambiar información con el entorno detecta esas fluctuaciones que son riesgosas para su permanencia y reacciona ante ellas, generando procesos de autoorganización que le permiten mantener su propia temperatura. Un organismo vivo no solo tiene la alternativa de resistir, tiene además la alternativa de la movilidad (cambiar de entorno) y otra alternativa que Wagensberg denomina tecnológica (cambiar el entorno). Esta es la segunda forma de rebelión contra la incertidumbre que la realidad trae a los entes: los individuos vivos pueden modificarse a sí mismos y modificar el entorno para seguir estando vivos, para permanecer en la realidad. 
En esta escalada contra la incertidumbre hay estrategias aún más sofisticadas, más potentes y más rápidas que posibilitan seguir viviendo. La materia inteligente, consciente o culta, como la denomina Wagensberg, no solo resiste la incertidumbre o la modifica, sino que además la puede anticipar para reducirla. Con la materia pensante surgen nuevas posibilidades en la naturaleza: por primera vez el seleccionador no es el azar, sino la mente (Wagensberg, 2007, p. 70). El organismo dotado de inteligencia abstracta se enfrenta a situaciones inciertas, inéditas y cambiantes, con proyectos, intenciones, voluntad, objetivos. La mente y su capacidad de conocer es la tercera forma de rebelión contra la incertidumbre (Wagensberg, 2007, p. 76).

En síntesis, el tipo de selección que tiene lugar en el primer nivel de observación de la realidad, el de la materia inerte, es la selección fundamental. En el segundo nivel de la realidad, el de la materia viva, opera la selección natural. Y en el tercer nivel, el de la materia pensante, consciente o con mente, tiene lugar la selección cultural.

En este punto caemos en un debate que se ha dado en la filosofía y la ciencia sobre el progreso. Especialmente después de la primera y la segunda guerra mundial se cuestionó la idea de progreso que se fue gestando en el pensamiento europeo de la Ilustración. En el siglo XX - la escuela de Frankfurt como punta de lanza- se cuestionó la idea de considerar al ser humano el culmen del progreso, la vanguardia de la evolución, argumentando que justamente lo que se consideraba progreso llevó al ser humano a las peores atrocidades: en nombre del progreso se emprendieron guerras, colonizaciones y el exterminio de grupos humanos. El progreso, entendido a la europea, consideraba que había razas, culturas, religiones, cosmovisiones mejores que otras, y que las que se consideraban mejores tenían derecho a colonizar, explotar, esclavizar o exterminar a las demás. Las ideas en contra del progreso se fueron difundiendo en todo el pensamiento científico, especialmente en la biología, hasta el punto de considerar poco riguroso, subjetivista, prejuicioso y antropocentrista emplear la palabra progreso en la ciencia.

Entrar en este debate nos demoraría aún más llegar a los puntos centrales de esta investigación, y ya bastante hemos hecho esperar al lector con este recorrido por el azar en la ciencia contemporánea. Al respecto solo considero importante mencionar que así como fue cuestionada la carga ideológica que tenía la idea de progreso de la Ilustración, igualmente ideológico es el rechazo y casi prohibición del uso de esta palabra en la ciencia. Proscribir esta palabra en la ciencia, en la biología, en la teoría de la evolución quizá tenga la carga ideológica del pensamiento europeo del siglo XX, del pesimismo que la guerra y las atrocidades del colonialismo les han dejado a los intelectuales europeos. Pero el pensamiento de la humanidad no se reduce al pensamiento europeo ni la historia de Europa es la historia de la humanidad. No todos los países vivieron la Edad Media, ni el oscurantismo, sin embargo, es un periodo del 
que se habla como si hubiera sido mundial, sin considerar que China, el imperio persa o América no vivieron las condiciones de ese periodo histórico.

Baste entonces con mencionar que en esta investigación se toma una posición frente a ese debate, y no se considera proscrito ni políticamente incorrecto hablar de progreso en la naturaleza y en la evolución. Para afirmar lo que se considera progreso basta con establecer un criterio para evaluar el cambio, a partir del cual digamos si el cambio va en la dirección que consideramos progresiva (Ramírez, 2012b, sec. 29. El antievolucionismo, p. 71). Wagensberg, por ejemplo, propone como criterio las posibilidades de respuesta, y con base en ese criterio se puede establecer si ha habido progreso o no. Nos parece evidente que si el criterio de inteligencia, por ejemplo, es tener un repertorio de respuestas más amplio, un ser humano tiene posibilidades de respuesta más amplias y variadas que una planta, y la planta tiene más posibilidades de respuesta que un mineral. Al respecto afirma Wagensberg: "entre la emergencia de la primera bacteria y el nacimiento de Shakespeare algo ha progresado, algo, de abajo arriba, ha tenido que ocurrir..." (Wagensberg, 2007, p. 73). En esta misma vía, Ramírez propone la complejización como el criterio de evolución:

El evolucionismo científico considera evolutivo el proceso de complejización, e involutiva la descomposición, el regreso a formas más simples. De cierta manera, hay una valoración ética de la complejidad que se opone a la propuesta de algún radicalismo oriental, que considera conveniente el retorno a las formas más primitivas y arcaicas (Ramírez, 2012b, sec. 28. Evolucionismo científico, p. 71)

Esta forma de definir lo que se considera progreso, a partir de un criterio que permita evaluar los cambios, se opone al relativismo al que tienden muchos pensadores posmodernos que consideran que todo es igualmente válido o de validez relativa, $\mathrm{y}$ que las teorías, los argumentos, las ideologías, las costumbres, las culturas, las opiniones son inconmensurables y sus diferencias son indecidibles. En el pensamiento científico, por el contrario, es fundamental poder demostrar o refutar un planteamiento, reconocer y rechazar la validez de las ideas, reconocer jerarquías y diferencias. Es cierto que en lo social y lo político la jerarquización se ha usado de forma despótica, tiránica y autoritaria, pero también es importante reconocer que ese no es un problema intrínseco de la jerarquización, puesto que también se puede apelar a las jerarquías y a las diferencias para evitar los abusos y las inequidades, para que aquel más inteligente o más fuerte proteja a los que, según el criterio de la fuerza o la inteligencia, estén en una escala inferior de la jerarquía. Así, por ejemplo, un adulto más fuerte físicamente que un bebé es responsable de su cuidado, de la preservación de otras especies, etc.

Desconocer las diferencias y las jerarquías, además de ser ideológico, poco realista e ineficiente, puede llevar también a despotismos e inequidades, suponer que no hay niveles en la realidad, que todos somos iguales, que tenemos las mismas capacidades, tendría como consecuencia que sobre todos recaigan las mismas exigencias, para niños, ancianos, mujeres, discapacitados, animales, comunidades marginadas de 
educación y recursos, etc... En el I Ching, un libro ancestral de sabiduría china, hay una bella referencia a la importancia de las jerarquías y las diferenciaciones de nivel para conservar el orden natural y social:

El cielo y el lago revelan una diferencia de altura que se ha producido por sí misma conforme a la naturaleza de ambos; por lo tanto ninguna forma de envidia enturbia esta relación. Así también en el seno de la humanidad tiene que haber diferencias de nivel. Es imposible lograr que la igualdad general sea una realidad. De lo que se trata es que las diferencias de rango en la sociedad humana no sean arbitrarias e injustas, pues de otro modo la envidia y la lucha de clases será consecuencia inevitable. Si, en cambio, las diferencias de rango externas responden a una justificación interior, y si la dignidad interior forma la pauta para el rango externo, reinará la calma entre los hombres y la sociedad logrará el orden (Wilhelm, 2008)

Para ampliar este debate sugiero los textos El progreso ¿Un concepto acabado o emergente? (Agustí et al., 1998) y Sexo, ecología y espiritualidad: el alma de la evolución (Wilber, 2005).

La sustentación que se ha hecho del determinismo dialéctico no cierra ni concluye el debate, pero muestra, por lo menos, que la hipótesis en favor de la existencia y la incidencia del azar en la realidad no es una idea inverosímil ni extraña en la ciencia contemporánea, que se ha ido distanciando de la visión fatalista del mundo. Una visión de la realidad en la que todo es ley y cuya dosis de azar es nula "[...] encoge el alma de unos y alivia la de otros. Pensadores como Einstein o Spinoza se sienten cómodos en este caso límite. Einstein, Spinoza o Dostoievsky encuentran consuelo en la idea de que la condición humana no es, en el fondo, responsable de nada. Ni siquiera tiene la facultad de tirar de los hilos de su propio futuro. Todo está escrito en alguna parte. No existe la responsabilidad, pero tampoco la culpabilidad. No existe la bondad, pero tampoco la crueldad. No existe la mediocridad, pero tampoco la creatividad. Todo es una ilusión, aunque la ilusión sea tenaz. Lo que tiene que ocurrir sencillamente ocurre" (Wagensberg, 2007, p. 37). Otros autores, como Darwin, Borges, Prigogine, Popper, Wagensberg o Ramírez, se sienten más cómodos en una realidad con restricciones y con cierta dosis de azar, una realidad con cierto derecho a la contingencia, plagada de bifurcaciones, donde no solo se puede, sino que se debe elegir.

De la mano de conceptos como el de azar, elección, emergencia, creación y evolución, llegamos a las elecciones al nivel del ser humano, lo que nos pone en un plano de la realidad en el que comenzamos a preguntarnos por conceptos como el de causalidad psíquica, libertad, elección subjetiva, ética y responsabilidad. Estos son los conceptos que constituyen el marco conceptual de los siguientes capítulos. 


\title{
CAPÍTULO III Determinismo y Azar en el Proyecto Científico de Freud
}

\begin{abstract}
Ya en una ocasión anterior me permití reprocharles que existía profundamente arraigada en ustedes una creencia en la libertad y la arbitrariedad psíquicas, creencia en un todo acientífica y que debe ceder ante el reclamo de un determinismo que gobierne también la vida animica (Conferencias de introducción al psicoanálisis, Freud, 1916b, p. 96)
\end{abstract}

En el capítulo anterior presentamos el azar tal como se concibe en la ciencia contemporánea y la sustentación de la propuesta de Ramírez sobre el determinismo dialéctico y las formaciones de lo aleatorio. En este capítulo queremos trasladar la pregunta de la existencia del azar al ámbito de lo psíquico. Veíamos en el capítulo anterior que el azar (la ausencia de determinaciones, causas o regularidades) es lo que da lugar a la libertad, entendiendo por libertad la posibilidad de elegir (Ramírez, 2012b). Entonces, preguntarse si en el ámbito de lo psíquico hay azar o no, finalmente, es preguntarse si el ser humano es libre, si puede elegir su destino. Para comenzar se mostrará un panorama de las nociones de determinismo y elección en los fundamentos del psicoanálisis. Luego se considerarán las posibilidades de transformación subjetiva a pesar de la fuerza que tiene el concepto de repetición en psicoanálisis. Finalmente se establecerá una importante distinción entre el azar freudiano, entendido como accidente o contingencia, y el azar en Ramírez, entendido como ausencia de causas.

\subsection{El determinismo del proyecto científico de Freud}

Al buscar en la obra de Freud el lugar que le da al azar (lo indeterminado) se reconoce rápidamente su interés científico por encontrar causas y determinaciones 
subyacentes a lo aparentemente indeterminado: las elecciones, los síntomas conversivos, las obsesiones y compulsiones, las fobias, los sueños y, posteriormente, fenómenos de la vida cotidiana, como lapsus, olvidos, chistes y actos fallidos. A pesar de su formación como neurólogo, sus descubrimientos lo distancian del determinismo biológico y lo llevan a crear la noción de determinismo psíquico al sostener que el hombre está determinado por relaciones lingüísticas, afectivas e históricas; determinaciones que, además, no conoce, son inconscientes. De este modo Freud cierra mucho más las posibilidades de la libre elección al evidenciar las determinaciones que subyacen a esos actos en apariencia accidentales e involuntarios (Blas Lahitte et al., 2013, p. 63).

El descubrimiento del determinismo psíquico conlleva que la conducta del hombre no puede explicarse por una arbitraria decisión de una voluntad que escapa a toda causa, pero tampoco por un estado actual del organismo. La explicación que aporta el psicoanálisis de las intenciones humanas es histórica y circunstancial, es decir, la historia que comienza desde el nacimiento y las condiciones actuales en que el hombre vive, "en lugar de creer que unas intenciones irreductibles, producto de nada, lo explican todo" (Zuleta, 2004, p. 26). Es la suposición de un determinismo psíquico inconsciente de las elecciones lo que subyace bajo la técnica de la asociación "libre":

La elección de la asociación libre como recurso para explorar lo inconsciente olvidado parece tan sorprendente que no serán superfluas algunas palabras para justificarla. En su adopción, Freud se guiaba por la expectativa de que la llamada «asociación libre» en realidad demostraría ser no libre, pues tras la sofocación de todos los propósitos de pensamiento consciente saldría a la luz una determinación de las ocurrencias por parte del material inconsciente (Freud, 1923a, p. 207).

En el vuelco hacia esa técnica, destinada a sustituir a la hipnosis, desempeñó sin duda un papel la sólida confianza en la existencia de un rígido determinismo dentro de lo anímico (Freud, 1923b, p. 234).

Es claro entonces que uno de los presupuestos básicos del psicoanálisis es el determinismo:

El postulado primero del psicoanálisis es ante todo, extender a la vida anímica de los hombres el criterio de determinismo, por el que se guían todas las ciencias exactas y naturales y aplicar a la vida humana el criterio general de la ciencia [...] Si consideramos que los actos humanos no están determinados por causas que los expliquen, entonces, de paso hemos dicho que no pueden ser objeto de una ciencia ${ }^{7}$, que solo pueden ser, por

7 Esta afirmación de Zuleta es válida dentro del paradigma de la ciencia moderna. Justamente el segundo capítulo de esta investigación muestra cómo la ciencia contemporánea no sólo admite una noción de azar sino que también hace del azar un objeto susceptible de estudio o, más precisamente, estudia los efectos del azar, puesto que el azar es, por definición, inconmensurable. 
ejemplo, objeto de un intento de comprensión por medio de la simpatía, pero no de una explicación ${ }^{8}$ (Zuleta, 2004, p. 10).

La comprensión, propia de las ciencias del espíritu, es el método apropiado para dilucidar las motivaciones de los fenómenos humanos, "asumiendo que estas no resultan determinadas por leyes universales, sino por el libre albedrío de los agentes. Tal y como hemos podido advertir, para Freud los fenómenos humanos están determinados y es por ello que son susceptibles de ser explicados por apelación a leyes universales; lo cual legitima la ubicación del psicoanálisis del lado de las ciencias naturales" (Blas Lahitte et al., 2013, p. 63).

Sin embargo, podemos señalar al menos tres aspectos dificultan la afirmación del modelo determinista en psicoanálisis. El primero de ellos es la sobredeterminación psíquica que, paradójicamente, da lugar al azar, pues una de las maneras de entender el azar es precisamente como el entrecruzamiento de series determinísticas alejadas entre sí . La sola inclusión de lo contingente como factor causal deja un amplio margen a la indeterminación y dificulta la aplicación de un modelo determinista en el psicoanálisis. El segundo problema que afronta el psicoanálisis para hablar de determinismo absoluto es la predicción, pues los fenómenos psíquicos de los que se ocupa son en gran medida impredecibles, sólo a posteriori se podrían establecer los factores que intervinieron, pero no es posible conocer a priori cómo van a ocurrir. Por ejemplo: "Podemos desentrañar los mecanismos del sueño, «pero no podemos a priori determinar cómo va a ser un sueño en particular». «Un sueño es una creación, donde no es predecible cuál será su resultado, lo que no quiere decir que no esté determinado y que por lo tanto no sea interpretable»" (Bleichmar et al., 1994, p. 27), volveremos sobre este tema más adelante. Y el tercero es la temporalidad: el fantaseo retrospectivo puede sexualizar vivencias infantiles que, en principio, no lo estaban. Asimismo, una vivencia puede llegar a producir efectos y tomar el estatuto de trauma mucho tiempo después de haber ocurrido, cuando adquiere una nueva significación gracias a nuevas vivencias. Esta forma en la que opera el tiempo en la realidad psíquica abre la pregunta de si la interpretación psicoanalítica descubre o crea el pasado y, por tanto, si el psicoanálisis busca en el pasado una etiología de los fenómenos actuales, si procede bajo el modelo científico de buscar explicaciones causa-efecto con procedimientos rigurosos para establecer conexiones entre los fenómenos... o si es una hermenéutica, ajena al problema de las determinaciones causales, que ofrece interpretaciones que no excluyen otras $y$, de ser así, se

8 Es esta la discusión entre Wundt y Dilthey; el primero propone inscribir la psicología en el campo de las ciencias naturales y utilizar el método experimental, como es propio de las ciencias naturales; mientras que el segundo la considera una ciencia del espíritu, y como tal no debe proceder al modo de las ciencias naturales, formulando hipótesis de explicación, sino que lo más apropiado a su objeto de estudio es el método de la comprensión y la interpretación, por eso propone como método y propósito de la psicología la comprensión de la vida psíquica desarrollada.

9 Esta noción de azar es aristotélica y se desarrolla ampliamente en el apartado 3.4. Azar como accidente y azar como ausencia de causas de este mismo capítulo. 
desdibujaría la pretensión de buscar determinaciones y causas psíquicas. Quienes ubican al psicoanálisis dentro de las disciplinas hermenéuticas (Habermas, Gadamer, Ricoeur) señalan que "Freud fue víctima de un mal entendido cientificista que hizo que intentara dar a sus descubrimientos el carácter de leyes de la naturaleza, confundiendo de esa manera los motivos inconscientes con las causas naturales" (Bleichmar et al., 1994, p. 19). Persiste el debate de si el psicoanálisis pretende explicar (remitir un fenómeno a sus causas) o comprender. Quizá porque Freud dialectizó ambos propósitos queda abierta la pregunta de si el psicoanálisis está en el ámbito de las ciencias naturales, como él mismo pretendía, o del espíritu, que usa la hermenéutica como forma de aproximación a los fenómenos. Freud hace un tratamiento de la interpretación como una hipótesis, una conjetura que debe pasar por el proceso de validación científica (consistencia y eficacia). Pero la retranscripción de los signos de percepción, de las huellas mnémicas, también abre la posibilidad de transformación de las determinaciones y ubicaría al psicoanálisis más del lado de una hermenéutica que de una ciencia. Para Habermas es una ciencia crítico-emancipatoria (Habermas, 1982).

El determinismo ineludible de la ciencia moderna es incompatible con los presupuestos de otros campos, por ejemplo la religión, el derecho e incluso con los propósitos de responsabilización, emancipación y transformación de la clínica psicológica y psicoanalítica. En la religión las ideas de pecado y culpa solo son concebibles bajo el supuesto del libre albedrío, la concepción religiosa del hombre presupone la libertad, que los actos humanos no están absolutamente determinados. Lo mismo ocurre con la idea de culpa y dolo en la estructura del pensamiento jurídico (Zuleta, 2004, p. 19).

Lo que se viene produciendo en la investigación de la sociedad y del individuo es el abandono progresivo de la teleología, es decir, la creencia en que los fenómenos son producto de la elección, la intención o el plan de alguien orientado hacia un propósito final. En el estudio de la naturaleza la idea de causa final ya ha sido abandonada para dar paso a la búsqueda de causas eficientes, por ejemplo, de la lluvia: no llueve para algo, con un propósito o intención, sino por algo, por un proceso de condensación del agua ${ }^{10}$, "es decir, que las causas eficientes son determinantes en la naturaleza y las causas finales no operan en la naturaleza sino en el hombre" (Zuleta, 2004, p. 25). Sin embargo, la causalidad que descubre Freud en la conducta humana no es intencional, no es una causalidad final como sí lo es en Aristóteles. El interés de Freud va en la vía de desentrañar las causas eficientes, los mecanismos que subyacen bajo los fenómenos psíquicos.

10 La optimización de la energía, que parece ser un principio que rige la naturaleza, ha generado formas y procesos propicios para la emergencia de la vida, pero esto no quiere decir que haya un plan predeterminado o que esas formas se busquen deliberada y premeditadamente. En el segundo capítulo se amplía el concepto de teleonomía, en oposición al de teleología. 
Tan firmemente sustenta Freud el determinismo psíquico inconsciente de las elecciones y conductas humanas, que plantea que ese determinismo es el que produce lo que los creyentes llaman destino, un supuesto poder sobrenatural, divino, inevitable, que guía la vida del ser humano hacia un fin predeterminado. Freud ve en la creencia de un poder de esa índole una proyección infantil de la instancia parental:

El destino es visto como sustituto de la instancia parental; si se es desdichado, ello significa que ya no se es amado por esos poderes supremos y, bajo la amenaza de esta pérdida de amor, uno se inclina de nuevo ante la subrogación de los progenitores en el superyó, que en la época dichosa se pretendió descuidar. Esto es particularmente nítido si en sentido estrictamente religioso se discierne en el destino sólo la expresión de la voluntad divina (Freud, 1929, pp. 122-123).

Y el destino mismo no es en definitiva sino una tardía proyección del padre (Freud, 1927a, p. 182).

Para los creyentes y supersticiosos los acontecimientos se explican por una causa final, teleológica; mientras que Freud aporta una explicación en términos de causas eficientes, de mecanismos psíquicos. Así pues, el destino, aparentemente dictaminado por un poder sobrenatural, es para Freud una expresión de las aspiraciones inconscientes:

El destino fatal y el oráculo no eran sino las materializaciones de la necesidad interior; que el héroe pecara sin saberlo y contra sus propósitos era, evidentemente, la expresión correcta de la naturaleza inconsciente de sus aspiraciones criminales (Freud, 1924b, p. 59).

Lo que hace Freud con sus descubrimientos es desplazar el determinismo desde una instancia sobrehumana (mítica, divina) a un determinismo inconsciente. Es el deseo inconsciente, determinado por influjos de la temprana infancia, el que va configurando el destino. El hombre ya no solo está sujetado por las fuerzas de la naturaleza sino también por las fuerzas psíquicas inconscientes. Sin embargo, Ramírez (Ramírez, 2012b, sec. 170. Determinismo y libertad, p. 285) afirma que Freud, así como la ciencia, concibe un determinismo a posteriori que no es fatalista. Veamos de qué se trata.

Es posible sostener, como lo hace la ciencia, que todo hecho tiene una o varias causas que lo determinan, y el estudio de estas leyes o causas es precisamente su objeto, pero esto no implica que dado un hecho solo se pueda producir única y fatalmente otro específico (predeterminado), ese sería un determinismo a priori. El determinismo a posteriori, en cambio, sostiene que, "dado el hecho, debe haber habido otros hechos previos que lo hicieron posible, esto es, probable, en el sentido de "factible" o realizable dentro de una gama de posibilidades, de opciones, todas ellas posibles pero no inevitables" (p. 285). Así que defender, como lo hace Freud, que hasta el más insignificante acto psíquico - decir "al azar" unos números, cometer un lapsus o acto fallido - tiene unos determinantes psíquicos que pueden investigarse, no significa que 
ese acto esté predeterminado y que pueda predecirse (fatalmente) el comportamiento de un sujeto.

El determinismo a posteriori es tan fundamental dentro del desarrollo científico, que uno de los teoremas de la lógica matemática, la regla de la implicación, afirma que dada una proposición $\mathrm{Q}$, cualquier otra proposición $\mathrm{P}$, puede colocarse como su condición o hipótesis (dado $Q$, entonces $P \Rightarrow Q$ ); lo que, por otra parte, ilustra el hecho de que producido un acontecimiento, todos nos sentiremos capacitados para dar razones de su ocurrencia.

En este punto surge inevitablemente, la pregunta: ¿De qué sirve explicar un suceso, si no es para predecir sus futuras apariciones?; con la cual entramos de lleno en el difícil campo de la predicción científica (Ramírez, 2012b, sec. 170. Determinismo y libertad, p. 286)

En el intento de Freud por aprehender las determinaciones que hay en juego en la conducta humana, paradójicamente, se vislumbra que es una elección o una autodeterminación, aunque inconsciente, lo que está en juego en lo que llamamos destino:

Lo que parece un destino que persigue, un sesgo demoníaco, ese destino fatal es autoinducido y está determinado por influjos de la temprana infancia, es otra exteriorización de la compulsión a la repetición (Freud, 1992l, p. 21, el resaltado es nuestro).

Pareciera haber un papel activo del sujeto en la configuración de su destino:

Este «eterno retorno de lo igual» nos asombra poco cuando se trata de una conducta activa de tales personas y podemos descubrir el rasgo de carácter que permanece igual en ellas, exteriorizándose forzosamente en la repetición de idénticas vivencias. Nos sorprenden mucho más los casos en que la persona parece vivenciar pasivamente algo sustraído a su poder, a despecho de lo cual vivencia una y otra vez la repetición del mismo destino (Freud, 1920, p. 22).

Hay personas que durante su vida repiten sin enmienda siempre las mismas reacciones en su perjuicio, o que parecen perseguidas por un destino implacable, cuando una indagación más atenta enseña que en verdad son ellas mismas quienes sin saberlo se deparan ese destino. En tales casos adscribimos a la compulsión de repetición el carácter de lo demoníaco (Freud, 1992b, p. 99, el resaltado es nuestro).

El destino para los griegos era un designio divino, una suerte implacable, predeterminada y fatal que no deja ningún lugar al libre albedrío; es lo que ilustran las tragedias de Edipo, Prometeo, Sísifo. Para Freud el destino es el deseo inconsciente, es decir, la confluencia de todas las determinaciones (biológicas, discursivas y ocasionales). Por eso la propuesta ética de Lacan es asumir el deseo, que se expresa como destino personal (Ramírez, 2012b, sec. 185. El sentido existencial, p. 301), la valentía ante fatal destino (Lacan, 1982, p. 174). Pero Ramírez plantea que el deseo no tiene que configurar un fatal destino; además del deseo está la voluntad (la facultad de querer) y el libre albedrío, que son nuestra cuota en el destino personal y cósmico. Al reconocer su deseo el ser humano puede "responsabilizarse por su destino y decidir el 
camino que habrá de recorrer, las renuncias, aceptaciones y modificaciones que elegirá" (Ramírez, 2012b, sec. 240. Psicopatología, p. 367). Por efecto del azar, el deseo puede ser modulado por la voluntad y el libre albedrío.

Pasaremos entonces a profundizar si en las indagaciones de Freud el determinismo psíquico deja lugar a la elección subjetiva y en qué consiste esta elección.

\title{
3.2. La elección en la obra de Freud
}

Desde los manuscritos prepsicoanalíticos de Freud aparece su interés por el tema de la elección. Sus primeras explicaciones de la elección las buscó en el funcionamiento del mecanismo neuronal. Así aparece en el comentario al Proyecto de psicología para neurólogos, donde se destaca cómo Freud se anticipa a los planteamientos de la teoría de la información y la cibernética, además, ya hay aquí una elaboración de lo que posteriormente el neurólogo Rodolfo Llinás va a denominar memoria referencial ${ }^{11}$ en el ser humano:

\begin{abstract}
Se ha señalado, verosímilmente, que en los complejos sucesos «neuronales» que aquí describe Freud y en los principios que los gobiernan puede verse más de un indicio de las hipótesis sustentadas por la teoría de la información y la cibernética en su aplicación al sistema nervioso. Para mencionar unos pocos casos de esta similitud de enfoque, observemos ante todo la insistencia de Freud en la necesidad primaria de proporcionar al aparato una «memoria»; está, además, su sistema de «barreras-contacto», que permite al aparato hacer una «elección» adecuada (basándose en la memoria de los sucesos anteriores) entre distintas respuestas frente a un estímulo exterior; y ateniéndonos a las elucidaciones de Freud sobre el mecanismo de la percepción, tenemos también su introducción de la idea fundamental de la realimentación como medio de corregir los errores que se producen en el comercio del aparato con su ambiente (Freud, 1895, p.
\end{abstract} $355)$.

Según lo anterior, la elección ejecutada por el aparato psíquico no surge de la nada; se basa en los registros (huellas, memorias) de los sucesos anteriores. Y estos registros tienen lugar gracias al sistema de barreras-contacto que recubre a algunas neuronas. En virtud de esas barreras, que se resisten al paso de la excitación, las neuronas se van modificando por las excitaciones que sufren y queda así un registro de tales excitaciones. Ante esta explicación más orgánica de la elección, aún podemos plantear una pregunta: el pasado (los recuerdos, las huellas mnémicas, las experiencias tempranas) determina absolutamente las elecciones o simplemente ejerce una influencia que las orientan, pero no de manera inevitable.

Desde el comienzo de sus investigaciones Freud planteó también el problema de la elección de neurosis, al que retorna varias veces en su obra, y que formulado como

11 En el cuarto capítulo de esta investigación se amplía este concepto. 
pregunta sería así: ¿qué determina la elección de neurosis? Inicialmente, la causa de esta elección fue atribuida a la edad en que ocurren los traumas sexuales, la edad que se tenía al vivenciar (Freud, 1892, p. 322), pero abandona esa hipótesis cuando vislumbra el nexo entre la elección de neurosis y la teoría sexual (Freud, 1892, p. 322). De tal modo que la explicación de la irritación sexual precoz y la cuestión de saber cuál de las neurosis, histeria u obsesiones, se desarrollará en un caso dado, no se resuelve por la vía de la herencia biológica, "sino por un carácter especial de este acontecimiento sexual de la niñez temprana" (Freud, 1896b, pp. 55-56). La diferencia entre la histeria y la obsesión es en algún punto atribuida al carácter de las escenas sexuales infantiles, si este vivenciar sexual fue meramente pasivo o placentero respectivamente (Freud, 1896a, pp. 217-218). Las explicaciones biológicas comienzan a retroceder al papel de factor propiciador o de una condición, para dar el papel principal a la teoría sexual y a la historia de desarrollo de la libido y del yo (Freud, 1910a, p. 73).

A pesar de todos estos esfuerzos por explicar las causas subyacentes a la elección de neurosis, a veces parece ineludible que las determinaciones últimas de esa elección le resultan a Freud insondables; es lo que aparece al describir el mecanismo de la fobia:

\footnotetext{
El mecanismo de las fobias es totalmente diferente del de las obsesiones. Ya no es el reino de la sustitución. Aquí ya no se revela mediante el análisis psíquico una idea inconciliable, sustituida. Nunca se encuentra otra cosa que el estado emotivo de la ansiedad, que por una suerte de elección ha puesto en primer plano todas las ideas aptas para devenir objeto de una fobia (Freud, 1894, p. 81, el resaltado es nuestro).
}

Lo inaprehensible en la elección de neurosis parece estar más claro cuando de la elección de objeto se trata. Detrás de las elecciones objetales Freud vislumbra más claramente las determinaciones en juego: la elección de objeto, dice, es correlativa a la organización de la libido (Freud, 1924b, p. 34).

Es importante retomar los términos en los que Freud se expresa cuando se refiere a la elección. En las conferencias de introducción al psicoanálisis hace alusión a una recomendación general para los pacientes: que suspendan las elecciones cruciales que tengan por ese momento, debido a los influjos que pueden afectarlas; dice que las elecciones se pueden ver facilitadas por las circunstancias; habla de influjos que comandan la elección y de influencias decisivas para el destino. De nuevo: ¿son influjos que orientan la elección o la gobiernan completamente? Pareciera que las determinaciones inconscientes no tienen que ser repeticiones infalibles.

\subsection{Repetición y transformación}

Una formulación fundamental del psicoanálisis es la compulsión a la repetición, concepto que Lacan denominó goce. Consiste en una tendencia inherente a los 
organismos vivos, incluso más originaria, más elemental que el principio del placer que parecía regir todos los fenómenos psíquicos (Freud, 1920, p. 23). En tanto pulsión sería "un esfuerzo, inherente a lo orgánico vivo, de reproducción de un estado anterior. Es la exteriorización de la inercia en la vida orgánica" (Freud, 1920, p. 36). La función psíquica que cumple la repetición es descargar la carga afectiva que produjo una impresión, es un intento por adueñarse y dominar una situación traumática (Freud, 1920, p. 16). Freud encuentra evidencia de ese esfuerzo en las neurosis traumáticas, las neurosis de destino, las neurosis de transferencia y los juegos infantiles; se exterioriza allí una tendencia lo suficientemente poderosa como para hacer caso omiso del principio del placer. En su carácter doloroso y repetitivo hay una determinación desconocida para el sujeto que lo lleva a transitar siempre los mismos caminos, a gozar de cierta manera, un empuje que el sujeto vive como inevitable, incontenible, por fuera de su voluntad, es decir, un empuje que pone en entredicho su libertad. Es este el gran descubrimiento freudiano: tendencias y vivencias que aunque escapan de nuestra consciencia determinan enfermedades, accidentes, elecciones, destinos que parecían ocurrir libremente o por azar, sin causa alguna, evidenciando que hay muchas cosas que se ponen en juego en lo que parece ser una libre elección ${ }^{12}$.

Se deriva de aquí otra pregunta fundamental para esta investigación: ¿si lo inconsciente determina al sujeto, puede este, al mismo tiempo, ser responsable de su destino? Esta es una de las principales razones que da sentido a esta indagación por el papel del azar y la elección subjetiva en la configuración psíquica, ya que las prácticas clínicas se emprenden presuponiendo, por un lado, que hay causas tras los síntomas, los trastornos o el padecimiento de los sujetos, pero, por otro lado, que estos pueden elegir y modificar aspectos de su vida que les generan sufrimiento. La clínica se encuentra entonces entre lo determinado y lo indeterminado de los fenómenos psíquicos.

Miremos de qué manera los psicoanalistas, actualmente, formulan la pregunta por el determinismo absoluto y la libertad. Silvia Bleichmar toca uno de los puntos más importantes que están en juego: "cómo articular el eje de la repetición, sin el cual el psicoanálisis cae de sus fundamentos, con aquel de la transformación, sin el cual la clínica carecería de objeto"; en el origen del inconsciente ¿las condiciones iniciales determinan toda la trayectoria psíquica?; ¿esa demanda de los analizantes de cambiar y transformar algo es una mera ilusión que habría que desvanecer con el trabajo analítico? (Bleichmar, 1994, p. 47). Luis Hornstein, por su parte, formula de este modo la cuestión: se pregunta si el acontecimiento azaroso puede hacer surgir nuevas posibilidades de historia o es solo un disfraz que forja la compulsión de repetición, apenas un pretexto para el idéntico retorno de lo ya inscripto (Hornstein, 1994, p. 101). ¿Se trata simplemente de aceptar que solo elegimos lo impuesto y solo

12 Psicopatología de la vida cotidiana es un texto paradigmático de cómo las elecciones que parecen ser al azar son encausadas por Freud hasta sus motivaciones inconscientes. Al respecto véase el apartado XII. Determinismo, creencia en el azar y superstición: puntos de vista (Freud, 1901, p. 233). 
queremos lo inevitable? En El motivo de la elección del cofre dice Freud que "uno elige ahí donde en la realidad efectiva obedece a la compulsión" (Freud, 1992, 315).

Estas inquietudes son abordadas por Bleichmar partiendo de un profundo y riguroso conocimiento de la metapsicología; se pregunta por la dialéctica entre las determinaciones y el azar (entendido como lo contingente, lo accidental) en la teoría freudiana del inconsciente, de la libido y de la neurosis.

En cuanto al origen del inconsciente, plantea que los puntos de partida, tales como la estructura del Edipo, el carácter dividido y contradictorio del aparato psíquico (que con el Ello pulsa y con el Superyó normatiza), son justamente eso, condiciones de partida, y en tal sentido abren un abanico predictivo, un abanico de posibilidades, pero no de determinación última, ya que los accidentes dejan planteada la pregunta por lo que pudo haber sido de otra manera, lo que no se hubiera producido sin ellos (Bleichmar, 1994, p. 54). A pesar de las sucesivas reformulaciones que hace Freud a la teoría, en la fundación de lo inconsciente lo contingente traumático ocupa siempre un lugar central:

Nos negamos a estatuir una oposición de principio entre las series de factores etiológicos; más bien suponemos una regular acción conjugada de ambas para producir el efecto observado. Disposición y azar determinan el destino de un ser humano; rara vez, quizá nunca, lo hace uno solo de esos poderes. La distribución de la eficiencia etiológica entre ellos sólo se podrá obtener individualmente y en cada caso (Freud, 1912, p. 97)

En la teoría de la libido de Freud hay una concepción genético-evolutiva que apuntala el surgimiento de la sexualidad en lo somático y se resuelve bajo formas de determinación endógenas, esto quiere decir que el desarrollo pulsional, en parte, está regido por leyes biológicas, por lo que va evolucionando desde la fase oral y anal hasta la fase fálica. Pero, al mismo tiempo, se concibe la contingencia del objeto de la pulsión, es decir, aunque los objetos de la pulsión guardan una relación con las funciones primarias, son contingentes. El objeto es accidental, pero complementa unas predisposiciones y se vuelve una impronta en la elección del objeto. Sobre el azar en la teoría de la libido, Bleichmar afirma que la pulsión se vuelve determinación en la relación con el objeto, en ese encuentro que es contingente, que no está determinado: es el objeto ofrecido por el semejante el que da origen a la pulsión y hace posible la libido como conversión, transmutación de la energía somática en energía psíquica (Bleichmar, 1994, p. 55).

En la teoría de la psicogénesis de la neurosis Freud reconoce las predisposiciones biológicas, habla incluso de un sistema nervioso débil o muy sensible que predispone a enfermar de los nervios (neurosis), pero lo contingente ocupa un lugar privilegiado en la causación de la patología mental, pues esta se produce por un episodio que Freud denomina desencadenante, que tiene la suficiente fuerza para ser traumático. 
No se trata entonces de negar las determinaciones y regularidades del aparato psíquico; Freud elabora toda una teoría sobre sus leyes: procesos primarios en el inconsciente y secundarios en el sistema preconsciente-consciente; contenidos relacionados con la sexualidad en el inconsciente y contenidos que responden a los intereses del yo en el preconsciente; representaciones cosa en el inconsciente y representaciones palabra en la consciencia. Son dos legalidades, dos modos de funcionamiento presentes universalmente siempre y cuando haya operado la represión. Este modo de funcionamiento psíquico es común a los seres humanos, "si un ser humano no poseyera este aparato psíquico atravesado por estos modos de legalidad descritos, no se tratará de colocarlo "fuera de la estadística", sino de saber cómo se establece la legalidad intrínseca que en él opera y buscar el orden de determinación que así lo ha constituido" (Bleichmar, 1994, p. 57).

Hasta este punto podemos decir que las contingencias, lo que Lacan llama encuentros con lo real (lo sexual y la muerte), aspectos que no dependen del sujeto, que se sustraen de su control, terminan instituyendo un orden, se vuelven determinaciones: "los efectos del azar producen mutaciones estructurales" (Hornstein, 1994, p. 110), es decir, el azar cuando aparece es aleatorio, pero se vuelve determinación al dejar huellas; en palabras de Freud, "la experiencia analítica nos obliga sin más a suponer que unas vivencias puramente contingentes de la infancia son capaces de dejar como secuela fijaciones de la libido" (Freud, 1916a, p. 329).

Habíamos mencionado previamente que el azar, entendido como lo accidental, también es un factor determinante de lo psíquico. Lo interesante es que en este factor Bleichmar ve la posibilidad de que los accidentes no solo determinen al sujeto, sino también de que cambien el curso de lo previamente instituido, ya que las contingencias instalan en el psiquismo un punto de bifurcación, generan un desequilibrio vital que a la vez genera un reacomodamiento de la economía libidinal. Es así como opera el aparato psíquico en tanto sistema complejo (Bleichmar, 1994, p. 62). "En los puntos de inestabilidad del psiquismo, tanto en su constitución como en el proceso analítico, una fluctuación menor puede producir una bifurcación que altera la trayectoria previa" (Hornstein, 1994, p. 110).

Ante la cuestión del aparato psíquico como abierto (indeterminado) o cerrado (determinado), Bleichmar reconoce que el inconsciente implica un orden de determinación y que la realidad está atravesada por líneas de fuerza marcadas libidinalmente, pero lo azaroso se engarza en ese entramado de determinaciones:

El aparato psíquico es entonces un sistema abierto, capaz de sufrir transformaciones no sólo como efecto del análisis sino de las recomposiciones a las cuales nuevos procesos histórico-vivenciales lo obligan. Al mismo tiempo, y desde el punto de vista de la recepción, el inconsciente es también transformable: el hecho de que los elementos de base que lo componen sean indestructibles no quiere decir que sean inmodificables (Bleichmar, 1994, pp. 52). 
El médico y psicoanalista Luis Hornstein coincide con que los sistemas complejos o el modelo de las estructuras disipativas brindan mejores herramientas conceptuales para dilucidar el funcionamiento psíquico. Los sistemas complejos son sistemas que lejos del equilibrio (en el caos) pueden instituir un nuevo orden. Según esto el psiquismo funcionaría como un sistema que ante las perturbaciones puede autoorganizarse, complejizarse. En esa autoorganización se combinan el azar de las fluctuaciones o perturbaciones y las leyes del sistema para producir un nuevo régimen de funcionamiento (Hornstein, 1994, p. 107), nuevas leyes, nuevas reglas: "la represión originaria, el pasaje del yo del placer al yo de realidad, el sepultamiento del complejo de Edipo, la metamorfosis de la pubertad y todo duelo que produce una recomposición identificatoria, ¿no son acaso procesos de autoorganización?" (Hornstein, 1994, p. 118). El azar se transforma en organización y de esta forma el psiquismo puede desarrollar potencialidades al incrementar su complejidad. Lo psíquico en tanto sistema complejo no sólo cuenta con el azar, sino que necesita de él para desplegarse, para desarrollarse (Morin, 1984).

Por fuertes que sean las fijaciones, la insistencia del goce, lo contingente abre la posibilidad de trascender las determinaciones y crear nuevas normas, nuevas leyes de funcionamiento. Justamente así es como el médico y filósofo George Canguilhem define la salud, como la capacidad del ser vivo de instituir nuevas normas y ajustarse a ellas. La enfermedad, por el contrario, se presenta cuando un organismo pierde la capacidad de crear nuevas normas ante los cambios del medio o se rigidiza en una norma que pasa a ser caduca. El hombre sano es el hombre normativo, es decir, un ser que es capaz de instituir nuevas normas, incluso orgánicas. Una única norma de vida es sentida de un modo privativo y no de un modo positivo (Canguilhem, 1984, p. 104). Juan Diego Lopera afirma que la vida misma es normativa, esto significa que continuamente se franquean las normas existentes para crear otras superiores: la naturaleza de la vida es, paradójicamente, cambiar para permanecer, cambiar para persistir (Lopera, 2016, p. 176). Incluso la enfermedad puede verse como una creación de nuevas leyes de funcionamiento, una alternativa que en cierto momento fue óptima para afrontar una situación, pero que al rigidizarse se convierte en un impedimento para instituir otras normas, entonces se enferma. Es la misma idea que expresa Jean Laplanche pero refiriéndose específicamente al funcionamiento psíquico: "Hay seguramente una muerte del psiquismo por desintegración, muerte por la pulsión de muerte, pero hay también muerte del psiquismo por la rigidización y síntesis excesiva, muerte del psiquismo por el yo" (Laplanche, 1987, p. 149).

Así como la vida y toda la realidad, el psiquismo es un sistema que depende del equilibrio entre la rigidez de la repetición y el azar; recordemos que en este equilibrio Jacques Monod fundamenta la permanencia de la vida y su evolución. Cuando alguno de los dos extremos anula al otro se destruye el sistema. Desde el capítulo anterior se vislumbra algo que aquí podemos explicitar como una tensión intrínseca de la realidad, más aún, todo cuanto existe es producto de esta tensión irresoluble: 


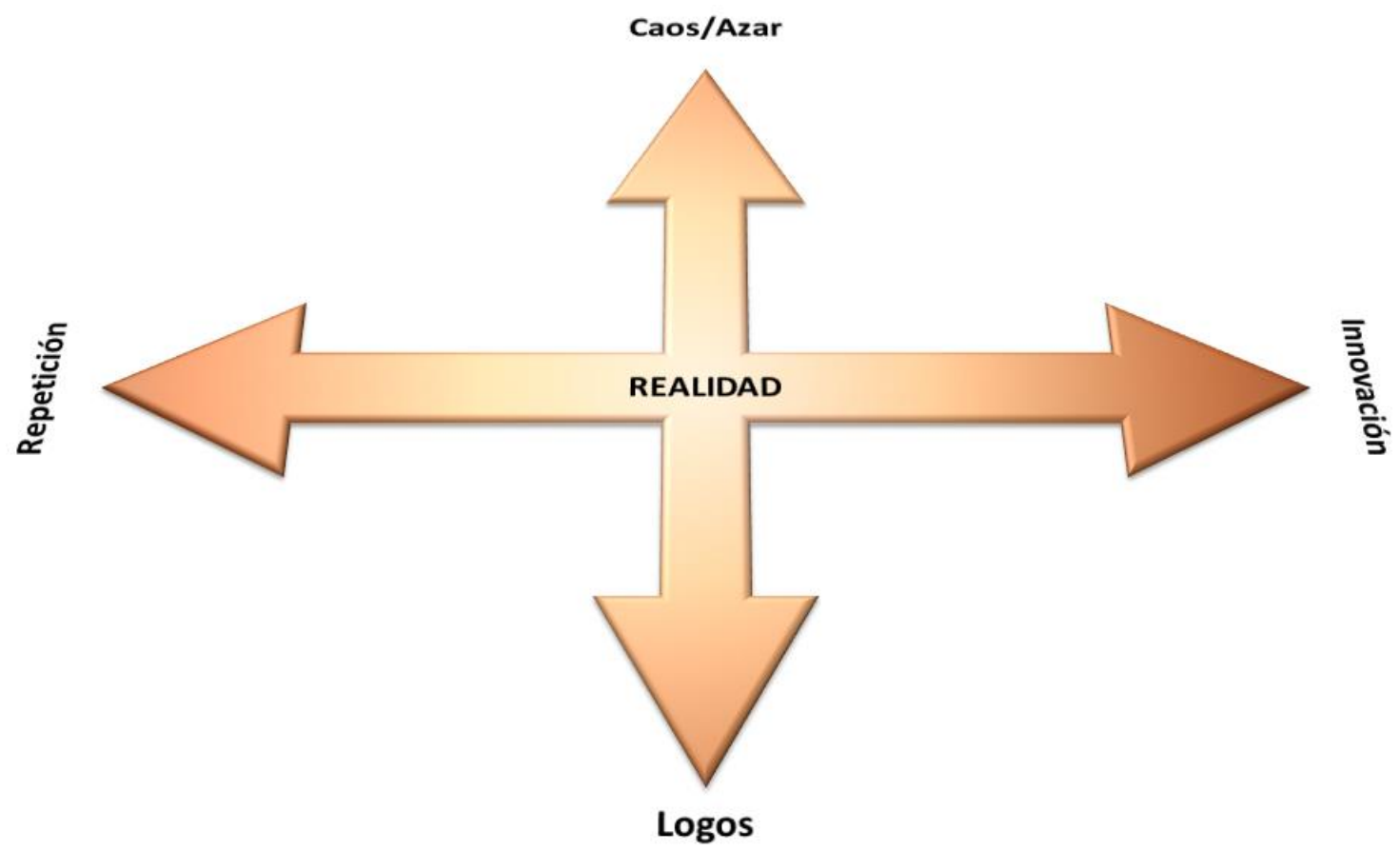

Las determinaciones, la repetición (Ananké), las tendencias conservadoras son necesarias para la preservación de lo que existe, pero cuando la repetición se vuelve mortífera, excesiva, la propuesta de Ramírez es recurrir a Logos, el principio creador. Por esta razón, Freud está de acuerdo con el escritor Multatuli al sustituir el destino de los griegos por la pareja divina de Logos y Ananké (Freud, 1992, p. 174). Originariamente Logos se considera una tendencia a articular que se expresa en todo lo existente, es el principio articulante, y articular es crear leyes de interacción entre los elementos, es entonces una tendencia creativa que provee lógica al cosmos, lo ordena y es, por tanto, ley. Ramírez concibe la realidad como producto de la interacción entre estas tendencias cósmicas: del Caos originario y absoluto (la nada) emerge Logos, la lógica, la articulación, la ley; las leyes creadas por Logos son reiteradas por Ananké (la repetición, la inercia) y se vuelven determinaciones. En la concepción griega el cosmos es un caos organizado por logos, pero se cae en un fatalismo al creer que todo queda sometido a ananké (la repetición de las leyes), que es un cosmos sin azar. Para Ramírez, en cambio, quedan aspectos caóticos, desarticulados, libres ${ }^{13}$.

En el segundo capítulo enfatizamos la relación estrecha que hay entre el azar y la emergencia de lo nuevo, la creación. Asimismo, Luis Hornstein considera que la no determinación de lo que es, no es simple "indeterminación", es creación, "es decir,

13 En el segundo capítulo se sustentó esta hipótesis con los planteamientos de la ciencia contemporánea y en el cuarto capítulo se sustenta la subsistencia de un resto de indeterminación en la realidad desde la perspectiva del filósofo francés Gilbert Simondon y el concepto de peculiaridad elaborado por Carlos Arturo Ramírez. 
surgimiento de otras determinaciones, de nuevos dominios de legalidad. La "indeterminación" tiene un sentido preciso: ningún estado del ser es tal que haga imposible el surgimiento de otras determinaciones respecto de las ya existentes" (Hornstein, 1994, p. 119).

Logos, este principio articulante y creador de nuevas leyes, se expresa en el ser humano como razón y como palabra (verbo), por eso la herramienta humana para hacer frente a la repetición es la verbalización, la palabra, que intenta incesantemente ligar las huellas mnémicas no ligadas, la palabra que da la posibilidad de crear, de articular algo nuevo, de resignificar, como transitando una espiral hermenéutica (Ramírez, 2009) en la que no se repite lo mismo, como en un círculo (un eterno retorno de lo mismo), sino que al dar vueltas también se avanza en la comprensión por un camino en espiral, de allí el valor tan grande que le otorga el psicoanálisis a la verbalización (la acción del verbo, logos, la palabra). La neurosis de destino era para Freud paradigmática del predominio de la repetición y la ausencia de creación. Una vida comandada por un determinismo inexorable. Hornstein la define como una simbolización que se repite $\mathrm{y}$, a la vez, se pregunta si toda simbolización está condenada a la repetición. Recuerda entonces el camino que propone Freud: el pasaje de la repetición al recuerdo, a la reelaboración, y considera que esta es una creación, al igual que el chiste, el jugar, la sublimación, el humor y los vínculos actuales que resultan de procesos creativos (Hornstein, 1994, p. 117). En El porvenir de una ilusión

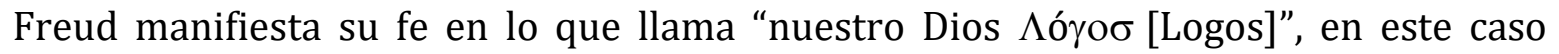
entendido como razón, intelecto (Freud, 1927b, p. 53):

No importa cuán a menudo insistamos, y con derecho, en que el intelecto humano es impotente en comparación con la vida pulsional. Hay algo notable en esa endeblez; la voz del intelecto es leve, mas no descansa hasta ser escuchada. $\mathrm{Y}$ al final lo consigue, tras incontables, repetidos rechazos. Este es uno de los pocos puntos en que es lícito ser optimista respecto del futuro de la humanidad, pero en sí no vale poco. Y aún pueden sumársele otras esperanzas. El primado del intelecto se sitúa por cierto en épocas futuras muy, pero muy distantes, aunque quizá no infinitamente remotas (Freud, 1998, p. 52).

Lacan resalta esa relación entre Logos y capacidad creativa cuando se refiere a la sublimación, diciendo que esta se da "en el nivel del sujeto lógico, donde se despliega, o se instaura, donde se instituye todo este trabajo que es propiamente hablando el trabajo creador en el orden del logos" (Lacan, 1959). Pareciera entonces que la respuesta más razonable a la pregunta que nos hemos formulado — si la elección está fatalmente determinada o tan solo influenciada por las determinaciones - es que las determinaciones operan como tendencias, preferencias, inclinaciones, pero no impiden la transformación y la instauración de un nuevo orden psíquico. Ramírez no concibe la identidad y el ser humano como poseedor de una esencia inmutable, sino que su esencia deviene: “(...) puede pensarse en un ser en devenir, como el río de Heráclito, compuesto de formas que se trans-forman continuamente, conservando una parte de la forma anterior (el pretérito), abandonando otra parte (el pasado) y empezando algo nuevo (el futuro) que prepara el porvenir" (Ramírez, 2011). 


\subsection{Azar como accidente y azar como ausencia de causas}

Destacamos en estos autores, Ramírez, Bleichmar, Hornstein, Canguilhem, Lopera, Morin, que sin desconocer la existencia de las determinaciones reconocen las posibilidades de transformación. Conciben el psiquismo como un sistema abierto a las perturbaciones, transformable. Es clara la incidencia de lo contingente, lo inesperado que puede cambiar el orden previamente establecido, lo que abre la posibilidad de la transformación subjetiva. Pero de esto no se deriva necesariamente que haya una elección en juego, que esas transformaciones o autoorganizaciones a las que avocan las contingencias dependan en algo de las elecciones del sujeto, podrían ser una recomposición espontánea, como lo dice Bleichmar (1994, p. 75).

Hemos venido afirmando que es la existencia del azar lo que da lugar a la libertad, a la posibilidad de elección. Sin embargo, llegamos a un punto en el que es importante hilar muy fino y aclarar muy bien los conceptos, pues esa afirmación es cierta dependiendo de cómo se defina azar. Veremos a continuación que aun cuando Freud le da un lugar determinante al azar, tal como él lo entiende no implica una afirmación de la libertad.

Respecto a la determinación psíquica Freud va arribando a una conclusión: los fenómenos y los rasgos psíquicos están sobredeterminados, es decir, se producen por una confluencia de factores que coadyuvan a la consecución de un síntoma o una neurosis, más específicamente por la interacción de lo biológico (lo innato, que con frecuencia es llamado por Freud lo constitucional) con el azar (la tyché, entendida como lo contingente, lo fortuito, lo inesperado, los accidentes). En palabras de Hadot:

La tyche representa, por el contrario, los movimientos que nos son exteriores y no dependen de nosotros: los encuentros con los otros hombres, pero también el azar de los acontecimientos, ese juego de azar que es la vida cotidiana. La doble acción de Daimon y de Tyche es pues decisiva para el destino del individuo. Se trata del encuentro entre los factores innatos y los factores accidentales. "Daimon y Tyche", dirá Freud, que conocía bien a Goethe, "determinan el destino de un ser humano". Es lo que llama la interacción entre la constitución y la experiencia (Hadot, 2010, p. 101).

Por la relevancia que tiene para esta investigación se citará en extenso un apartado donde Freud desarrolla ampliamente cómo concibe el azar y su papel determinante en el psiquismo y la vida misma:

[...] ¿no cabe escandalizarse por los resultados de una indagación que concede a las contingencias de la constelación parental tan decisivo influjo sobre el destino de un hombre; que en el caso de Leonardo, por ejemplo, lo hace depender de su nacimiento ilegítimo y la infecundidad de su primera madrastra, Donna Albiera? Creo que no hay ningún derecho al escándalo; cuando se considera al azar indigno de decidir sobre nuestro destino, ello no es más que una recaída en la cosmovisión piadosa cuya superación el propio Leonardo preparó al escribir que el Sol no se mueve. Naturalmente, nos afrenta que un Dios justo y una Providencia bondadosa no nos protejan mejor de tales 
contingencias en el período más indefenso de nuestra vida. Así, de buena gana olvidamos que en verdad todo es en nuestra vida azar, desde nuestra génesis por la unión de espermatozoide y óvulo, azar que como tal tiene su parte en la legalidad y necesidad de la naturaleza, sólo que no posee vínculo alguno con nuestros deseos e ilusiones. La partición de nuestro determinismo vital entre las «necesidades» de nuestra constitución y las «contingencias» de nuestra niñez puede que resulte incierta en sus detalles; pero en el conjunto no cabe ninguna duda sobre la significatividad, justamente, de nuestra primera infancia. Todos nosotros mostramos aún muy poco respeto hacia esa naturaleza que, según las oscuras palabras de Leonardo (que nos traen a la memoria el dicho de Hamlet), «está llena de infinitas causas \{ragioni\} que nunca estuvieron en la experiencia». Cada uno de nosotros, criaturas humanas, corresponde a uno de los incontables experimentos en que esas ragioni de la naturaleza penetran en la experiencia (Freud, 1910b, p. 127).

Tanto Freud como Lacan (1987) tienen una noción de azar, a su vez retomada de Aristóteles, que es lo contingente, lo inesperado, lo accidental. Ramírez, en cambio, plantea un azar diferente, sustentado por la ciencia contemporánea, tal como quisimos mostrarlo en el segundo capítulo. Explicitemos entonces las diferencias entre el azar aristotélico y el azar tal como lo entiende Ramírez.

En el libro La física Aristóteles se ocupa de los conceptos tyché (suerte, fortuna) y autómaton (azar, casualidad). Lo que el estagirita busca, parece ser, antes que nada, es aclarar y explicar el lenguaje popular y el sentido común de los griegos, a qué se refiere un griego cuando dice: "esto sucedió por suerte o por azar", es decir, explicar en qué sentido se habla de tyché y autómaton como causas (Aristóteles, 1995).

La tyché es traducida por los romanos como fortuna o suerte, y autómaton es traducida como casualidad, casus o spontaneus. Ambas son exactamente lo mismo, causas accidentales, la diferencia radica en que la tyché se utiliza sólo para referirse a los seres racionales, porque la suerte (buena o mala) es todo lo accidental que ocurre por haber hecho una elección con un propósito, y para Aristóteles sólo los seres humanos tienen capacidad de elección, la tyché resulta de la capacidad de elegir. Mientras que se habla de autómaton para referirse a las cosas inanimadas, los animales y los niños (pues según Aristóteles no tienen la capacidad de elegir) que desencadenan sucesos sin ningún propósito, en vano (sin que alguien esté buscando algo), sin que medie una elección.

Vamos rápidamente a los ejemplos que ayudan a comprender estos conceptos: si alguien elije salir a caminar para ejercitarse y al salir es atropellado por un auto, se dice que esa persona tuvo mala suerte, porque su elección de salir terminó siendo la causa accidental de que lo atropellaran. Mientras que si un árbol cae sobre un arroyo y termina siendo usado como un puente, se dice que esto ocurrió por casualidad, puesto que de un árbol no se dice que tuvo suerte, ni buena ni mala, por caer en determinado lugar, porque el árbol no eligió nada. Dicho de otro modo, se usa la palabra tyché para referirse a los eventos (ser atropellado) que coinciden con una elección (salir a caminar), y autómaton para referirse a los eventos que coinciden con lo que ocurre sin que medie una elección (la caída de un árbol, de la lluvia). Aunque tyché y autómaton 
son azar sólo se puede hablar de suerte (tyché) cuando se trata de seres pensantes que eligen, no cuando se trata de piedras.

Lacan retoma este concepto de Aristóteles para mostrar que el trauma se produce al modo de la tyché, es decir, como un encuentro inesperado con lo real (la sexualidad, la muerte), una experiencia inasimilable "que determina todo lo que sigue y le impone un origen, al parecer, accidental" (Lacan, 1987, p. 63). "Lo que se repite, en efecto, es siempre algo que se produce - la expresión dice bastante sobre su relación con la tyché- como el azar" (Lacan, 1987, p. 62). El sujeto queda sometido a la causalidad que le impone lo inesperado, es causado por algo que no puede conocer. El azar o lo real aparece por una incapacidad de conocer, lo real se relaciona con el sujeto de una forma que no logra comprender y se construye la repetición en torno a "eso" que no puede saber (Lacan, 2009).

En Ramírez hay otra noción de azar que no es sólo lo accidental, lo contingente, lo inesperado, la suerte o tyché aristotélica, sino el azar como lo que ocurre sin causa, la ausencia de determinaciones que deja un campo libre para que, dentro de las posibilidades, cualquier camino ocurra. Ensayemos un ejercicio dialéctico para mostrar más claramente la diferencia entre lo accidental (el azar aristotélico) y lo aleatorio (el azar en Ramírez).

Aristóteles, al definir el azar como series causales que confluyen, lo que aporta es una descripción, pero no una explicación de lo que ocurre, porque un escéptico podría preguntar: ¿qué ha hecho que esas dos series causales, la del caminante y el auto que lo atropella por ejemplo, confluyan? Desde la concepción aristotélica se podría responder: una elección que opera como causa accidental. El escéptico preguntaría: ¿y cuál ha sido la causa de esa elección? En este punto el determinista siempre encontrará una causa, llegando así al fatalismo. Mientras que el determinista dialéctico supondría que en algún punto de ese encuentro de series causales hubo una variable libre y, al no haber un determinismo absoluto, la confluencia sería, en parte, obra del azar y de la elección subjetiva a la que da lugar. Por tanto, en Ramírez el azar no se trata sólo de eventos que confluyen por accidente, es también lo no causado, como el lanzamiento de un dado: quizá no haya ley, ni determinación, ni cadena causal que conduzca a que el resultado sea el uno o el seis. Ramírez se refiere al azar cuando las determinaciones no son suficientes para obligar un camino, las determinaciones se agotan y se tiene que elegir. El ejemplo paradigmático de este azar, además del lanzamiento de un dado, es el asno hambriento que en su camino se encuentra frente a dos haces de heno de la misma cosecha, del mismo tamaño, a la misma distancia, ¿qué determina que elija el haz de la derecha o de la izquierda?, en este caso se supone que no hay determinaciones que obliguen la elección, por tanto, sería libre, al azar.

Paradójicamente, es el caos el que permite la elección y la libertad. La mayor parte de las veces elegimos lo más razonable: sopesamos las razones de parte y parte —consciente o inconscientemente- y luego decidimos lo preferible. Pero cuando la balanza no se inclina 
desde la razón, desde el logos, solo queda la elección azarosa, la voluntad (que hace acto), la apuesta. Allí reside la verdadera libertad; o cuando decidimos contra lo razonable, cuando nuestra voluntad inclina la balanza al lado contrario al que ya la inclinaban las determinaciones. Por eso la suerte es solo escucha y elección (buena y mala: es nuestra responsabilidad) (Ramírez, 2012, sec. 173. La suerte, p. 290).

Una síntesis de lo anterior es que para Aristóteles elegir es lo que da lugar al azar (los accidentes, la suerte, la tyché), mientras que para Ramírez el azar (lo aleatorio, no causado) es lo que da lugar a la elección. Esta es la fórmula que diferencia a los dos autores. En Ramírez lo azaroso es un hecho que no tiene causas, esto para Aristóteles se opondría a su idea de naturaleza, en la que todo ocurre por necesidad (por Nous o physis), por lo que el azar en Aristóteles no se trata de hechos sin causa, sino de causas accidentales a las que se les llama suerte o azar. Tomás de Aquino lo expresa claramente cuando define lo que es el azar para el filósofo: cuando un efecto tiene varias causas y esas causas son independientes entre sí se dice que el efecto es casual (Aquino, 1977, Libro II, Capítulo XLII, Numeral 1).

Para Aristóteles decir que algo ocurrió por accidente, por azar o por suerte es simplemente una forma de hablar, de decir, porque, tal como se plantea el tema en el libro La Física, Aristóteles pareciera adherir al determinismo de los atomistas, que siempre supone una causa a todo fenómeno, por tanto, los hechos que concurren tienen causas internas: las motivaciones que conducen a una elección o la gravedad que causa la caída de un árbol por ejemplo. Nada accidental (azaroso) es anterior a lo que es por sí, es decir, a lo que tiene una causa necesaria, propia, interna (una causa en sentido estricto) (Aristóteles, 1995, p. 158). La casualidad y la suerte son, entonces, posteriores a la inteligencia y la naturaleza (Aristóteles, 1995, p. 158), porque nous y physis son las causas primeras, principales o propias de todo lo existente: "Así, incluso aunque se concediese que la casualidad es la causa del cielo, sería necesario que la inteligencia y la naturaleza fuesen antes causas no sólo de muchas otras cosas, sino también de este Universo" (Aristóteles, 1995, p. 158). La diversidad de todas las cosas proviene del concurso de todas las causas (Aquino, 1977, Libro II, Capítulo XLII, Numeral 1) o como lo dice Borges (1983) en la Historia Universal de la Infamia, el destino sería la infinita operación incesante de millares de causas entreveradas.

Guillermo R. de Echandía también aclara que lo fortuito y lo casual para Aristóteles son los efectos que se generan al concurrir los sucesos, no la trama causal de la que resultan y que los determina, ya que, en tanto causas, un griego no ve ninguna oposición entre tyché y necesidad (Guillermo R. de Echandía, en: Aristóteles, 1995, nota 43, p. 147). Dicho de otro modo, el azar, para Aristóteles, no es más que un efecto que se produce al elegir. Para los atomistas, la tyché hay que entenderla según su tesis de la necesidad, según la cual "lo que tomamos como producto de la tyché respondería en realidad a un complejísimo entramado de innumerables causas necesarias, tantas que su determinación y predicción estarían fuera del alcance de la comprensión humana" (Aristóteles, 1995, p. 153), pero en sentido estricto la tyché no es causa de nada, afirmación que también es de origen atomista. Se trata entonces de un 
indeterminismo aparente, producto de las limitaciones humanas para conocer todas las variables en juego. Esta creencia implica asumir que toda la realidad es causal y determinista, y que el azar o la suerte es la sensación que deja el desconocimiento de todas las causas.

Aunque en su obra Ramírez siempre trata el tema del azar con escepticismo y no se explicita una posición acerca de si el azar es ontológico (hay hechos que no tienen causas) o epistemológico (hay hechos de los que no se conocen las causas, aunque podrían tenerlas), dilucido que hay de fondo una idea de azar ontológico (fuerte, duro), porque sólo en ella se pueden fundamentar sus planteamientos sobre la libertad, la elección y la responsabilidad, ya que un azar meramente epistemológico no deja lugar a la libertad entendida como autodeterminación, que consiste en acciones, decisiones, elecciones que no se deben a nada más que a la elección misma que puede elevarse por encima de las determinaciones, leyes o tendencias biológicas, discursivas y ocasionales. La libertad sólo es posible si se admite que hay hechos o eventos no determinados. Justamente ese era el propósito de este apartado, mostrar que con incluir en la teoría psicoanalítica el azar aristotélico, tal como lo hicieron Freud y Lacan, no alcanza para fundamentar la elección subjetiva, es necesario apelar a otra concepción de azar para que la libertad y la elección subjetiva tengan lugar.

Hecha esta distinción entre lo que es el azar para Aristóteles y lo que Ramírez, en concordancia con la ciencia contemporánea, plantea como azar, podemos afirmar que el azar aristotélico es incluso compatible con una visión determinista del mundo. Sólo la admisión de que hay hechos no causados, que las determinaciones se agotan y no dirigen todo el curso de los acontecimientos, da lugar a la libertad, la elección y la responsabilidad. Conceptos de los que nos ocuparemos en el último capítulo de esta investigación.

\subsection{El problema del determinismo psíquico y la libertad de volición.}

Como cierre de este capítulo y apertura del siguiente, es importante hacer mención del problema clásico al que nos ha llevado esta indagación: determinismo absoluto versus libertad. La libertad es la condición necesaria para la autodeterminación, la responsabilidad y la moral: solo si estamos en situación de decidir y actuar libremente podemos considerarnos seres que determinan lo que hacen, si no seríamos marionetas de las fuerzas causales, de las determinaciones. Sólo se es responsable de una acción si había posibilidad de actuar de otra manera, pero esa posibilidad queda anulada en un mundo en el que cualquier movimiento y pensamiento está regido por leyes causales.

Sin embargo, es necesario precisar qué se entiende por libertad, ya que en el ámbito de las ciencias sociales y políticas se puede entender como ausencia de coacción 
externa, estar en una situación tal que ningún ser humano ejerza o amenace con ejercer sobre otro una fuerza física o psíquica; se trata de la libertad de poder hacer lo que se quiere sin que nadie lo impida. Dicho en otras palabras, la libertad en este caso se entiende como autonomía. Sin embargo, en la práctica esta libertad no puede ser absoluta, ya que si muchos seres humanos hacen todo lo que quieren, muchos otros verán su libertad muy restringida, así que lo más razonable es preservar el mayor grado de libertad posible y compatible con una libertad igualitaria, esto hace que a veces sea necesaria la coacción para proteger la igualdad de la libertad. Se puede reformular esta idea de libertad como la ausencia de coacción injustificada, que no se ejerce para proteger la libertad de todos, sino que la limita innecesariamente.

Así entendida, en un sentido político y social, la libertad no es una afirmación del azar (aleatoriedad, ausencia de regularidades y determinaciones), pues aun cuando haya la menor coacción externa nuestras decisiones podrían estar regidas por coacciones internas y el control voluntario de ellas ser una mera ilusión. Podemos poner como ejemplo de los influjos internos que impiden el control voluntario de nuestras acciones una fuerte emoción o una adicción a la heroína. Tener el control voluntario de los actos significa ser de capaz de hacer consideraciones racionales y de atender a puntos de vista morales (Gadenne, 2006), pero una coacción interior puede ser tan fuerte que impida el ejercicio de la racionalidad o que las reflexiones logren tener algún influjo en las acciones. En este caso la libertad exige también ausencia de coacción interior.

Este es el centro de nuestra pregunta: mientras que la ausencia de coacción externa no entra en conflicto con el determinismo, la ausencia de coacción interna sí, porque las razones de actuar, las decisiones, los actos de voluntad, las reflexiones, las consideraciones morales, todos estos fenómenos no serían más que elementos de un acontecer causal determinado (Gadenne, 2006, p. 183). Solo la libertad de volición y libertad de acto presuponen el indeterminismo. Estamos ante el clásico problema del libre albedrío.

Por un lado, los deterministas radicales sostienen que la volición y la acción humana están determinadas por deseos, intenciones, que son estados mentales que operan como causas de la conducta; mientras que la visión contrapuesta afirma que no hay leyes causales que relacionen las razones con los actos, se niegan a interpretar las razones como causas, o no admiten que estas sean suficientes para determinar una acción, o afirman que las razones por las que actúa un ser humano son libremente elegidas. "Las razones consideradas por nosotros en un primer momento no nos obligan a hacer algo determinado. Aparte de nuestra acción, nos es posible también escoger qué razones queremos nosotros traducir en acción" (Gadenne, 2006, p. 186). John Searle, por ejemplo, considera falsa la tesis de que en toda acción hay que presuponer siempre algún deseo o interés, por eso con "el término «vacío» [que ubica entre las razones de actuar y la acción] pretende indicar que se ha roto la cadena causal: nosotros somos libres al decidir o al formarnos nuestras intenciones porque 
las razones que tenemos no representan causas suficientes. También somos libres al actuar porque, igualmente, las intenciones no son causas suficientes. Y, finalmente, somos también libres al interrumpir una acción (más larga) comenzada, porque podemos cambiar las intenciones antes de que acabe la acción completa" (Gadenne, 2006, p. 188).

Cuando se afirma al ser humano como agente o la causalidad del agente, se está proponiendo que hay una causa primera. Si se considera que los actos están causados por estados mentales, es preciso preguntar por la causa de los estados mentales. Esta regresión de preguntar siempre por una causa anterior se pretende acabar considerando a la persona como la causa misma, por la que ya no tiene sentido preguntar. La voluntad humana sería un motor primero, no movido a su vez por nada, convirtiendo al hombre en un ser agente que se eleva por encima de sus razones, motivaciones, deseos... en fin, que se eleva por encima de sus determinaciones y puede crear. El determinismo absoluto, por el contrario, acaba con la idea de lo nuevo, de lo creativo, sin libertad no habría responsabilidad ni moral. Moralmente responsable sólo puede ser alguien que ha tenido la posibilidad de actuar de otro modo, o sea, quien optó por uno de los caminos posibles.

Esta relación entre moral y libertad fue muy importante para Kant. En la Crítica de la razón práctica se refiere a la consciencia de un deber moral incondicionado. Considera una realidad innegable que nosotros somos conscientes de la ley moral, y esta consciencia de un deber incondicionado demostraría, además, que la libertad existe, que tenemos una voluntad libre (Gadenne, 2006, p. 198). La conciencia moral nos da la intuición de que somos libres, que no está predeterminado qué va a suceder, sino que soy yo quien debo elegir qué va a suceder, cómo actuar; se abren opciones de acción. Sin embargo, esta argumentación no tiene en cuenta que la aparición de la conciencia moral puede explicarse psicológicamente por procesos de condicionamiento y de aprendizaje por imitación, y que las normas morales tienen un cuño cultural.

Kant defendió la libertad de volición intentando varios argumentos: limita el determinismo al mundo fenoménico y la libertad al mundo nouménico; que nuestro conocimiento del mundo fenoménico no nos autoriza a decir cómo está hecho el mundo de las cosas en sí, propiamente que las cosas en sí están sometidas a la causalidad, pues esta es una categoría de la mente y no se la puede relacionar con el mundo real. Ramírez encuentra varios problemas en los artilugios teóricos que usa Kant en su defensa de la libertad. En primer lugar, se puede defender la libertad sin apelar a esa idea dualista de dos mundos, mostrando que en todos los niveles de la realidad hay azar, tal como se concibe en el determinismo dialéctico. Ramírez no antropomorfiza la libertad, al contrario, defiende que hay libertad en todos los niveles de la realidad, de hecho esta es concebida como una aleación de regularidades (repeticiones, constantes expresadas como leyes naturales o sociales) y azar. En segundo lugar, esta aparente solución que propone Kant, llevada hasta sus últimas 
consecuencias, implica una renuncia al realismo, dejar nuestros esfuerzos por obtener un conocimiento del mundo real lo más aproximado posible. En tercer lugar, aun cuando se admita que la causalidad es un a priori del pensamiento, que está en el pensamiento como categoría, también es cierto que, más allá de cualquier construcción mental, en la realidad hay regularidades, repeticiones que la ciencia ha logrado conocer y aprovechar con un alto grado de confiabilidad, dicho de otro modo, la eficacia de la ciencia, el alto grado de predictibilidad que logra, ejemplarmente en astronomía y óptica, hace incontestable que en la naturaleza hay regularidades que el ser humano ha formalizado como leyes naturales. En cuarto lugar, con esa división de dos mundos Kant sitúa al sujeto por fuera del mundo empírico.

En favor de la libertad también se ha argumentado que, partiendo de la observación fenomenológica, no nos sentimos determinados, ningún argumento o teoría determinista es capaz de invalidar la intuición de la libertad de volición, pero esa intuición por sí misma no es una prueba convincente de la libertad, podría ser una ilusión cognitiva que resulta "útil para la orientación en el mundo y para la planificación de nuestro actuar" (Gadenne, 2006, p. 192).

En favor del determinismo se ha dicho que es una condición previa de toda ciencia, pero en psicología ¿hay hechos o investigaciones que confirmen el determinismo absoluto en este ámbito?, ¿hay leyes causales en psicología que logren explicar el comportamiento? "En la psicología de la percepción es donde, ciertamente, más cerca se llega al ideal de leyes estrictas o probabilistas auténticas, porque en ella se trata de procesos psíquicos automáticos" (Gadenne, 2006, p. 202), pero se aleja de ese ideal cuando se estudian procesos más complejos, como la toma de decisiones y la resolución de problemas, justamente el ámbito de la ética. Miremos entonces, en el último capítulo de esta investigación, cómo concibe Ramírez lo psíquico y sus determinaciones, la elección subjetiva y la propuesta ética a la que da lugar. 


\title{
CAPÍTULO IV La Ética del Jugador Existencial
}

\author{
Nosotros tenemos herramientas para volver a pensar hoy \\ cómo se constituye un sujeto, que, inscripto en legalidades, \\ sea al mismo tiempo capaz de constituir una ética más allá de ellas. \\ (Bleichmar, 2011, p. 17)
}

En este capítulo se profundizará en la propuesta ética y existencial de Ramírez basada, a su vez, en el concepto de elección subjetiva. Se fundamentará esta propuesta en autores contemporáneos que han servido de referencia para el desarrollo de la obra de Ramírez.

Debido a que la idea de elección subjetiva en Ramírez está estrechamente relacionada con la formalización que este autor ha elaborado sobre los factores que determinan o causan lo psíquico, es preciso exponer qué entiende Ramírez por psiquismo, para luego discutir si estos determinantes dan lugar al azar, la libertad, la elección, la responsabilidad y la ética, que en el caso del jugador existencial se trata de fe y apuesta.

\subsection{Definición de psiquismo}

Definir la psique o alma, explicar su surgimiento, su naturaleza y su relación con el cuerpo ha representado un problema para la filosofía y la ciencia. Tradicionalmente se han propuesto dos alternativas: el monismo y el dualismo. El monismo materialista ${ }^{14}$

14 Dentro de la perspectiva monista también se incluye el monismo espiritualista o idealista, que niega la existencia de la materia y concibe que la realidad es espiritual, todo cuanto vemos y todo lo que somos serían representaciones o ideas de una mente superior. Una posición que, al ser descartada por la ciencia, ha quedado relegada a la filosofía y la literatura. Es lo que puede verse recurrentemente en la obra literaria de Jorge Luis Borges, que ante la perplejidad que le generaba existir se preguntaba permanentemente si esta realidad no era más que un sueño. 
defiende la existencia de una sola realidad, la materia, y todo cuanto existe sería una expresión de ella, por tanto, no existiría el alma o la mente como una realidad independiente, simplemente eso que en el lenguaje común se llama alma o mente sería un conjunto de procesos físico-químicos y neurofisiológicos. La otra alternativa es el dualismo ${ }^{15}$, según el cual existen dos realidades completamente diferenciables, una realidad material y otra espiritual, por tanto, el alma o la mente sería una realidad espiritual independiente del cuerpo aunque interactúa con él; una idea heredada de Platón y afianzada por Descartes.

Ramírez propone otra alternativa, el monismo dialéctico (Ramírez, 2012b, p. 263). Monismo porque considera que la realidad es una, pero dialéctico porque en esa realidad única se integran y dialectizan dos principios: la materia y la forma. Aristóteles expresaba esta misma idea cuando describía la realidad como un compuesto indisoluble de materia y forma (Aristóteles, 1983). La materia es aquello de lo que está hecho algo, mientras que la forma se entiende como el principio que informa la materia y le da una forma específica, por eso en la realidad encontramos materia con diferentes formas físicas (figuras), materia con diferentes formas biológicas (diferente in-forma-ción genética que da lugar a toda la diversidad de plantas y animales) y materia con diferentes formas simbólicas (formas de ser, tipos de personalidad, diferentes culturas, diferentes sistemas de valores, diferentes discursos, tradiciones). Decir que la realidad es un compuesto indisoluble de materia y forma significa que la una no puede existir sin la otra: es impensable una materia sin forma y una forma sin materia, son dos aspectos diferentes, pero siempre unidos.

En lo que se refiere al psiquismo o alma, el monismo dialéctico expresa que de la conjunción de un principio material (el organismo humano) y un principio formal (el lenguaje) surge una sola realidad que puede ser nombrada de dos maneras: alma, si se quiere enfatizar su aspecto discursivo, simbólico; o cuerpo, si se desea hacer énfasis en su aspecto biológico, carnal. 0 sea que, desde esta perspectiva, alma y cuerpo son lo mismo, son dos maneras de nombrar la misma realidad, dos maneras de mirarla, tal como ocurre con una moneda, que puede mirarse desde la cara o el sello, pero es una sola, "[...] igual que un estrábico, vemos doble una realidad indivisible del todo orgánico; vemos el cuerpo y el alma cuando en la realidad extrasubjetiva sólo hay una cosa en sí" (Lorenz, 1993, p. 238).

Ampliemos un poco más esta idea: lo psíquico se va desarrollando y se adquiere cuando un organismo humano (la cría, el cachorro humano) en el proceso de crianza, se apropia del lenguaje y, en consecuencia, de la cultura (las costumbres, las normas, los valores, las tradiciones de su comunidad) transmitida a través de instituciones

15 La perspectiva dualista engloba diversas posiciones que conciben de manera distinta la relación entre el alma y el cuerpo o la mente y el cerebro, que son los términos contemporáneos para referirse a este problema: paralelista, interaccionista, radical, moderado, emergentista y razonable son algunas de ellas (Martínez-Freire, 1995; Pagels, 1991) 
como la familia y la escuela. De allí que podamos definir lo psíquico, el alma, como cultura encarnada (Lopera et al., 2010).

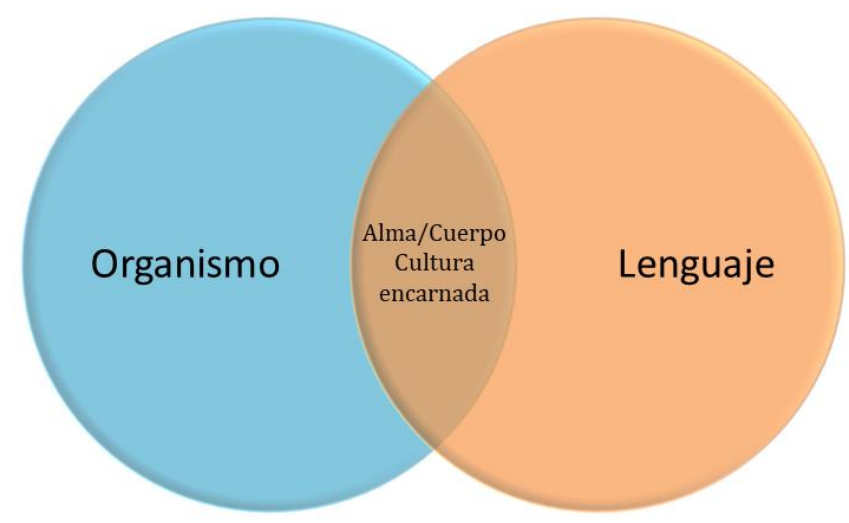

La implicación directa de definir el alma de esta manera es que no se nace con alma, tal como lo plantean muchas doctrinas religiosas, pues desde esta perspectiva no se trata de una entidad metafísica que preexiste al cuerpo, que llega a ocuparlo y lo abandona cuando muere. Al contrario, la que estamos presentando es una concepción monista y laica del alma. Si decimos que el alma se adquiere en el proceso de sujetación a la cultura, y que cuerpo y alma son lo mismo, esto significa que tampoco nacemos con cuerpo, una afirmación que a primera vista es contraintuitiva, por eso requiere ser explicada.

Según esta propuesta nacemos con un organismo, con las disposiciones biológicas heredadas genéticamente, pero se reserva el término cuerpo para denominar un organismo ya culturizado, es decir, un organismo que ha pasado por el proceso de sujetación a la cultura y se ha apropiado del lenguaje, de las costumbres, valores, normas y formas de ser de su comunidad, que se reconoce y se diferencia de los demás, que se atribuye un género, en ocasiones diferente al sexo del organismo.

Todos las corrientes psicológicas reconocen que el infante humano al nacer es incapaz de diferenciarse a sí mismo del entorno (Vygotsky, Luria, Piaget, Bandura, Freud, Spitz, Mahler, Klein, Hartman, Bruner, Maslow, Wilber); esta es una capacidad posibilitada por el lenguaje y se va adquiriendo en la interacción con otros miembros de la especie en un largo proceso de formación y aprendizaje; esto evidencia que lo que experimentamos y sentimos como nuestro cuerpo (el esquema corporal y la identidad que nos otorga) se adquiere, no se nace con él. Algunos ejemplos que ilustran esta diferencia entre organismo y cuerpo los podemos encontrar en casos extremos de psicopatología: un esquizofrénico, aunque su organismo está integrado, completo y conforma una unidad que lo mantiene con vida, puede experimentar su cuerpo como disgregado, desintegrado, algunos pueden llegar a sentir que les han quitado partes de su cuerpo. Es el caso de dos pacientes: uno de ellos se despertó 
enojado con el personal de salud que lo atendía porque le habían robado su nariz y pedía que se la devolvieran; el otro paciente se negaba a comer porque sospechaba que en las comidas le estaban dando sus propios órganos internos. Algunos casos de trastornos de la alimentación también ilustran esta diferencia: aunque el organismo está desnutrido, frágil, delgado, liviano, algunas de las personas que padecen estos trastornos llegan a presentar incluso alteraciones en la percepción, y perciben su cuerpo gordo, voluminoso y pesado al ingerir alimentos. Estos casos extremos ilustran claramente la distinción entre lo que denominamos organismo y cuerpo (un organismo culturizado, con lenguaje, el alma).

El proceso por medio del cual se desarrolla y se adquiere el alma/cuerpo es denominado de diversas maneras por las distintas escuelas psicológicas: crianza, aprendizaje, educación, formación, sujetación, individuación, socialización, culturización o humanización. Todas estas son formas de referirse al proceso por medio del cual el organismo humano va incorporando (haciendo cuerpo) la cultura, el lenguaje, el discurso, el pacto simbólico, transmitido por los representantes de su cultura: los padres, los profesores, los pares, el estado. Genéricamente podemos denominar a este proceso estructuración, con el fin de resaltar que de él emerge una estructura, la estructura psíquica, que también es denominada de diferentes formas por cada escuela psicológica: aparato psíquico, sujeto, individuo, mente ${ }^{16}$, personalidad, identidad, ego. Aunque cada término enfatiza aspectos diferentes, todos se refieren a la misma realidad emergente. Finalmente, decimos que de esa estructura derivan unos efectos, que serían las conductas o comportamientos observables, y pueden ser patológicos o no. Por tanto, decimos que cualquier expresión de un sujeto es un efecto o producto de su estructura psíquica Y precisamente esta estructura (el alma) es el objeto de estudio de la psicología, cuyo significado etimológico es literalmente estudio del alma.

Este objeto de estudio es lo que tienen en común todas las corrientes psicológicas, esa es la razón por la cual pueden denominarse, a pesar de sus grandes diferencias, psicología. Las diferencias radican, no en el objeto que estudian, sino en las concepciones filosóficas, epistemológicas y antropológicas que tienen de él. Para estudiar el alma todas las escuelas psicológicas se ocupan de estas tres categorías: el proceso de estructuración, la estructura misma (el alma) y sus efectos. Veamos, de manera muy esquemática, la manera particular en que cada una lo hace:

16 La mente, tal como lo define la RAE y como ha sido abordada por la tradición filosófica desde Descartes, es una de las facultades del alma, la facultad racional. Por eso consideramos que alma es un concepto más amplio que el concepto de mente. En consecuencia, es reduccionista afirmar que la psicología es el estudio de la mente, porque se estarían dejando por fuera de la psicología las demás facultades del alma: las emociones, los sentimientos, las pasiones, su dimensión inconsciente, ascética, espiritual... Decimos entonces que la psicología incluye el estudio de la mente, pero no se limita a ella. Para ampliar esta idea véase Cav. 28. Mente. En: Apuntes (Ramírez, 2011a); Sabiduría práctica y salud psíquica (Lopera, 2016, pp. 135-140) y la definición del concepto "Mente" en el Diccionario de Filosofía de José Ferrater Mora (1965). 


\begin{tabular}{|c|c|c|c|}
\hline ESCUELA PSICOLÓGICA & $\begin{array}{c}\text { PROCESO DE } \\
\text { ESTRUCTURACIÓN }\end{array}$ & $\begin{array}{l}\text { ESTRUCTURA } \\
\text { RESULTANTE }\end{array}$ & EFECTOS \\
\hline Conductista $^{17}$ & Condicionamiento & $\begin{array}{l}\text { El conductismo clásico o } \\
\text { radical niega su existencia o } \\
\text { la excluye del campo de } \\
\text { estudio de la psicología. } \\
\text { El neoconductismo } \\
\text { reconoce que hay un } \\
\text { procesamiento interno de la } \\
\text { información, pero } \\
\text { consideran que los } \\
\text { llamados procesos mentales } \\
\text { son también conductas. }\end{array}$ & $\begin{array}{c}\text { Conducta } \\
\text { Comportamiento }\end{array}$ \\
\hline Cognitiva & $\begin{array}{c}\text { Aprendizaje. } \\
\text { Etapas de desarrollo } \\
\text { psíquico: sensorio-motora, } \\
\text { preoperacional, de } \\
\text { operaciones concretas y de } \\
\text { operaciones formales. }\end{array}$ & $\begin{array}{c}\text { Mente } \\
\text { Esquemas mentales } \\
\text { Procesos mentales } \\
\text { Conciencia } \\
\text { Personalidad }\end{array}$ & $\begin{array}{c}\text { Conducta } \\
\text { Comportamiento }\end{array}$ \\
\hline
\end{tabular}

17 El conductismo clásico o radical, tal como lo propuso Watson y es retomado por Skinner, sería la única escuela psicológica que no tiene por objeto de estudio la estructura (la consciencia, la mente, la personalidad, el alma), pues niega su existencia o la desconoce al no poder ser abordada por el método experimental ni encajar en los parámetros del positivismo, por tener aspectos no observables, intangibles, inconmensurables, subjetivos. Sería entonces una psicología incompleta, sin alma. 


\begin{tabular}{|c|c|c|c|}
\hline ESCUELA PSICOLÓGICA & $\begin{array}{c}\text { PROCESO DE } \\
\text { ESTRUCTURACIÓN }\end{array}$ & $\begin{array}{l}\text { ESTRUCTURA } \\
\text { RESULTANTE }\end{array}$ & EFECTOS \\
\hline Psicoanalíticas & $\begin{array}{l}\text { Desarrollo pulsional (oral, } \\
\text { anal, fálico). } \\
\text { Complejo de Edipo. } \\
\text { Fases de desarrollo: } \\
\text { autística, simbiótica, } \\
\text { separación-individuación. }\end{array}$ & $\begin{array}{c}\text { Aparato psíquico } \\
\text { Estructura psíquica } \\
\text { Sujeto }\end{array}$ & $\begin{array}{c}\text { Síntomas } \\
\text { Sueños } \\
\text { Lapsus } \\
\text { Actos fallidos } \\
\text { Chistes } \\
\text { Producciones artísticas }\end{array}$ \\
\hline Humanista & $\begin{array}{l}\text { Jerarquía de necesidades: } \\
\text { fisiológicas, de seguridad, de } \\
\text { afiliación, de } \\
\text { reconocimiento, de auto- } \\
\text { realización (espirituales) }\end{array}$ & Ser humano & $\begin{array}{c}\text { Expresiones } \\
\text { Creaciones }\end{array}$ \\
\hline Transpersonal & $\begin{array}{c}\text { Fase prepersonal, personal y } \\
\text { transpersonal } \\
\text { (trascendencia del ego) }\end{array}$ & $\begin{array}{l}\text { Persona } \\
\text { Identidad }\end{array}$ & $\begin{array}{c}\text { Expresiones } \\
\text { Creaciones }\end{array}$ \\
\hline
\end{tabular}


En la primera columna podemos reconocer un abordaje evolutivo que hacen todas las propuestas psicológicas, la segunda columna es el abordaje estructural y la tercera columna es un abordaje fenomenológico. Aunque todas las corrientes psicológicas estudian el alma, algunas lo hacen privilegiando su dimensión biológica, orgánica, como la neuropsicología y el conductismo. Mientras que otras hacen énfasis en su dimensión discursiva, como el psicoanálisis, la psicología humanista o la cognitiva.

Lo que constituye lo específicamente humano no es solamente el organismo, el organismo es una dimensión necesaria, pero no suficiente (Bruner, 1998). Por supuesto que para desarrollar un psiquismo se necesita un organismo dotado con las potencialidades para hacerlo, pero además estar en contacto con esa realidad simbólica y afectiva propia de los humanos.

El sociólogo alemán Norbert Elias define el alma tal como la venimos planteando. En un bello pasaje de su lúcido ensayo La sociedad de los individuos escribió:

Puesto que la relativamente indiferenciada dirección de las relaciones del recién nacido sólo se diferencia y se regula de manera humana en la relación del niño con otras personas, aquello que conocemos como «alma» del individuo adulto no es «en sí mismo» algo ajeno a la sociedad y asocial, sino que está desde la base en función de aquella unidad relacional de mayores dimensiones que denominamos «sociedad»; el modo en que la persona se ve y se dirige a sí misma en sus relaciones con los otros depende totalmente de la estructura de aquel grupo o aquellos grupos humanos a los que hemos aprendido a llamar «nosotros» (Elias, 1990a, p. 56).

Además, afirma que "el niño no sólo es mucho más moldeable que el adulto. El niño necesita ser moldeado por otros, necesita la sociedad para convertirse en un adulto psíquico [...] si las funciones psíquicas del niño no son modeladas por éstos, el pequeño, digámoslo una vez más, es durante toda su vida poco más que un animal" (Elias, 1990, p. 42), por lo que insistimos en que no basta con la herencia biológica para que un ser humano llegue a constituirse como tal, es preciso apropiarse también de la herencia cultural (Tomasello, 1999). Por esta flexibilidad biológica del infante humano, que requiere un largo moldeamiento social para individuarse, Elias afirma que los estudios de la psicología constituyen un puente entre las ciencias naturales y las ciencias sociales (1990, pp. 58-59).

Esta es también la visión de la psicología rusa: Vygotsky y Luria enfatizan que la explicación de las funciones psíquicas superiores del hombre no se encuentra en la fisiología del cerebro ni en un principio divino y metafísico, sino en la historia social de la humanidad y las formas del trabajo social, posibilitados por el lenguaje, es esto lo que hace posible las nuevas formas de actividad consciente (Luria, 1982, p. 104). No vemos el mundo simplemente con colores y formas, percibimos el mundo con sentido y significado (Vygotsky, 1966). 
Un ejemplo de que el organismo no es el único factor necesario para que emerja lo psíquico lo hallamos en los niños salvajes, niños que crecieron completamente aislados de la sociedad y, por tanto, no adquirieron un lenguaje, ni las costumbres y valores de su época. Fue el caso de Víctor de Aveyron, Kaspar Hauser, Genie y, más recientemente, Oxana Malaya. Aunque estos niños tenían un organismo humano, no se les transmitió, y por tanto no incorporaron, el lenguaje, que es el vehículo que lleva a desarrollar procesos de pensamiento, a constituir una identidad y, en últimas, una actitud o forma de ser específicamente humana. Al estar privados de esta dimensión discursiva su conducta era más cercana a la de los animales, centrada únicamente en la satisfacción de las necesidades básicas, primarias, orgánicas, biológicas, pero no contaban con esa dimensión espiritual (el espíritu de la cultura, el espíritu de su época, concretado en valores y tradiciones) que posibilita la autoconsciencia, las preguntas por el propio ser, por los otros y el entorno. Esto da cuenta de la disociación que puede existir entre la forma biológica humana y la forma de ser humana.

Esta concepción monista dialéctica del alma, desde la cual se la define como cultura encarnada, es reafirmada no solo por todas las escuelas psicológicas, sino también por la neurología. "Probablemente no se pueda concebir la mente sin algún tipo de encarnación" (Damasio, 2001, p. 217). El neurólogo que acabamos de citar, Antonio Damasio, plantea que la mente no surge del cerebro; según sus investigaciones eso sería reduccionista, sino que la mente emerge del organismo completo (es decir, de la interacción del cerebro con el resto del cuerpo) en relación con el medio físico y social (el lenguaje) (Damasio, 2001, p. 231).

Esta afirmación de Damasio se sustenta en una perspectiva evolucionista del surgimiento de la mente, esto quiere decir que la evolución seleccionó cerebros que no solo emiten respuestas motrices, sino también respuestas mentales (imágenes en la mente), probablemente porque estas respuestas acrecentaban la supervivencia del organismo al tener una mejor apreciación de las circunstancias externas, al generar respuestas motrices más refinadas y posibilitar la predicción de consecuencias mediante la imaginación. por tanto "cuando aparecieron cerebros capaces de pensar, empezaron pensando en el cuerpo" (Damasio, 2001, p. 213), "el cuerpo contribuye al cerebro con algo más que el soporte vital y los efectos moduladores. Contribuye con un contenido que es una parte fundamental de los mecanismos de la mente normal" (Damasio, 2001, p. 210). El contenido de la mente humana consiste entonces en representaciones primordiales del cuerpo en acción, y estas representaciones primordiales del cuerpo ofrecerían un armazón espacial y temporal, sobre el que se apoyan luego otras representaciones secundarias, lingüísticas.

Sin embargo, Damasio insiste en que el hecho de que la mente emerja evolutivamente de la materia no implica que pierda su valor. El desprecio por esta realidad material quizá sea un residuo religioso que nos queda, y nos impide reconocer y respetar todas las maravillas y misterios que alberga: 
Sin embargo, la mente completamente integrada en el cuerpo que yo concibo no renuncia a sus niveles de operación más refinados, los que constituyen su alma y su espíritu. Desde mi perspectiva, es solo que alma y espíritu, con toda su dignidad y escala humanas, son ahora estados complejos y únicos de un organismo. Quizá la cosa más indispensable que podamos hacer como seres humanos, cada día de nuestra vida, es recordarnos a nosotros mismos y a los demás que somos complejos, frágiles, finitos y únicos. Y esta es, desde luego, la tarea difícil: desplazar el espíritu desde su pedestal en ninguna parte hasta un lugar concreto, al tiempo que se conserva su dignidad y su importancia; reconocer su humilde origen y su vulnerabilidad, pero seguir dirigiendo una llamada a su gobierno (Damasio, 2001, p. 231).

Al afirmar que lo psíquico, el alma, es el objeto de la psicología, no se desconocen las diferencias entre las corrientes psicológicas, simplemente se propone un campo común a todas ellas, las reconocemos y validamos como parte de una disciplina, y destacamos la importancia tanto de los abordajes epistémicos como ascéticos que pueden hacerse de este objeto ${ }^{18}$ :

Se pretende mostrar que, con la adopción del alma como objeto de estudio de la psicología -con la aceptación del objeto que siempre le ha correspondido- se amplían las posibilidades de un diálogo intradisciplinar, interdisciplinar y transdisciplinar, que es a todas luces conveniente para el avance de la psicología, al mismo tiempo que se reconoce toda la tradición filosófica que sigue aún vigente en las elaboraciones sobre el alma, lo que aporta más aspectos para su comprensión y estudio, tanto epistémico como ascético. También, como valor agregado, se logra mediante este diálogo una actitud más analítica, menos dogmática, más pluralista, que opera como antídoto a las posiciones cerradas, casi religiosas, que muchos autores han asumido al atrincherarse en su propia escuela y mirar con desprecio, o incluso con plena indiferencia, los planteamientos de las demás escuelas. Se obtiene, finalmente, una actitud ética de reconocimiento del otro como un interlocutor válido, así como la aceptación de que el propio discurso, la escuela de preferencia, es una mirada más (no la única ni la verdadera) sobre el alma (Lopera et al., 2010, p. 258).

\subsection{Determinantes psíquicos}

Una vez definido lo que consideramos psiquismo, profundicemos, ahora sí, cuáles serían los factores que lo causan y determinan, y cómo introduce Ramírez el azar, la libertad y la elección subjetiva en la causalidad psíquica.

Basado en la propuesta Freudiana de la sobredeterminación psíquica, Ramírez, más que de determinismo, habla de determinantes psíquicos, pues de acuerdo con el determinismo dialéctico se acepta que hay determinaciones biológicas y discursivas,

$18 \mathrm{El}$ abordaje epistémico tiene el propósito de construir un conocimiento sistemático sobre el alma, al modo de la ciencia. Mientras que el objetivo de un abordaje ascético es el tratamiento del alma, la ascesis o transformación subjetiva. Estas dos perspectivas pueden ampliarse en el artículo Psicología ascética y psicología epistémica (Lopera, 2006). 
pero estas interactúan con lo ocasional, lo contingente, lo accidental, la tyché aristotélica, la suerte y el azar propiamente dicho ${ }^{19}$.

Cualquier fenómeno psíquico, así como la configuración psíquica misma (el aparato psíquico, la estructura psíquica, la personalidad, el alma), emerge de la mezcla de estos tres factores: biológico, discursivo y ocasional, y cada uno de ellos se manifiesta de dos formas, que denominaremos ejes: singular y ambiental. El eje singular son los determinantes que operan sólo en el sujeto, mientras que el ambiental son los determinantes que operan colectivamente, en todo el entorno.

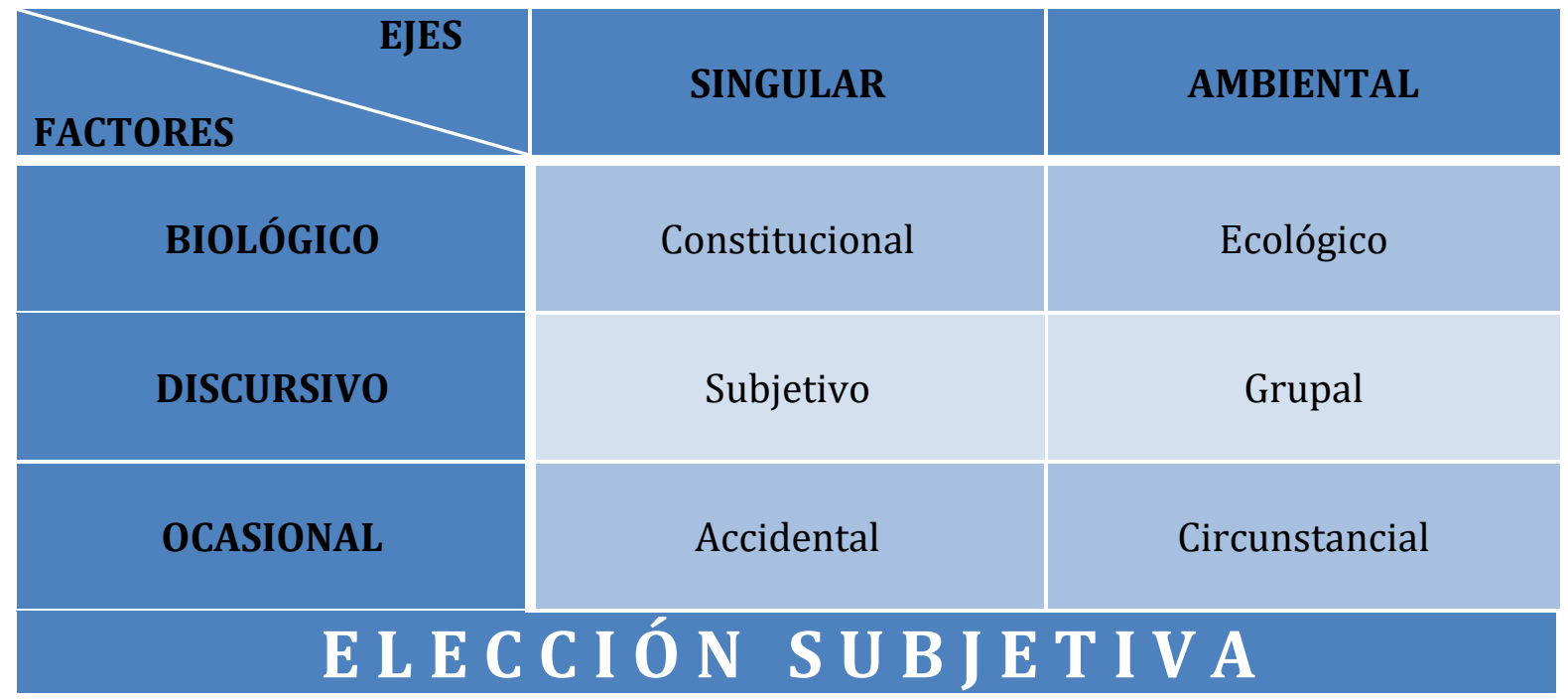

El factor biológico en su eje singular sería lo constitucional, esto es, las particularidades fisiológicas del individuo, ya sean heredadas de los padres (genéticas) o adquiridas a lo largo de la vida. Tener el cabello rojo, la piel blanca o negra, una cicatriz, la amputación de una extremidad, una deformidad causada por una postura corporal inapropiada, tener cierta figura por ejercitación recurrente o por los hábitos alimenticios, etc... El factor biológico en su eje ambiental sería lo ecológico, el entorno físico en el que nace y se desarrolla el sujeto, la geografía, el clima, la alimentación, las condiciones de la vivienda. Las características biológicas de raza, estatura, color, peculiaridades fisiológicas, pueden influir y modificar lo discursivo, al determinar valores, preferencias, creencias, discriminaciones, prejuicios. En las estructuras melancólicas, en la psicosis depresiva, la manía, la esquizofrenia, en los autismos tempranos, el retardo mental, los trastornos neurológicos, los fenómenos psicosomáticos, las psicopatías y las sociopatías, hay una prevalencia del factor biológico, sin que esto implique desconocer que todo sujeto construye un discurso sobre su enfermedad o sus características físicas, y este discurso puede cambiar completamente su significación y su importancia en la vida.

19 En el tercer capítulo de esta tesis se explicitó la diferencia entre el azar tal como lo formula Aristóteles (la tyché) y el azar tal como es entendido por Ramírez. 
El factor discursivo en su eje singular sería lo subjetivo, la historia individual que va constituyendo un sujeto único con un discurso singular y una forma peculiar de goce (Ramírez, 2012b, p. 35). Son los significantes singulares que marcan la existencia de un ser humano, por ejemplo el nombre propio. El factor discursivo en su eje ambiental sería el discurso grupal, colectivo que rodea al sujeto, su universo simbólico, el discurso de la familia, el barrio, la ciudad, el país, la cultura y la civilización. Las posiciones discursivas (culturales, grupales o individuales) afectan lo biológico y pueden también favorecer la aparición de accidentes, contingencias y traumas. La preponderancia de este factor aparece en estructuras con determinantes simbólicos: la paranoia, la debilidad mental, la perversión, las psiconeurosis (histeria y obsesión), que resultan de la posición que adopta el individuo frente al grupo cultural. Esto teniendo en cuenta que cualquier discurso está basado en unas particularidades biológicas que determinan también su temperamento y su constitución.

El factor ocasional en su eje singular es lo accidental, las contingencias singulares que determinan la suerte o el destino personal. Accidentes, encuentros o desencuentros con un real, a veces inesperado. El factor ocasional en su eje ambiental es lo circunstancial, las catástrofes, las circunstancias del entorno determinadas por "la fortuna" o el azar (Ramírez, 2012b, p. 36). Los acontecimientos actuales influyen y pueden cambiar las determinaciones anteriores o desencadenar posibilidades que estaban latentes en el sujeto. Este factor es fundamental, por ejemplo, en las neurosis traumáticas, a las que Freud llamaba neurosis actuales, y todos los trastornos causados por accidentes o traumas contingentes. Sin dejar de ser cierto que las características discursivas y fisiológicas pueden predisponer, facilitar y coadyuvar la ocurrencia de accidentes, contingencias y traumas.

Estos tres factores, el biológico, el discursivo y el ocasional son el conjunto de todo lo que está dado, lo que se le impone al sujeto y él no ha tenido la potestad de elegir, pero contando con esas determinaciones, basado en ellas, hay aspectos que el sujeto puede e incluso debe elegir. Esta elección subjetiva es el séptimo factor que Ramírez incluye como determinante de lo psíquico, y es transversal a todos los demás, la elección individual, que es el punto de partida del libre albedrío, de la libertad de escoger y de la responsabilidad. Sobre el factor de la elección subjetiva dice Ramírez: "Es el resultado de la confluencia de todos los factores singulares en un deseo subjetivo. Si no se admite esta posibilidad se cae en el fatalismo, pero si se sobrevalora con respecto a los otros factores se llega al voluntarismo, reflejado en el dicho popular "querer es poder", o en la omnipotencia del deseo, típica del pensamiento mágico" (Ramírez, 2012b, p. 36).

Vemos que estos siete factores confluyen e interactúan entre ellos, se combinan, se interpenetran, y esa mezcla determina el psiquismo y cualquier manifestación humana. "Un hombre es un ser a la vez biológico y social y esa doble configuración constituye su naturaleza propia. [...] hay muchos fenómenos que siendo sociales 
tienen efectos orgánicos y hay otros fenómenos que siendo orgánicos producen efectos en nuestra vida social" (Zuleta, 2004, p. 13). Por esto Ramírez advierte el riesgo de caer en un reduccionismo cuando al momento de explicar los fenómenos psíquicos se privilegia sólo un factor en detrimento de los demás.

Si se tiene en cuenta sólo el factor biológico se puede caer en un reduccionismo biologista, ya sea fisiológico o ecológico. Es lo que ocurre cuando las enfermedades mentales, los síntomas, los trastornos se explican sólo desde su dimensión orgánica y se tratan solamente con medicamentos, dejando de lado la historia vital, los acontecimientos que rodean el surgimiento de un síntoma, el sentido que éste puede tener en la vida de alguien, las relaciones tóxicas o disfuncionales que pueden estar influyendo en la enfermedad $\mathrm{y}$, en general, en la forma de ser de cualquier ser humano. Así es como Norbert Elias destaca la incidencia de la experiencia social sobre la biología del ser humano:

Constituciones naturales parecidas pueden conducir, según este destino de las relaciones, según la estructura del tejido de relaciones en el que se crían los niños, a formas de conciencia y de instintos muy distintas entre sí. La individualidad que alcanzará finalmente una persona no depende simplemente de su constitución natural, sino de todo el proceso de individualización. Ciertamente, la constitución particular posee una enorme importancia para el destino de la persona. El destino de un niño sensible es de esperar que sea muy distinto al de un niño menos sensible de la misma familia o sociedad. Pero este destino, y con él la forma individual que un ser humano desarrolla paulatinamente durante su crecimiento, no vienen predeterminados definitivamente por la constitución, por la naturaleza heredada por el recién nacido. Aquello que surge de la constitución particular del recién nacido depende de la estructura de la sociedad en que éste crece. Su destino, como quiera que se desarrolle en los detalles, es, en su conjunto, específico de su sociedad (Elias, 1990a, pp. 38-39).

Sin embargo, tener en cuenta sólo el factor discursivo puede llevar a un reduccionismo subjetivista o culturalista. Son quienes proclaman la hegemonía del discurso y lo simbólico, quienes explican todos los problemas subjetivos a partir de las costumbres, los valores, las normas que regulan la vida social, atribuyendo todo el malestar al discurso cultural. El psicoanálisis, en ocasiones, ha caído en estos abusos de lo simbólico, desconociendo radicalmente la dimensión orgánica que también nos determina e influye en el comportamiento humano, en el temperamento, en la propensión a ciertas enfermedades. Lacan, por ejemplo, llegó a negar que el desarrollo psíquico y pulsional estuviera soportado o posibilitado, aunque fuera en parte, por el desarrollo biológico, orgánico:

Si el conocimiento, en los escritos teóricos [de Freud], está referido tan a menudo a algo análogo a la relación entre la ontogénesis y la filogénesis, ello se debe a una confusión, y la próxima vez vamos a mostrar que toda la originalidad del análisis radica en no centrar la ontogénesis psicológica en los pretendidos estadios, los cuales, literalmente, no tienen ningún fundamento discernible en el desarrollo observable en términos biológicos. El accidente, el tropiezo de la tyché anima el desarrollo entero [...] La descripción de los estadios, formadores de la libido, no debe ser referida a una pseudo-maduración natural, 
siempre opaca. Los estadios se organizan en torno a la angustia de castración (Lacan, 1987, pp. 71-72).

La psicoanalista argentina Silvia Bleichmar, muestra los inconvenientes que ha ocasionado el reduccionismo simbólico en el psicoanálisis, tales como la subordinación a otros saberes y su empobrecimiento:

El psicoanálisis ha sido atravesado, en la segunda mitad del siglo, por los movimientos filosóficos que Habermas ubica como constituyendo los grandes flujos que marcan el pensamiento postmetafísico: la filosofía analítica, la fenomenología, el marxismo occidental y el estructuralismo. Desde estas perspectivas se ha intentado, una y otra vez, refundar la ciencia del inconsciente desde una perspectiva no biologista. Ello no necesariamente ha implicado una perspectiva superadora; por el contrario, ha conducido, en muchos casos, a nuevas subordinaciones - sea a la lingüística o a la sociología- o incluso a un reduccionismo empobrecedor a teorías de la interacción o a ensamblajes de dudoso cuño con el cognoscitivismo (Bleichmar, 1994, p. 46).

Si se tiene en cuenta sólo el factor ocasional se cae en un reduccionismo ocasionalista o circunstancialista, según el cual el futuro es completamente azaroso, incierto, entonces no vale la pena preocuparse, pensar o planear el futuro, porque las consecuencias de cualquier opción que se realice se consideran incalculables.

Es importante diferenciar entre reduccionismo y focalización. Una cosa es explicar un fenómeno desconociendo todos los factores en juego, lo que sería reduccionista, y otra cosa es reconocer toda la diversidad de factores que influyen, pero privilegiar y centrarse en el estudio de uno de ellos:

\begin{abstract}
Usualmente un fenómeno es multicausado (Ramírez, 2012); cuando se describe, explica o predice a partir de una sola causa, también se habla de reduccionismo. Por ejemplo, el sociologismo se presenta cuando se explica un fenómeno psicológico exclusivamente con base en las reglas sociológicas, el psicologismo se presenta cuando se explica un fenómeno histórico a partir, exclusivamente, de reglas psicológicas. Sin embargo, dado que para el ser humano no es posible abarcar todos los diferentes niveles de la realidad cuando teoriza, la ciencia tiende a focalizarse en sectores de la realidad (Ramírez, 2012). La focalización es necesaria para profundizar en el conocimiento de un fenómeno. (Manrique \& De Castro, 2016)
\end{abstract}

Reconocer que todo fenómeno psíquico está sobredeterminado o es policausado no quiere decir que cada factor influya con la misma intensidad o sea igualmente determinante. En ciertos casos, la importancia o intensidad de un factor puede ser tan grande que pasa a ser decisiva, y en otros casos poco significativa, pero siempre intervienen todos. Esta es la posición dialéctica que caracterizó a Freud, que enfatiza la interrelación entre los factores, sin llegar a negar las diferencias de intensidad y de influencia que puede haber en cada caso.

Un ejemplo de cómo estos factores se pueden conjugar en la manifestación de un fenómeno psíquico, lo podemos ver en la depresión: por lo general se encuentran 
variables orgánicas como la regulación del litio, alteraciones hormonales, cansancio, anomalías orgánicas, enfermedades, inestabilidad de elementos bioquímicos que llenan de energía y euforia (manía) o desaniman. Pero a la vez, pusilanimidad, miedo al compromiso, a la vida y a sus exigencias, sobreestimación de lo negativo, pesimismo, privilegio de la crítica no constructiva. Y en los episodios críticos de una depresión siempre hay un factor ocasional desencadenantes, tales como un despido laboral, una separación, una pérdida, una quiebra económica o vivencias que para los demás pueden ser eventos irrelevantes, pero dadas las condiciones fisiológicas y discursivas del sujeto pueden desencadenar una crisis depresiva.

\begin{abstract}
Una concepción dialéctica de lo psíquico requiere entonces tener en cuenta los tres factores; por eso plantea que las palabras cuerpo y alma indican solamente perspectivas para abordar ese ser sufriente que habla, el hombre o animal verbal, es decir, la encarnación animal del logos. Cuando lo tratamos desde el organismo hablaremos de cuerpo, de fisiología; cuando lo hacemos desde su discurso, de alma, de sujeto; pero en ambos casos, para un trabajo integral, no reduccionista, habremos de llegar al otro aspecto: podemos empezar desde la carne para llegar al espíritu, o viceversa. Y siempre sin olvidar ese irreductible tercer factor: lo inesperado, lo contingente; la tyché aristotélica, que para Freud era lo ocasional y para Lacan, lo real, origen de lo traumático, de lo no simbolizado o no asimilado (Ramírez, 2012b, p. 39).
\end{abstract}

En este tercer factor determinante Ramírez incluye el azar y la elección, puesto que el hecho de no haber causas, determinaciones, leyes que obliguen a que ocurra algo, hace preciso elegir. Por eso, el concepto de elección ha sido muy importante en la teoría de Ramírez, por ser el fundamento de su propuesta ética, clínica y existencial. Pero antes de pasar a las implicaciones éticas y existenciales que tiene concebir la estructuración psíquica de esta manera, es preciso poner en discusión la incidencia del azar en el psiquismo. Miremos entonces algunos referentes desde los cuales puede sustentarse el determinismo dialéctico ${ }^{20}$ en la conformación del psiquismo.

\title{
4.3. Azar e indeterminación psíquica
}

Quizá la posición determinista más célebre en psicología es la que plantea Skinner en su ensayo Más allá de la libertad y la dignidad por la radicalidad que enarbola. Según este autor, la libertad y la dignidad son creencias fundamentadas en un supuesto falso: que la causa de la conducta está en el individuo y que el hombre es responsable de su conducta, cuando en realidad, dice Skinner, está completamente determinada por el ambiente y sus disposiciones genéticas, por tanto, no habría razones para castigar o elogiar a alguien por sus conductas. Argumenta que la creencia en la existencia de acciones libres de algún tipo de control, obstaculiza el progreso de una tecnología

20 En el segundo capítulo se presenta una definición detallada del determinismo dialéctico y se fundamenta con las ideas de importantes científicos contemporáneos, mientras que en este capítulo se desarrollará el monismo dialéctico, pero circunscrito al ámbito de lo psíquico. 
eficaz de la conducta y el diseño de una cultura hecha a la medida del hombre y planeada por la ciencia.

Sin embargo, estudios previos y posteriores a este ensayo de Skinner han enfatizado los aspectos no programados (indeterminados) en el ser humano, desde los cuales se relieva la indeterminación, la importancia de las elecciones, la ética de esas elecciones y la responsabilidad.

El neurocientífico Rodolfo Llinás (2003) desarrolla el concepto de Programas de Acción Fijos (PAF) para describir el desarrollo humano. Estos PAF son una memoria filogenética, una información que tiene nuestro organismo, pero que no es adquirida por la experiencia individual, sino heredada, nacemos con un programa estructural, referido a la arquitectura o estructura física de nuestros órganos, y con un programa dinámico, referido a la función, a la actividad que desempeña cada órgano. Pero hay un tercer tipo de memoria o programa, el referencial, que consiste en toda la información, las experiencias, las habilidades y los aprendizajes adquiridos por cada organismo a lo largo de la vida. La memoria referencial solo puede adquirirse en interacción con el entorno. Más aún, el programa estructural y dinámico con el que nacemos sólo puede desplegarse y desarrollar sus potencialidades en interacción con el entorno. En esta elaboración de Llinás podemos leer que las determinaciones innatas se despliegan y se modifican en interacción con el entorno. Entonces, aunque hay aspectos determinados en el ser humano, hay otros que sólo se inscriben con la experiencia, con el aprendizaje y pasan a ser determinaciones. Al profundizar en las determinaciones innatas, biológicas, es posible percatarse de que, en principio, fueron también azares que después de ocurrir se continúan repitiendo y transmitiendo como determinaciones ${ }^{21}$. En otras palabras, todo lo determinado fue en principio azar.

En términos generales se acepta el determinismo genético y ambiental en el ser humano, incluso el circunstancial (los accidentes, los encuentros contingentes); lo que está en discusión es si estos factores determinantes dejan en el ser humano variables no determinadas que den lugar a una elección autónoma, autodeterminada, libre.

Sobre esta pregunta conclusiva a la que hemos llegado, el sociólogo Norbert Elias destaca la flexibilidad biológica con la que nace la cría humana, y con ello se refiere a la indeterminación biológica del comportamiento humano. Justamente en ello radica su prolongada indefensión, puesto que el ser humano es el que más tarda en su desarrollo sexual y en alcanzar su autonomía, de allí la necesidad de un largo proceso de formación para adquirir comportamientos no biológicamente determinados, sino socialmente moldeados (lo que Llinás llama memoria referencial). Y es gracias a esa indeterminación biológica que en el ser humano emergen rasgos individuales (la individualidad, la personalidad, la subjetividad), el lenguaje y la sociedad:

21 En el segundo capítulo se describe cómo ocurre este proceso de repetición de errores (aleatorios, azarosos) desde la perspectiva de la biología molecular. 
Si los seres humanos no fueran, en lo que se refiere a la dirección de su comportamiento, por naturaleza mucho más flexibles y maleables que los animales, su reunión no daría forma a un continuo social autónomo, a una sociedad, ni poseerían cada uno de ellos una individualidad. Los grupos de animales no poseen más historia que una «historia natural»; y los animales particulares pertenecientes a uno de esos grupos no se diferencian unos de otros, en cuanto a la dirección de su comportamiento, en la misma medida en que se diferencian los seres humanos, no son tan individualizables como los seres humanos (Elias, 1990a, p. 81).

Desde esta cita de Norbert Elias podemos tender hilos hacia otros autores aparentemente muy alejados en el campo del conocimiento. Llinás, por ejemplo, llega a una conclusión similar cuando afirma que esa ductilidad de los Programas de Acción Fijos (la memoria biológica estructural y funcional del ser humano) es lo que posibilita la emergencia del lenguaje (Llinás, 2003, p. 201). El filósofo francés Gilbert Simondon también va a destacar las amplias posibilidades de individuación del ser humano gracias a su dimensión preindividual, que se refiere a las potencialidades, la energía disponible que aún no ha tomado forma y hace posible que se tomen diversos caminos, más allá de lo preconcebido. Esta dimensión preindividual en el ser humano ha dado lugar a la imaginación y la invención, y hace que esté en constante proceso de individuación. Estos conceptos serán retomados posteriormente con más detalle.

Elias no desconoce que en los animales también hay grados de flexibilidad biológica y diferenciación, pero en el hombre pareciera haber un grado de libertad mayor debido a que está "menos ligado a patrones de comportamiento prefijados orgánicamente que el resto de los animales" (Elias, 1990a), por lo cual tiene más posibilidades de adquirir rasgos comportamentales que lo diferencian de los demás individuos de su especie, en otras palabras, es gracias a eso que en el ser humano emerge la subjetividad, la personalidad, el alma (entendida como cultura encarnada). En ese continuo diálogo de los instintos con las personas del entorno se forma en el niño aquella autodirección psíquica diferenciada que distingue al ser humano de todas las otras criaturas vivientes: un carácter más o menos individual.

Gracias a esta conformación social, la estructura del comportamiento, la forma de la autodirección en la relación con otros, es en los seres humanos mucho más diversa y heterogénea que la de todos los otros animales; gracias a ella, la estructura del comportamiento se hace, en una palabra, «más individual» (Elias, 1990a, p. 54).

En este punto tenemos que hilar más fino, y preguntarnos por el carácter de esa autodirección psíquica, ¿podremos concluir de allí una elección autónoma? La autonomía se refiere a la "facultad de la persona o la entidad que puede obrar según su criterio, con independencia de la opinión o el deseo de otros" (DRAE, 2001). La autonomía en el comportamiento del ser humano sería la posibilidad de obrar según su criterio, según sus propias leyes y normas, con independencia de leyes o regulaciones externas (heteronomía). Pero aún en el caso de admitir que somos seres autónomos queda la posibilidad de que un ente autónomo sea gobernado por sus 
propias leyes, así que aún no despejamos el lugar del azar, entendido como indeterminación, ya que la indeterminación biológica del comportamiento humano se suple con nuevas determinaciones (regulaciones) sociales, por tanto no podemos afirmar todavía que haya en Elias un indeterminismo ontológico en el ser humano.

Pero sólo en el ser humano llegan este relajamiento y esta maleabilidad de las funciones relacionales a ser tan grandes que la persona individual necesita que su autodirección sea modelada durante años por otras personas, por una sociedad, para que avance de forma más o menos regulada en la relación con otras personas, para que asuma una forma diferenciada y específicamente humana. La parte de fijación heredada de la autodirección en el trato con los demás de la que carece el ser humano ha de ser reemplazada por una fijación social, por un modelado socio-genético de las funciones psíquicas (Elias, 1990a, p. 53).

Sin embargo, Elias muestra que la fijeza del entramado de relaciones sociales en el que nace un ser humano, al mismo tiempo le abre nuevas posibilidades de elección:

Todo tejido humano grande y diferenciado es, de hecho, ambas cosas: muy rígido y, al mismo tiempo, muy elástico. Dentro de él siempre se están abriendo a los seres humanos particulares nuevos márgenes para la determinación individual. Se les ofrecen oportunidades que pueden aprovechar o desperdiciar. Se les presentan encrucijadas en las que tienen que elegir, y de su elección pueden depender, según la posición social de cada uno, su destino personal inmediato o tal vez el de toda su familia y, en algunos casos, incluso el destino inmediato de naciones enteras o de determinadas capas funcionales de éstas. De esa decisión puede depender el que un eje de tensión sea superado en esta generación o en una generación venidera. De ella puede depender qué personas o grupos en pugna dentro de un determinado sistema en tensión se conviertan en los ejecutores de la transformación a la que empujaba esa tensión, y dónde descansarán los centros de las nuevas formas de integración a las que, debido a sus tensiones, apuntaban las antiguas. Pero las posibilidades entre las que una persona ha de realizar tal elección no las ha planteado la persona misma. Esas posibilidades están dadas y limitadas por la estructura específica de la sociedad a la que pertenece la persona y por el carácter de las funciones que la persona posee dentro de esa sociedad. Y, sea cual sea la posibilidad que elija, la acción de la persona pasa a entretejerse con las acciones de otros, desatando ulteriores cadenas de acciones, cuya dirección y efectos momentáneos ya no dependen de la persona, sino del reparto de poderes y de la estructura de tensiones del conjunto de este tejido humano móvil (Elias, 1990a, pp. 68-69).

Se vislumbra más claramente en esta cita, la posibilidad del ser humano de elegir entre múltiples caminos, aunque sean caminos ya trazados por la estructura social. "Los posibles caminos entre los que decide están ya trazados por la estructura del radio de acción y los entrelazamientos de la persona. Y, según cuál sea la decisión que tome el individuo, el propio peso de estos entrelazamientos actuará a favor o en contra de él" (Elias, 1990a, p. 73). Hay en esta elaboración de Elias una similitud con la definición de ley que aporta Wagensberg y que desarrollamos en el segundo capítulo: la ley es una restricción, una prohibición, pero no una obligación. Esa es la paradoja de la ley (en este caso social), al mismo tiempo que restringe, limita, domestica, abre posibilidades de acción y de elección que no tendría en un estado biológico natural: 
caminar erguido, expresarse con palabras, con dibujos, con música, imaginar, inventar. La cultura somete, enajena, sujeta, pero al mismo tiempo es una base desde la cual es posible buscar la emancipación, la creación, la innovación, la trascendencia con las herramientas que provee.

Este ideal conduce a que el individuo sea capaz de hacer uso del margen de elección relativamente amplio que se le presenta en una sociedad de este tipo. En su juventud puede, pero también debe, elegir -primero desde la posición de sus padres, luego desde posiciones alcanzadas personalmente- entre el gran número de posibles objetivos que se le ofrecen, aquel que prometa una mejor satisfacción de sus inclinaciones y anhelos personales. (Elias, 1990b, p. 167)

El psicólogo ruso Aleksandr Luria afirma que el lenguaje le otorga rasgos muy específicos a la actividad consciente del hombre. El primer rasgo es que no está forzosamente relacionada con motivaciones biológicas, sino con otras de orden superior, "espirituales" (1982, pp. 99-100), que para Luria son: la curiosidad, la necesidad de comunicación y la búsqueda de reconocimiento. Es importante recordar que en la obra de Ramírez el lenguaje es la forma específicamente humana en que se manifiesta el espíritu (Logos, la tendencia cósmica a articular); el lenguaje y la cultura son la forma de articulación específicamente humana. Es gracias al lenguaje que la actividad consciente del hombre no se subordina a los influjos y necesidades biológicas, sino que puede incluso entrar en conflicto con ellos y hasta los reprime. También Llinás destaca que la expansión del rango de la actividad motora que tiene el ser humano le permite incluso la eliminación de ciertos PAF (Llinás, 2003, p. 281). El ejemplo típico que Luria aporta de esta situación es el altruismo, cuando el ser humano está dispuesto a ir en contra de sus tendencias de autoconservación y morir por una causa, por una idea. En cambio ¿tienen ideas los animales?, ¿mueren por ellas?

El segundo rasgo es que el lenguaje permite, dice Luria, nuevas posibilidades de acción $\mathrm{y}$, en esa medida, mayor libertad de elección respecto a los determinantes biológicos, ya que no está obligado a guiarse por la percepción directa (impresiones recibidas), sino por un conocimiento más profundo de la realidad:

El segundo rasgo distintivo de la actividad consciente del hombre radica en que -a diferencia del comportamiento animal - ella no está determinada en absoluto ni forzosamente por impresiones vivas recibidas del entorno o por las pautas de la experiencia individual directa [...] La actividad consciente del hombre puede guiarse no por la impresión directa de la situación externa, sino por un conocimiento más profundo de las leyes intrínsecas que hay tras ella; de ahí que haya todas las razones para decir que la conducta del hombre basada en el conocimiento de la necesidad es libre (Luria, 1982, p. 100-101).

El tercer rasgo particular que introduce el lenguaje en la actividad consciente del hombre es que gran parte de sus saberes, habilidades y conocimientos no se deben a los programas de comportamiento heredados biológicamente ni son el resultado de la 
experiencia individual, sino que los adquiere por la asimilación de la cultura, la experiencia del género humano. El lenguaje abre la posibilidad de simbolizar experiencias y narrarlas, transmitirlas, esto es lo que va creando la intersubjetividad, la dimensión colectiva, social, cultural. Es lo que Ramírez plantea como el paso de los saberes imaginarios y empíricos (vivencias, huellas mnémicas) al conocimiento (huellas mnémicas expresadas en palabras). El lenguaje permite formalizar lo vivido y compartir con otros el legado de las experiencias.

Luria deja claro que el lenguaje no es una capacidad humana más; es tan trascendente que modifica todos los procesos psíquicos, los eleva a un nuevo nivel de operación (1982, p. 113), generando, en consecuencia, nuevas posibilidades de respuesta, más libertad de acción. La percepción humana se modifica con el lenguaje porque nombrar tiene el efecto de destacar los rasgos esenciales de los objetos, lo que permite generalizarlos, agruparlos, categorizarlos, es decir, se adquiere un nuevo nivel de operación con los objetos, por ejemplo: con la palabra triángulo se destaca una estructura que es independiente de las variaciones de esta figura en la realidad. Por medio del lenguaje la percepción humana se hace más profunda, generalizada y permanente. La afectividad en los animales cumple un papel regulador, "en el psiquismo, la afectividad es desbordada; plantea problemas en lugar de resolverlos" (Simondon, 2009, p. 242)

El lenguaje también hace posible que el ser humano dirija voluntariamente su atención, que ya no esté necesariamente dirigida por la novedad o las características biológicas del objeto. La memoria humana, por efecto del lenguaje, se basa en procesos discursivos y no en motivaciones biológicas directas, la memoria deviene una operación consciente en tanto el ser humano se plantea la finalidad de recordar, organiza los datos memorables y se hace capaz de recuperar y elegir información del pasado voluntariamente, "el lenguaje le permite al hombre desligarse de la experiencia directa y asegura el nacimiento de la imaginación" (Luria, 1982, p. 115). Con base en formulaciones discursivas el ser humano puede instituir nuevas normas de comportamiento con una inmediatez que poco se compara con el largo y repetitivo proceso que requiere el adiestramiento animal. En el ser humano este proceso de instituir normas por medio de formulaciones verbales (instrucciones) no solamente es más rápido (incluso inmediato), sino flexible: puede cambiarse una instrucción por la contraria y modificarse la conducta inmediatamente, es lo que ocurre con las instrucciones, las leyes de comportamiento que no son naturales sino sociales. "Todo ello habla de la enorme plasticidad y conductividad de los procesos que entraña la actividad consciente del hombre" (Luria, 1982, p. 117). El lenguaje permite hacer el tránsito de lo sensorial a lo racional, porque el lenguaje dobla el mundo perceptible, lo re-presenta y entonces se puede operar no solo a partir de la percepción directa, sino basados en esas representaciones. Silvia Bleichmar afirma que la aparición precoz en el ser humano de formas representacionales hacen que no quede reducido a su existencia biológica "sino, por el contrario, someten a la biología misma al campo representacional 
en el cual se articula lo sexual como modo de acceso al placer no regido por necesidades de supervivencia" (Bleichmar, 2005).

El lenguaje sería también lo que permite la transición desde los hábitos en el animal hasta las actitudes en el hombre. En la interacción con el entorno surgen regularidades en el comportamiento de un animal (los hábitos), que son producto de la influencia del entorno sobre el individuo, y se transforman en actitudes cuando interviene el lenguaje y ayuda a simbolizar las vivencias, convertirlas en palabras, verbalizarlas. "Una actitud es, entonces, un modo de hacer que hemos incorporado y simbolizado" (Ramírez, 2011, 313. Hábito y actitud, p. 283).

La posición de Ramírez no se ubica en el extremo de una diferencia radical entre el ser humano y otras especies animales, pero tampoco en el extremo en el que se borran las diferencias y las jerarquías; plantea más bien una transición gradual del animal al ser humano, una mayor complejización, dada por la capacidad de simbolización, de representación (procesos de pensamiento secundario) ${ }^{22}$. Es una diferencia de nivel, no de naturaleza:

[...] más que una grieta insondable, hay una rajita, marcada por la gradualidad: el sujeto cree que sólo él tiene voluntad, elección; pero también los animales eligen, con base en su sistema primario de señales (imaginario), y los vegetales. Si se plantea la elección como tomar una dirección entre varias posibles, también lo hacen los minerales, las partículas elementales. Todo gracias al azar, a los grados de libertad que crea en las determinaciones (Ramírez, 2011, 305. Azar como subversión, p. 279).

Así lo expresa Gilbert Simondon:

Esto no significa que haya seres solamente vivientes y otros vivientes y pensantes: es probable que los animales se encuentren a veces en situación psíquica. Solo que esas situaciones que conducen a actos de pensamiento son menos frecuentes en los animales. El hombre, disponiendo de posibilidades psíquicas más extendidas, en particular gracias al auxilio del simbolismo, apela más a menudo al psiquismo. (...) el animal está mejor equipado para vivir que para pensar, y el hombre para pensar que para vivir. Pero ambos viven y piensan, de forma corriente o excepcional (Simondon, 2009, p. 242n).

En estas conceptualizaciones de Llinás, Elias y Luria vemos cómo se van articulado en el ser humano las determinaciones biológicas (memoria estructural y dinámica), las determinaciones sociales y las ocasionales (memoria referencial). La vida de otras especies parece estar más condicionada, precableada y limitada por la programación biológica, mientras que en el ser humano la flexibilidad de esa programación genética hace que el aprendizaje y la elección jueguen un papel fundamental ${ }^{23}$. En otras

22 Ramírez destaca en su obra el evolucionismo dialéctico de Henri Wallon, que tiene en cuenta la acumulación que lleva al quantum y éste al cambio cualitativo. Propone entonces la continuidad cuantitativa y la discontinuidad cualitativa (Ramírez, 2012, p. 312 y p. 390).

23 Más adelante en este mismo capítulo se expondrá la concepción que tiene Ramírez de la elección, según la cual los animales, los vegetales, los minerales y hasta las partículas elementales eligen, lo que no significa 
especies el instinto preconfigura muchas de sus respuestas, mientras que en el ser humano la ausencia de estos automatismos hace preciso aprender y elegir. "El instinto actúa en presencia del objeto y no implica conflicto porque la solución ya está preestablecida en la relación individuo-medio, mientras que las conductas de reacción organizada, más complejas que el instinto y también presentes en algunos animales, introducen cierto nivel de conflicto porque requieren la invención de una estructura nueva para dar resolución al problema" (Gil, 2015, p. 58).

En el primer capítulo ya se había hecho referencia a la función evolutiva de la conciencia, entendida no sólo como sensación, sino como capacidad de reflexión; esta sería una herramienta para responder ante situaciones nuevas, cambiantes, en las que tenemos que hacer nuevos juicios y no solo responder desde nuestros automatismos, con reglas preestablecidas, sino siempre actualizadas según el contexto, lo que abre las posibilidades de adaptación y de respuesta para afrontar la incertidumbre, emitir juicios más ajustados a cada nueva situación o, como dice Wagensberg, para "domesticar la incertidumbre", según este autor la evolución ha favorecido la emergencia de agentes con mayor grado de indeterminación, de flexibilidad, porque deja más opciones de respuesta ante la incertidumbre que caracteriza a la vida.

En el ser humano emergen pues comportamientos nuevos, no programados y, en esa medida, no regulados completamente, no predecibles, azarosos. Si no son respuestas automáticas son entonces respuestas emergentes, creadas. En este acto de responder ante una situación es posible, incluso necesario, ir más allá de las determinaciones, hay una creación, una elección, aparece una autodeterminación producto de una formación de lo aleatorio.

El filósofo francés Gilbert Simondon construye una profunda teoría con el propósito de desentrañar cómo ocurre la individuación psíquica, y en el desarrollo de esa pregunta recurre a ideas de la física cuántica, la termodinámica y la complejidad.

Para desarrollar su teoría de la individuación (física, vital y psíquica) y describir cómo ocurre el devenir, cómo emerge lo nuevo, el cambio, Gilbert Simondon apela a los referentes conceptuales de su época, por ejemplo, el modelo cuántico de umbrales de indeterminación, que plantea la posibilidad de proceder por saltos cuánticos, admite la presencia de lo impredecible, del azar y concibe el devenir, el cambio, como algo intrínseco a la existencia gracias a las potencias que hay disponibles, que desde la física se entiende como la energía potencial de un sistema (Simondon, 2012, p. 36).

Para Simondon la individuación de una singularidad acontece por la interacción de unas predisposiciones con el entorno, y en esa interacción la singularidad se despliega. Una singularidad es definida por Ramírez como una confluencia de fuerzas

que decidan ni deliberen. Las elecciones basadas en deliberaciones y las decisiones sí serían específicas del ser humano. 
que se articula (por medio de regularidades o leyes: Logos) y de esa forma "se constituye en un ente, que entra a actuar con el universo y a producir una reacción por parte del entorno" (Ramírez, 2012b, p. 56). En esa articulación de fuerzas puede haber un aspecto ejemplar (las leyes que comparte con el entorno), un aspecto singular (las leyes propias) y un aspecto peculiar "o aleatorio del que se desconocen las leyes (y a veces, si las tiene o no). De esa peculiaridad pueden explorarse los límites y fronteras, su ubicación en el entorno articulado, sus efectos sobre este y la manera como determina o actúa sobre las regularidades o articulaciones de dicho entorno. Es el caso del objeto a en el psicoanálisis, o de los agujeros negros en la astronomía" (Ramírez, 2012b, p. 57). Esto significa que en toda singularidad que se conforma queda un margen de indeterminación, hipótesis que es concebida también por Simondon cuando plantea la realidad preindividual. Veamos en qué consiste.

Lo preindividual es un concepto fundamental en la estructura teórica de Simondon, sin el cual es impensable la individuación, y veremos cómo este concepto es homólogo a lo peculiar, lo caótico y el azar en cada ser individual.

Cuando se conforma una singularidad decimos que una determinada información que comporta la energía se hace compatible con un medio, se establece una relación como producto de la resolución de un problema, y esa relación (articulación, organización) adquiere el carácter de ser. La conformación ocurre cuando la información al discurrir deja huellas materiales, huellas que tienden a repetirse (Ramírez), a amplificarse (Simondon). Para que esta conformación inicial devenga un individuo se requiere la repetición, algo que permanece, se conserva y, a la vez, algo que se renueva gracias al potencial disponible que queda para nuevas individuaciones, lo preindividual. Es así como aparece el azar en la obra de Simondon, como indeterminación, ausencia de finalidad, ausencia de necesidad, imprevisibilidad, potencialidades, multiplicidad de posibilidades.

Con Ilya Prigogine se pueden pensar los individuos como sistemas abiertos, es decir, que intercambian energía con el entorno, se afectan mutuamente y se transforman como producto de la resolución de un problema (tensión) que surge en la interacción de ambos. La individuación sería, justamente, el resultado de la resolución de una diferencia energética entre una singularidad y el entorno; la individuación se produce cuando un sistema entra en un estado de tensión, crítico, pero logra transformarse (cambiar de forma) y pasar a un nuevo estado de equilibrio metaestable, es decir, que no aniquila las tensiones que implica vivir, sino que las vuelve compatibles, "solo la muerte sería la resolución de todas las tensiones; y la muerte no es la solución de ningún problema". La metaestabilidad es una reducción de tensiones sin eliminarlas, una organización de intensidades, "una resolución de un problema de compatibilidad" (Simondon, 2009, p. 362).

Esta forma de concebir la conformación de los individuos y sus sucesivas individuaciones, sustentada por la física cuántica y la termodinámica, renueva la 
manera de concebir la identidad, pues ya no se trata de una esencia permanente, inmutable o incluso eterna (como se afirma en los discursos religiosos), sino de una identidad en devenir (Zuluaga, 2014), que cambia, que se transforma, con límites borrosos y porosos (según la teoría de los fractales), porque los individuos físicos, orgánicos y psíquicos nunca están completamente cerrados sobre sí mismos, sino que intercambian información con el entorno, se afectan continuamente y se transforman mutuamente; un cambio de la relación entre individuo y entorno es también cambio del interior del individuo, de sus características, haciendo borrosa esa barrera que marca lo interior y lo exterior. El interior y el exterior es una imagen que no le permite a Simondon definir la individuación, porque no ocurre ni adentro ni afuera, es el desarrollo del ser a un lado y otro de sí mismo (Simondon, 2009, p. 219). La identidad no niega el cambio; si bien se acepta que no hay una finalidad predeterminada no todos los cambios son posibles, ya que las tensiones se vuelven tendencias, determinaciones, regularidades, leyes, normas, preferencias, inclinaciones, pero la identidad puede sufrir transformaciones, tan lentas o tan rápidas según sus contingencias y elecciones. La evolución hace referencia a opciones posibles, probables, que, debido a lo aleatorio, no están garantizadas. Sobre la identidad que cambia cita Ramírez:

¡Qué tristeza, sin embargo, ser uno, coincidir con su ser! La belleza de la existencia es escapar, abrirse a la multitud de destinos posibles que llevamos dentro de nosotros. En vez de ser alguien, ¿por qué no queréis ser varios? Conocerse sólo es útil para poder olvidarse, no estar ya colmado de uno mismo, volverse disponible al esplendor del mundo (Bruckner, 2003, p. 147).

Para Simondon "la realidad primera es preindividual, más rica que el individuo entendido como resultado de la individuación" (Simondon, 2009, p. 219). Lo preindividual se refiere, por tanto, a las potencialidades, lo no articulado, pero susceptible de serlo. En esa realidad preindividual acontece la individuación, pero el individuo conserva una remanencia de la fase preindividual que subsiste paralela al ser individuado y sigue siendo el germen de nuevas operaciones amplificantes (Simondon, 2009, p. 476). Asimismo, para Ramírez el arché o fundamento original sería el caos inaugural (Ramírez, 2011, 349. Pluralismo, p. 301), entendido como azar absoluto, energía pura, "el gran creador, pues continuamente hacía aparecer y desaparecer nuevos acontecimientos" (Ramírez, 2012b, p. 30), que al no repetirse no permanecían, por eso la nada es el caos, donde nada permanece:

Tenemos dos opciones: o consideramos el propio caos como una repetición (del cambio) o sostenemos que, al aparecer la primera reiteración, surge a la vez algo nuevo (en cuanto tal, logos) pero también ese algo es precisamente la repetición (ananké). Pensar el caos como intrínsecamente repetitivo no es tan absurdo como parece, pero tal vez sea más congruente decir que precisamente el cambio puro, sin repetición que se sostenga, que dure, es el logos en su máxima expresión. Quizás por eso: "En el principio era el Logos" (Ramírez, 2012b, p. 115). 
Caos y Logos son las dos posibilidades de la energía, que la física actual denomina entropía y neguentropía. Lo sagrado que funda el ser es la primera determinación que introduce Logos en lo aleatorio. El determinismo absoluto del desarrollo de un sistema, afirma Simondon, implica que no haya ninguna resonancia interna del sistema, "es decir ningún intercambio entre los diferentes niveles que encierra y que lo constituyen", mientras que el indeterminismo puro (Caos) sería una resonancia interna tan elevada que toda modificación que sobreviniera en un nivel determinado repercutiría inmediatamente en todos los niveles bajo la forma de un cambio de estructura (Simondon, 2009, p. 218). Pero en nuestra realidad hay repetición e innovación, permanencia y cambio, el determinismo y el indeterminismo serían casos límite (Simondon, 2009, p. 211). Popper, Monod, Simondon y Wagensberg, así como Ramírez, ubican dos tendencias en todo sistema: a la conservación y al cambio.

El ser individuado comporta entonces repetición, duración de una conformación inicial, pero las fases nuevas o que están en potencia (indeterminadas) introducen el cambio. El individuo es resultado y agente. De lo inmanente se llega a lo emergente y trascendente por el azar. "Es preciso que el ser pueda apelar en él y fuera de él a una realidad aún no individuada: esta realidad es la información relativa a un real preindividual que él contiene; es esta carga la que constituye el principio de lo transindividual; ella comunica directamente con las demás realidades preindividuales contenidas en los otros individuos" (Simondon, 2009, p. 326). El gran remanente preindividual del ser humano (que para Norbert Elias implica flexibilidad biológica) lo hace más frágil, pero al mismo tiempo aumenta sus posibilidades de individuación (complejización) porque nunca está acabado, sus opciones se despliegan a medida que crece.

Hay en la obra de Simondon una psicología de la individuación, desde la cual se describen y explican los procesos psíquicos. Se concibe lo psíquico como producto de la evolución, que por medio de sucesivas invenciones resuelve, etapa por etapa, las problemáticas del sistema individuo-medio (Simondon, 2009, p. 303), y cada etapa se convierte en el entorno indispensable de la siguiente: lo físico-químico es la base necesaria para los vegetales, y estos, a su vez, lo son para los animales. La vida sería producto de la capacidad de invención para compatibilizar la relación entre individuo y medio (ambiental, cultural, social, político, técnico). Se deriva de Simondon una forma muy optimista de ver los problemas, ya que son estos los que permiten actualizar los potenciales (preindividuales) siempre disponibles para nuevas individuaciones y así devenir otro, más complejo y con nuevos recursos para la resolución de las tensiones.

Digamos que en Simondon la evolución se expresa como las estrategias que los individuos encuentran para resolver los problemas que afrontan, es decir, dadas unas características, una conformación particular y unas potencialidades, los individuos afrontan determinadas tensiones, problemas, conflictos con el entorno, y la individuación son los modos que encuentra el sistema para resolverlos: en los 
animales el instinto es una estrategia para resolver los problemas relacionados con la supervivencia, la regulación y la adaptación, mientras que en el nivel psíquico se dan nuevas problemáticas relacionadas con la emoción y la acción.

La vida psíquica aparece cuando las funciones vitales ya no alcanzan para resolver los problemas planteados a lo viviente, el sistema se desfasa, pasa a otro estado, se transforma: "el verdadero psiquismo aparece cuando las funciones vitales ya no pueden resolver los problemas planteados a lo viviente, cuando la estructura tríadica de las funciones perceptivas, activas y afectivas ya no es utilizable" (Simondon, 2009, pp. 242-243). Lo psíquico es entonces una invención.

Sobre el proceso de percepción dice que este "no es la captación de una forma, sino la solución de un conflicto, el descubrimiento de una compatibilidad, la invención de una forma" (p. 349)." "Percibir es organizar, mantener o inventar una organización. No basta con decir que la percepción consiste en captar todos organizados; de hecho ella es el acto que organiza totalidades" (p. 361).

El lenguaje, en tanto invención y forma de resolver tensiones, propicia el despliegue de lo preindividual y de nuevas individuaciones, ya que por lo menos una parte de lo no articulado puede articularse vía el lenguaje, es esto lo que hace el tratamiento psicoanalítico con la verbalización, articular al discurso elementos inconscientes, "construir realidades simbólicas que permitan la metabolización de lo traumático" (Bleichmar, 2011, p. 368), pero siempre "queda algo residual, una escoria que no adopta significación, un resto luego de todas las operaciones de individuación" (Simondon, 2009, p. 318), lo peculiar, la parte azarosa de una singularidad, de la que se desconocen sus leyes o puede incluso no tenerlas.

\footnotetext{
También puede ocurrir (...) que haya siempre un grado de indeterminación (de libertad) en el cual se base precisamente la probabilidad de elección, la ética, y la peculiaridad (rasgo más individual de lo singular que no funciona de acuerdo con las leyes del entorno). Este núcleo (éxtimo) sin leyes, aleatorio, no estaría predeterminado, y sobre él tendríamos que elegir una y otra vez. Por eso es el objeto (a) de la angustia y de la posibilidad infinita, de la responsabilidad insoslayable.

Habría otra parte de nosotros, la singularidad regular, que se guía por sus propias leyes, sus determinaciones. Son nuestros hábitos, nuestras costumbres, que se han ido volviendo regularidades que nos determinan. Un análisis las descubre y las cuestiona. Pero también cierne, bordea lo aleatorio, la peculiaridad irreductible que nos hace "decididores", responsables únicos de nuestro destino (Ramírez, 2012, 173. La suerte, p. 290)
}

En el apartado anterior nos referimos al desplazamiento que puede hacerse desde el determinismo biológico al determinismo social, dicho de otro modo, es posible aceptar que hay un indeterminismo biológico en el ser humano, pero que es sustituido finalmente con regulaciones sociales, lo que inmediatamente conduce a la pregunta por la libertad. 


\title{
4.4. La elección en las grietas del determinismo
}

\author{
El jugador existencial juega con la incertidumbre \\ da igual si se desconocen o no existen las leyes. \\ Carlos Arturo Ramírez
}

Ramírez (2012, p. 31) propone el ejercicio de concebir la situación de un ente con libertad absoluta, ello implica no tener ninguna restricción, es decir, tener libertad de posición (estar en un lugar y al siguiente instante poder estar a millones de kilómetros de distancia), libertad de modo de ser (poder cambiar caprichosamente su ser, no estar obligado a conservar una manera de ser) y libertad de ser (poder crearse y autodestruirse arbitrariamente). Pero la libertad deja de ser absoluta si el espacio es finito, ya que habría una restricción espacial, o si hay no solo un ente sino dos, pues el ejercicio de la libertad de uno puede afectar la libertad del otro, en el caso de que uno de ellos eligiera, por ejemplo, destruir al otro, ocupar su lugar, modificarlo. Para dos o más entes la libertad absoluta se restringe por la leyes de interacción entre ellos, de cómo esos dos seres interfieren en sus posibilidades mutuas.

La interacción de varios entes supone restricciones y, al mismo tiempo, la interacción hace posible el surgimiento de nuevas propiedades y posibilidades de acción, imposibles para un solo ente. Más paradójico aún es que la combinación de dos o más entes permitiría superar restricciones imposibles de superar por un solo ente, es decir, la interacción restringe algunos aspectos, pero incrementa el poder de otros, es lo que hace el lenguaje, la cultura, el trabajo. Paradójicamente son necesarias las leyes, las regulaciones, las determinaciones para que emerja lo nuevo.

\footnotetext{
Pasando a un nivel superior, la articulación de átomos en una molécula crea restricciones (la primera sería la necesidad de perseverar en su condición de molécula) pero abre nuevas posibilidades: las propiedades de la molécula. Por ejemplo, la molécula de sal tiene restricciones pero también propiedades y posibilidades que no tenían los átomos de sodio y cloro. Hay una emergencia cualitativa. Un animal tiene restricciones físico-químicas y biológicas que no tenía la planta y nuevas exigencias (leyes, necesidades) para conservarse. Pero también puede moverse, buscar, sentir; lo que no era posible para la planta (Ramírez, 2012b, p. 32).
}

La consciencia representa entonces un nuevo poder, el de conocer las restricciones y posibilidades, lo que permite elaborar estrategias de acción orientadas por propósitos. El ser humano, por ejemplo, muchas veces no opta por caminos posibles porque los desconoce. Reconocer estos caminos posibilita una combinación de esfuerzos y estrategias que difícilmente se lograría al azar (por tanteo).

Al hacer este ejercicio de imaginación concebimos claramente que si hablamos de libertad en esta realidad se trata de una libertad parcial, grados de libertad, como dicen los matemáticos. "En el ser humano la llamamos libre albedrío. Pues entre numerosas restricciones, casi siempre hay alguna variable que queda a opción del 
sujeto, quien debe elegir" (p. 32). Es esto lo que Ramírez denomina variables libres, independientes, que al no estar total y directamente determinadas por leyes físicas o biológicas, "quedan sometidas a la influencia de fuerzas mucho más pequeñas como la voluntad, y puede ser la voluntad de otros (o el Otro) o la nuestra la que decida sobre ellas (p. 286).

La gracia es una de las formas en que la teología cristiana le da lugar al azar, aunque lo fundamenta en la voluntad de Dios. La gracia es un don divino que no se justifica por merecimientos propios, sino que es otorgado "graciosamente", de la nada, por nada. De allí deriva el término "gratuito", "gratis", es algo aleatorio, que no puede explicarse mediante razones (Ramírez, 2012b, p. 245).

Se podría insistir en que tanto el determinismo como el libre albedrío son indemostrables. Hemos llegado al límite de lo que podemos conocer, a las fronteras de la razón. Pero cuando la argumentación y la lógica ya no alcanzan para validar o refutar una hipótesis Ramírez (2012, p. 33) propone otros criterios a partir de los cuales es posible dirimir el debate, por ejemplo el criterio pragmático, que consiste en evaluar las consecuencias, los efectos de tomar un postulado como cierto, evaluar también su conveniencia y su utilidad, considerar si resulta fructífero dar una hipótesis por cierta.

Podríamos decir que ambas conjeturas son fructíferas: el determinismo para la ciencia, pues en ese supuesto se sostiene el esfuerzo por conocer las leyes que rigen los fenómenos, y el libre albedrío para la ética, la responsabilidad y, en últimas, para el sentido de la vida. Por eso para Ramírez no se trata de elegir entre determinismo o libertad, sino que reconoce el determinismo y la libertad. Pero dentro de este criterio pragmático, además de la fecundidad, queda por considerar aún la variante del Khan:

Hay un corolario que, tomando por cierta una divertida anécdota, llamaremos la variante del Khan: cuando éste llamó a su presencia a los sacerdotes de las diversas religiones, todos sostenían que la suya era el mejor camino de salvación, aunque aceptaban que las otras también lo eran, pero inferiores. Solo los cristianos afirmaban que fuera de su iglesia no había salvación; por eso el Khan la eligió: perteneciendo a ella se salvaría aunque resultasen ser verdaderas las demás; pero a la inversa no (Ramírez, 2012b, p. 35).

Queremos decir con esto que nada perdemos por creernos libres sin serlo, en cambio, si equivocadamente nos creemos predeterminados eso significaría haber desperdiciado las oportunidades que nos brindaba la libertad. Parece entonces que es más inteligente suponer que hay posibilidad de elegir y responsabilidad.

Elegir es responder; y emitir una respuesta acorde con el propio ser es la responsabilidad. Hay entonces tres clases de respuestas: elemental, primaria y secundaria; y respectivamente tres tipos de responsabilidad: fáctica, espontánea y ética. Puede haber un sistema tan determinado que el margen de aleatoriedad (y elección) sea muy poco, sin embargo, "un elemento de un sistema no está totalmente 
determinado por las leyes, regularidades o propiedades de este. Hay algunas variables libres o independientes que hacen que el sistema tenga grados de libertad. El comportamiento de una partícula, respecto a esas variables, se dice que es aleatorio o al azar; significando con ello que no se conocen posibles determinaciones por el sistema. Es desde la partícula, en cuanto es confluencia de leyes y procesos, que emerge un comportamiento, un acontecer propio" (Ramírez, 2012b, p. 45). A la elección de una dirección entre varias posibles, hecha por un cuerpo físico, la llamamos respuesta elemental ${ }^{24}$.

Ramírez entiende elegir como optar por una entre varias posibilidades, y no lo considera homologable a decidir, que se entiende precisamente como tomar una determinación (entre todas las posibles) e implica el pensamiento. Una persona puede elegir (responder) sin haber tomado una decisión; así como también puede tomar una decisión incluso antes de que haya llegado el momento de la elección (de responder). Esto evidencia las diferencias entre ambos conceptos y por qué plantea Ramírez que incluso una partícula elige, aunque no decide y mucho menos delibera, pero frente a diversos caminos igualmente probables "se va" por uno de ellos (Ramírez, 2012b, p. 112).

La respuesta o el tipo de elección que emite un animal es primaria, puesto que puede optar por uno de los caminos posibilitados por sus leyes intrínsecas, es decir, sus leyes como organismo (biológicas). Dicho de otro modo, al animal lo guían nuevos factores, los motivos, y opta entre ellos. Por su importancia para esta investigación, citaremos en extenso el tipo de respuesta secundaria, específicamente humana, tal y como la define Ramírez:

\begin{abstract}
El ser humano posee un sistema secundario (de signos), fundamentado en el lenguaje y las palabras, que le permite razonar. Puede analizar desde una perspectiva lógica (aristotélica, racional) las consecuencias de un acto; pero también puede tener en cuenta las motivaciones afectivas, pulsionales, emocionales, imaginarias o inconscientes: es lo que llamaríamos razonabilidad, que no estaría basada solamente en una lógica simbólica, ni tampoco sólo en una imaginaria, sino en la dialéctica de ambas. Evaluar y asumir las consecuencias de un acto es una respuesta secundaria, típicamente humana: implica una reflexión, un raciocinio, un juicio (Ramírez, 2012b, p. 46).
\end{abstract}

Un ser humano sería irresponsable si le eran posibles respuestas de orden superior más acordes con el propio ser, que hubieran surgido al reflexionar sobre las estrategias probables de acción y, sin embargo, responde de un modo primario (inconsciente) o elemental (como un cuerpo físico).

24 En el segundo capítulo se expuso la propuesta del físico Jorge Wagensberg, quien concibe, al igual que Ramírez, una dosis de azar y elección en todas las fases de la realidad (física, orgánica y psíquica). También concibe, aunque como caso límite, que las determinaciones de un ente o un sistema lleguen a ser tantas que sólo quede un camino posible. 
Ramírez no propone un racionalismo, basar las elecciones exclusivamente en la razón, pues considera fundamental escuchar y tener en cuenta otros registros no racionales: las sensaciones, las impresiones, las emociones, las pasiones, las motivaciones, los afectos, las intuiciones, ya que portan una información, un saber corporal que puede ser crucial en la elección de un camino, pues nos anotician de nuestras tendencias, gustos, preferencias, pero también de nuestros prejuicios. Se trata entonces de "trascender lo puramente racional, para llegar a lo razonable" (Ramírez, 2012b, p. 234), que puede entenderse con una condensación como escuchar el co-razón. Quizá sea posible volar con un ala, la de la razón o la de la intuición, pero el jugador existencial prefiere volar con las dos.

Se destaca entonces la importancia del séptimo eje causal, el de la elección subjetiva, porque, de todos, es el único factor que depende de cada uno de nosotros, del que somos responsables. En lugar de quejarnos, lamentarnos y sufrir por lo inmodificable, podemos ocuparnos de la parte que sí podemos cambiar, que sí depende de nosotros. Por ínfima que en ocasiones parezca, es lo que tenemos y podemos hacer. Incluso Freud señala algunas grietas en los enormes muros del determinismo, por las cuales podría vislumbrarse un resto de libertad, una elección posible y la responsabilidad de intentar cambiar la minúscula parte del universo que depende de nuestra voluntad:

Quien vislumbró la grandiosidad de la trabazón universal y empezó a ver sus leyes necesarias, es fácil que pierda su propio, pequeño, yo. Abismado en el asombro, en verdad humillado, uno olvida demasiado fácilmente que uno mismo es un fragmento de aquellas fuerzas eficaces y le es lícito intentar, en la medida de su fuerza personal, la modificación de una parcela en ese discurso necesario del universo, ese universo en que lo pequeño no es menos sustantivo ni asombroso que lo grande (Freud, 1910b, p. 71).

Justamente en ese intento de incidir sobre la pequeña parte del cosmos que depende de nuestra fuerza (de voluntad) se basa la ética del jugador existencial.

El jugador existencial concibe la vida como un juego. Es existencial porque es la existencia misma la que pone en juego: los ideales, los sueños, los proyectos; se pone en acto la existencia. En tanto juego consiste en "un procedimiento guiado mediante un guión, esto es, un discurso algorítmico que produce un discurrir con guías (reglas, pautas o normas). Las reglas de juego son el encuadre, el conjunto de regulaciones" (Ramírez, 2011b, Frag. El juego). Como en todos los juegos hay aspectos dejados al azar (los territorios sin leyes de los que habla Wagensberg), lo que hace posible que en la vida las reglas del juego cambien y se dialectizen con las acciones y estrategias de los jugadores (Cav. 17. La vida es un juego), por eso para el jugador existencial vivir es más un deporte que un arte:

Como la guerra, el deporte de existir tiene niveles: político, ético, estratégico, táctico y, en último término, la jugada. La jugada es la actualización de la apuesta del jugador existencial, la intervención en el camino. Puede ser deliberada ("de laboratorio" incluso, como dicen en el fútbol) o espontánea: una ocurrencia. Puede ser un gambito, un enroque, una artimaña; pero también una floritura, un gesto, un divertimento: es un deporte plural 
que no tiene técnicas o estrategias específicas, pues aprovecha las de todos los deportes (Ramírez, 2011a, p. 335).

Según la RAE un juego es un ejercicio recreativo sometido a reglas, y en el cual se gana o se pierde. Sin embargo, no todos los juegos consisten en intentar ganarle a otros o por lo menos no es ese el propósito del jugador existencial en el juego re-creativo de vivir; simplemente jugar con ellos. Es juguetón, gozón: disfruta, degusta el vivir (Ramírez, 2011a, p. 321). "Le importa el espíritu deportivo, el juego limpio, la elegancia en las maniobras, más que la competencia y el afán de ganar. La alegría de jugar comanda todo el despliegue de su habilidad" (p. 335). La vida puede vivirse como un juego si se asume que en ella hay indeterminación y elección, cuando no se elige, no hay nada a qué jugar. Cuando de antemano se sabe cuál será el resultado de un juego, pierde sentido jugar. Un ejemplo paradigmático es el del jugador de ajedrez que cuando evalúa como inevitable el jaque mate que le proporcionará su adversario, declara: "Resigno" (p. 333). Por eso para el jugador existencial la incertidumbre es lo que vuelve interesante la vida; juega con el azar, no contra él: "lo inesperado es lo que da a la vida categoría de aventura, perderlo o ganarlo todo a la vuelta de una esquina sin uno saber siquiera para dónde iba, por eso no me he matado" (El dios fingido, Gonzalo Arango).

Como buen jugador tiene estrategias y jugadas. $\mathrm{Su}$ principal estrategia es la conciencia, la razón, pues es la forma como el Espíritu (Logos, tendencia creativa, articulante) se expresa en él. La reflexión es la estrategia específicamente humana de jugar el juego existencial. Por eso, como lo afirma Bleichmar en el epígrafe que de ella hemos retomado, el jugador existencial intenta conocer, reflexionando, las reglas del juego para trascenderlas cuando sea conveniente.

El jugador existencial asume que sus elecciones son determinantes (en todo el sentido de la palabra), aunque sea de manera parcial e incluso ínfima; no importa, porque al fin y al cabo es la única parte que depende de él. De allí que una de sus principales jugadas sea la acción local, propuesta por Foucault, que puede producir efectos insospechados. "Una letra diferente en el discurso, un signo de puntuación, un acento, un rasgo que modifique una letra o una palabra... y quizás la sentencia implacable del destino cambie de sentido" (Ramírez, 2011a, p. 320).

Para algunos elegir es perder, lamentan que siempre decidir, elegir, implique renunciar a lo no elegido. Y temen porque saben que toda decisión se convierte en una determinación que no están dispuestos a asumir. Pero se olvida incluso percibir es elegir; nuestros sentidos tamizan y criban los estímulos, seleccionando algunos. "Los caminos neuronales que son descartados, y los hábitos o costumbres que son rutinas cerebrales y conductuales, limitan las opciones, pero también facilitan las acciones y la ejecución de objetivos vitales. La cristalización de la estructura es inevitable y, hasta cierto punto, conveniente; lo que hay que mantener es la flexibilidad, la fluidez que permite algunos cambios, conservando lo fundamental de lo adquirido" (Ramírez, 
2012, sec. 254. Una crítica de Lacan a Jean Piaget, p. 389). El jugador existencial cuando elige no se queda lamentando los caminos no elegidos, sino que reconoce y busca las posibilidades que le ofrece el camino que eligió. Otros, como el neurótico obsesivo, quieren evitar a toda costa ser responsables de sus elecciones, de su destino, de sus problemas, por eso cuando captan la responsabilidad de decidir, vacilan, no quieren comprometerse. Y cuando captan el papel del azar se vuelven supersticiosos (Ramírez, 2012b, p. 396).

La posibilidad de buscar por uno mismo y mediante, sobre todo, los propios esfuerzos y decisiones la satisfacción de un anhelo personal entraña en sí misma riesgos de índole muy particular. No sólo exige un considerable grado de perseverancia y visión a largo plazo; también empuja una y otra vez a la persona a dejar escapar posibilidades de felicidad momentánea y a relegar impulsos inmediatos en favor de objetivos a largo plazo que prometen una satisfacción duradera. A veces es posible conciliar ambas cosas, a veces no. Uno puede arriesgarse. Una mayor libertad de elección lleva implícita un mayor riesgo. Puede ser que uno alcance lo objetivos de sus aspiraciones personales y encuentre en ellos la satisfacción que esperaba. Puede ser que los alcance a medias. (Elias, 1990b, p. 153).

Debido a la incertidumbre intrínseca a la vida, no hay reglas generales que nos prescriban cómo actuar en momentos en los que se presentan dudas existenciales, dilemas éticos, aporías. A cada quien le corresponde arriesgar, ensayar, apostar, elegir con base en lo que considera mejor; de ahí la importancia de la trans-formación subjetiva, la ascesis de la que habla Foucault, entendida como la transformación que el sujeto efectúa sobre su ser para acceder a la verdad (Foucault, 2006, pp. 15-38). El método analítico es la propuesta de Ramírez para lograr esa transformación subjetiva. Método no sólo se entiende como procedimiento o serie ordenada de pasos, método es también camino y actitud, una manera de proceder que se vuelve un modo de ser, un estilo de vida cuando se incorpora (Lopera et al., 2017, p. 60; Ramírez, 2011a). Por tanto, el método analítico es mucho más que un método de investigación, es un camino de evolución espiritual. Llevado a la propia existencia es una práctica de cuidado de sí, y cuidar de sí es, tal como lo recomendaba el Oráculo de Delfos, conocerse y ocuparse de sí mismo (Foucault, 2006, p. 15).

[E]n los griegos y los romanos - sobre todo en los griegos-, para conducirse bien, para practicar como es debido la libertad, era preciso ocuparse de sí, cuidar de sí, a la vez para conocerse - es el aspecto con el se está más familiarizado del gnóthi seautón- como para formarse, para superarse a sí mismo, para dominar en sí los apetitos que amenazan con arrastrarnos por la fuerza (Foucault, 2000, p. 261).

El jugador existencial sabe que para recorrer libremente un territorio es conveniente conocer detalladamente sus rincones, vericuetos y senderos, por eso empieza explorando su propia alma, donde hallará la versión personal de las sendas y lugares del universo (Ramírez, 2011a, p. 350). 
El método analítico consiste en analizar un discurso (las expresiones de una estructura subjetiva), descomponerlo en sus elementos constitutivos para comprenderlo y reelaborarlo, resignificarlo, hacer una nueva síntesis. Ramírez propone cinco pasos constitutivos del método analítico: entender, criticar, contrastar, incorporar y explicar. Cuando se analiza un discurso se realizan estos cinco procesos aunque no necesariamente en ese orden. Así destaca Juan Diego Lopera la importancia de analizar:

En muchas situaciones es extremadamente útil y valioso analizar previamente antes de actuar, considerar situaciones similares y ver la manera como hemos actuado en otros momentos, examinar los factores positivos y los negativos, analizar las posibles consecuencias de tomar una u otra decisión, acudir a la experiencia de otros. Nunca tendremos certeza, pero ese análisis previo nos permitirá saber cuáles de las opciones son más arriesgadas y cuáles menos, y qué tanto estamos dispuestos a apostar o a perder. Hay situaciones en las que tenemos un alto grado de probabilidad de que las cosas resultarán como las hemos planeado, aunque no dejemos de contar con el azar. Todo esto muestra la importancia de analizar antes (deliberar) de la acción y analizar después de conocer los efectos de la decisión tomada. Pero en el momento de la acción, ni analizar, ni dudar, ni vacilar. Seguir el espíritu, la disposición del alma (Lopera, 2016, p. 246).

Un efecto del análisis es el desprejuiciamiento de la intuición, fundamental para hacer elecciones acertadas, pues en muchas ocasiones nuestras elecciones son orientadas por lo que intuimos y estas opiniones que surgen en nosotros como por inspiración, espontáneamente, "como de la nada", son juicios que hacemos automáticamente sin saber explicar por qué, y en muchas ocasiones pueden ser estereotipos equivocados. La formación de la intuición, de la escucha, explicitar nuestra jerarquía de valores, conocer las determinaciones que hay en juego en una situación... todos estos aspectos permiten una aprehensión de la realidad cada vez más abierta, incluyente, comprensiva, se captan cada vez más variables para, finalmente, elegir, apostar.

La actitud analítica del jugador existencial favorece que se conduzca no sólo como un hombre libre (que elige), sino responsable, esto es que hace elecciones correspondientes a su ser.

Un hombre libre es el que no es amo ni esclavo (ni siquiera de sí mismo). No se deja arrastrar por las circunstancias, esto es, por las determinaciones, sino que intenta aprovechar al máximo las variables libres que hay en toda constelación etiológica. Si elegir es tomar (ir por) un camino entre varios posibles, y libertad es la capacidad (potencia) de elegir, el hombre libre no es el que habitualmente elige (pues todo ser lo hace constantemente) sino el que logra ejercer esa capacidad para crear nuevas condiciones, ir más allá de las determinaciones, ser creativo (no sólo con el pasado ni con el futuro, sino en el presente, hacia el porvenir) (Ramírez, 2011a, p. 350, el resaltado es nuestro).

Si queremos prever y preparar el porvenir hemos de calcular el influjo de cada fuerza, sobre todo de las más determinantes; eso definirá el grado de probabilidad de que algo ocurra, nuestro lugar en la situación y la potencia del esfuerzo (individual o 
grupal) que se requiere para que la trayectoria del destino se oriente según nuestros objetivos.

Además de la consciencia y el análisis, la carta secreta más poderosa del jugador existencial es invocar el destino, es decir, llamar, invitar o convocar a jugar al destino. Esta idea está inspirada en el experimento invocado, del que hablan Piaget y Fraisse (como se cita en Pasternac, 1979, p. 137), en el que no hay control de variables; lo único que se controla es la propia actitud como investigador y las condiciones de observación. En la experiencia invocada el sujeto no espera que las cosas simplemente ocurran, sino que se dispone, propicia y aprovecha la ocasión para que ocurra lo que desea (Ramírez, 2011a, p. 317). Como dice Chang Chao: plantar flores es una invitación para las mariposas, y hacer una antología de poesía invita a la crítica afirma Yungshing (Lin Yutang, 1961, p. 59). Se aceptan activa y conscientemente las reglas de juego y se está atento para escuchar los indicios de oportunidades favorables. “¿Qué es lo que está en juego en toda invocación? [...] hacer lo necesario para poner de su parte a los dioses de los otros" (Lacan, 1999, p. 156157). De este modo el jugador existencial convoca a la diosa Fortuna y se prepara para asir, aunque sea por los pelos, a su ayudante la Ocasión, que según Francisco de Quevedo es calva, escurridiza, arisca.

Es fundamental destacar que en su forma de vivir el jugador existencial privilegia el presente, no se queda anclado en el pasado ni vive ensoñando el futuro, pensando en todo lo que quizá nunca llegue a hacer. "Vive lo que hace, lo siente, lo degusta, lo disfruta. Es un presente que la vida le brinda y que él atiende en todos sus detalles, en una forma de contemplación activa" (Ramírez, 2011a, p. 328). Vivir el presente es concentrarse en lo que puede hacer ya, lo que tiene en las manos, lo que puede influir con su acción, sin que ello conduzca a un descuido del futuro, pues a veces lo que corresponde hacer en el presente es planear y trabajar para el futuro. "Si queremos cuidar del universo debemos empezar por nosotros mismos y nuestro entorno más cercano, que es nuestra responsabilidad inmediata. Por eso siempre hay que preferir lo que está ante nosotros, presentándosenos: el problema que aparece, la oportunidad que nos ocurre; esa es nuestra coyuntura clave, "nuestro centímetro cúbico de suerte", como decía el brujo Don Juan” (Ramírez, 2012, p. 334).

Se tiene en cuenta la prospectiva, pero sin desasosiego y, sobretodo, sin sacrificar las pequeñas satisfacciones de la vida cotidiana, el disfrute del ahora, por ideales porvenir. Esta forma de vida es también una propuesta política que invita a dialectizar los fines (futuros) y los medios (presentes), que invita a hacer proyectos políticos que tengan en cuenta la calidad de vida de sus ejecutores durante todo el proceso de ejecución, que sean proyectos que preserven el contento actual; que el trabajo por un ideal no signifique el sacrificio y la inmolación de quienes luchan por él. Hay un cuestionamiento a los proyectos políticos que han sacrificado el presente de generaciones enteras por ideales futuros como el reino de Dios, la sociedad sin clases, la fraternidad universal o el Tercer Reich; el bienestar y el disfrute solo está previsto 
para la utópica meta final (el cielo), mientras que el presente es siempre recorrer un valle de lágrimas (Ramírez, 2012, p. 333).

Este modo de vivir que hemos presentado se basa en el valor soberano para el jugador existencial, que es el que orienta sus acciones. "Para el jugador existencial transtópico existe un valor fundamental: la armonía cósmica, que produce la alegría, y que orienta sus actos dando dirección y sentido a su existencia" (Ramírez, 2011a, p. 320). La armonía cósmica procura que las distintas tendencias se manifiesten en la proporción adecuada, tanto las que son moralmente aceptadas, como las que son censuradas (la pulsión de apoderamiento, la agresividad, el sadismo, el masoquismo); no se trata de aniquilarlas sino de buscar su expresión acorde con el entorno. La armonía se manifiesta en el ser humano como alegría. El criterio para saber si se ha tomado la dirección adecuada no puede ser otro que la alegría, la armonía entre la razón y el saber (Lopera, 2016; Ramírez, 2011a, 2012b).

El equilibrio y optimización de las tendencias es el proceso mismo de la evolución, en principio realizado por tanteo, luego por ensayo y error y con el ser humano se vuelve un proceso consciente cuando a este se le agrega la simbolización. Es por ello que Ramírez afirma que con el hombre el cosmos llegó a ser consciente de sí mismo ${ }^{25}$ y ahora, por medio de esos seres conscientes el cosmos va asumiendo su propio destino y el rumbo que debe darle a sus fuerzas (Ramírez, 2012b, p. 43).

Muchos pensadores posmodernos y doctrinas orientales, como el taoísmo, rechazan la razón y la existencia de seres conscientes, unos por los efectos desastrosos que han derivado de la ciencia y la tecnología que ella genera, otros por las dificultades y el sufrimiento que entraña ser seres pensantes. Para Lacan, por ejemplo, el lenguaje llegó a ser la mayor desgracia del ser humano, porque en él radicaba también su angustia. Frente a esa posición "nihilista o derrotista de algunos intelectuales decadentes contemporáneos" (Ramírez, 2012b, p. 35), Ramírez defiende y reivindica el lugar de la consciencia, el lenguaje, la razón y la reflexión. El jugador existencial no asume ni la ingenuidad del optimista ni el fatalismo del pesimista:

Un pesimista es un optimista despechado. Es un extremista: antes consideraba al mundo óptimo; y como él sólo quiere lo máximo, lo mejor, cuando descubrió que en todo hay fallas, errores, se pasó al otro extremo: ahora cree que todo es pésimo, lo peor. Es además, un fatalista: da por supuesto que todo está predeterminado para que ocurra lo peor. No acepta el azar, que podría traer cosas buenas.

El jugador existencial es un realista científico que se esfuerza por establecer los criterios que permitan saber cuál proposición es más válida y más probable que otra, y basado en esos resultados elige lo que más se adecúa a sus objetivos vitales: la consistencia y la eficacia, por eso es científico, y realista porque "sabe que nada es

25 Con ese mismo sentido decimos que por medio de Neil Armstrong la humanidad llegó a la Luna, representada en un solo hombre. 
extremo: todo tiene ventajas y desventajas, es bueno en parte y malo también. Siempre se puede estar mejor o peor. Por eso aprovecha lo bueno y corrige o acepta lo malo. No solamente adhiere al proverbio "Del ahogado, el sombrero"; sino que añade: "Y del sombrero, la cinta" (Ramírez, 2012b, p. 76).

El jugador existencial no solo acepta, aprovecha que una parte del cosmos se ha hecho autoconsciente y puede establecer criterios para decidir qué se considera bueno y malo en función de los propósitos y los proyectos que se ha trazado. No teme ni lamenta ser responsable de su existencia, de su entorno, de la vida y del destino cósmico. La propuesta taoísta de dejarse llevar, no elegir, es renunciar a la responsabilidad, negar nuestra mente. Paradójicamente, es una no aceptación de nuestra naturaleza humana que también hace parte del tao. Para el jugador existencial no basta con permanecer y transcurrir, porque -como dicen los versos de Eladia Blázquez- no es lo mismo vivir que honrar la vida.

Vivir de este modo, haciendo continuas apuestas en medio de la incertidumbre, sin ninguna garantía de obtener los resultados esperados, requiere fe. No una fe dogmática y religiosa, sino una fe matemática porque se basa en probabilidades. La fe del jugador existencial se manifiesta cuando apuesta por un ideal, por un camino, por un proyecto, por un amigo, por un amor. Erich Fromm hace un bello comentario sobre la fe, diferenciando la fe racional de la irracional. La fe no es necesariamente una cuestión de creencia en Dios, o en doctrinas religiosas ni se opone a la razón y el pensamiento racional (Fromm, 1985). La fe irracional, religiosa o dogmática implica renunciar a las capacidades personales, al poder y la inteligencia propios, en una total sumisión a un poder que se considera omnisapiente y omnipotente. La fe racional, por el contrario, se produce como resultado de nuestras propias observaciones y nuestro pensamiento. La historia de la ciencia está llena de ejemplos de fe en la razón: "Copérnico, Kepler, Galileo y Newton estaban imbuidos de una inconmovible fe en la razón. Por ella Bruno murió quemado en la hoguera y Spinoza sufrió la excomunión" (Fromm, 1985). Antes de que se llegue a un consenso general sobre la validez de una teoría, el científico se basa en la fe, fe en la hipótesis como una proposición probable y plausible. Esa fe está arraigada en la propia experiencia, en la confianza en el propio poder de pensamiento, observación y juicio. Si la fe irracional es la aceptación de algo como verdadero sólo porque así lo afirma una autoridad o la mayoría, la fe racional tiene sus raíces en una convicción independiente, basada en el propio pensamiento y observación productivos, incluso en contra de la opinión de la mayoría. Pero no solo en el ámbito de la ciencia se manifiesta la fe racional, se puede tener fe en otra persona en sus potencialidades.

En la esfera de las relaciones humanas, la fe es una cualidad indispensable de cualquier amistad o amor significativos. «Tener fe» en otra persona significa estar seguro de la confianza e inmutabilidad de sus actitudes fundamentales, de la esencia de su personalidad, de su amor. No me refiero aquí a que una persona no pueda modificar sus opiniones, sino a que sus motivaciones básicas son siempre las mismas; que, por ejemplo, 
su respeto por la vida y la dignidad humanas sea parte de ella, no algo tornadizo (Fromm, 1985).

Las potencialidades biológicas como nacer o crecer se dan con tanta regularidad que pareciera que no se necesita fe para que se desplieguen, pero con las potencialidades que pueden no desarrollarse, como la capacidad de amar, de utilizar la razón, de aprender un arte, ocurre algo distinto, estas potencialidades se despliegan si se dan las condiciones apropiadas para su desarrollo y pueden truncarse cuando esas condiciones faltan. Parte de las condiciones que favorecen el despliegue del ser es que la persona de mayor influencia en la vida del niño tenga fe en sus potencialidades. "La presencia de dicha fe es lo que determina la diferencia entre educación y manipulación. Educación significa ayudar al niño a realizar sus potencialidades. (La raíz de la palabra educación es e-ducere, literalmente, conducir desde, o extraer algo que existía potencialmente). Lo contrario de la educación es la manipulación, que se basa en la ausencia de fe en el desarrollo de las potencialidades y en la convicción de que un niño será como corresponde sólo si los adultos le inculcan lo que es deseable y suprimen lo que parece indeseable. No hay necesidad de tener fe en el robot, puesto que tampoco hay vida en él" (Fromm, 1985).

Un planteamiento importante de Fromm es que logramos tener fe en las potencialidades de los demás, en las nuestras y en las de la humanidad, en la medida que hemos experimentado el desarrollo de nuestras propias potencialidades, la realidad del crecimiento en nosotros mismos y la fuerza de nuestro propia capacidad de amar. La fe en los demás culmina en la fe en la humanidad. Y completa concordancia con el realismo científico del jugador existencial afirma:

\begin{abstract}
$\mathrm{Al}$ igual que la fe en el niño, se basa en la idea de que las potencialidades del hombre son tales que, dadas las condiciones apropiadas, podrá construir un orden social gobernado por los principios de igualdad, justicia y amor. El hombre no ha logrado aún construir ese orden, $\mathrm{y}$, por lo tanto, la convicción de que puede hacerlo necesita fe. Pero como toda fe racional, tampoco esa es una mera expresión de deseos, sino que se basa en la evidencia de los logros del pasado de la raza humana y en la experiencia interior de cada individuo en su propia experiencia de la razón y el amor (Fromm, 1985).
\end{abstract}

El jugador existencial apuesta con toda su fe y su voluntad al progreso, a la armonización de las tendencias, a la evolución espiritual, al despliegue del ser, de la humanidad y del cosmos. Aunque no hay ninguna garantía de triunfo, de felicidad, de éxito, es este proyecto existencial el que ponemos en juego, "en comunidad, en compañía de otros que también le apuestan (aunque sea inconscientemente) a un nosotros, a una obra común" (Ramírez, 2011a, p. 324). El proyecto del jugador existencial no es personal, sino Nóstrico, común, cósmico, porque sabe que el progreso de otros y de su entorno es también el suyo; cuidar de sí, es cuidar de los otros, dice Foucault, "buscar el propio bien es buscar el del nosotros; porque para yo estar bien lo ha de estar mi entorno. Y si mi entorno sufre, eso repercute sobre mí, por 
más que yo me proteja bajo una corteza de egoísmo o de cinismo" (Ramírez, 2011a, p. 324).

"Aún no es demasiado tarde. - es la perspectiva de la ciencia que presenta Neil deGrass Tyson en la serie cosmos-. Hay un futuro por el que vale la pena luchar. ¿Cómo lo sé? Cada uno de nosotros proviene de una larga lista de supervivientes. Nuestra especie es sobretodo adaptativa. Fue solo porque nuestros ancestros aprendieron a pensar a largo plazo y a actuar de acuerdo a eso que estamos aquí. Hemos tenido la espalda contra la pared antes y logramos alcanzar alturas nuevas, de hecho, los más legendarios logros humanos surgieron de nuestra hora más oscura" (Hanich \& Holtzman, 2014). Y muestra cómo en el pasado, en ocasiones decisivas, la humanidad ha elegido preservar la vida, al no accionar ninguna de las 60 mil armas nucleares con las que contaban los países más poderosos de la tierra, y, en cambio, decidió usar los mismos recursos, la misma tecnología y la misma energía que puede destruir una ciudad, para realizar misiones espaciales y ampliar nuestro conocimiento sobre el espacio exterior. Una empresa de guerra y muerte se transformó en un proyecto científico. Quizá esta sea esta la expresión de los sistemas complejos, planteados por la termodinámica, pero a un nivel social: un sistema que evoluciona hacia puntos críticos y, al borde de la aniquilación, logra trascender a una nueva fase, hacia una nueva forma de organización, que como todas implicará nuevos problemas y nuevos retos; afrontarlos: en eso consiste vivir.

Ahora, el gran problema que afecta la humanidad es el acelerado calentamiento del planeta. Emitimos $\mathrm{CO2}$, que es el residuo de nuestra forma de vida urbana e industrializada, más rápido y en cantidades superiores a las que los pulmones de la tierra, los bosques, pueden absorberlo, esto generan una capa de gas alrededor del planeta que no deja salir la radiación, es lo que se conoce como efecto invernadero. Y esto genera un desequilibrio en el ecosistema que puede ser devastador para la vida de muchas especies en la tierra, incluida la nuestra. Los científicos advierten que cada vez nos acercamos más a un punto donde el daño puede ser irreversible.

Desde comienzos del siglo XX se ha venido desarrollando tecnología que provee energía limpia: solar, fábricas de viento, la fuerza del agua. Algún día en el mundo se agotará el carbón, pero el sol estará por muchos millones de años más para nosotros. En este caso la humanidad sería irresponsable si, ignorando todo este saber que abre la posibilidad de elegir otras alternativas, responde de manera primaria (con indiferencia), o incluso pasiva (dejándose llevar por la inercia). En esta decisión cada individuo tendrá grados de responsabilidad distintos, según su rol en el sistema, sus recursos y posibilidades de acción. No es igual la responsabilidad de un dirigente político, el presidente de una nación poderosa, por ejemplo, que la responsabilidad de una científica, la de un docente, la de un pequeño empresario o la de un campesino sin educación. Cada uno tiene recursos y posibilidades de acción distintas, pero posibilidades al fin y al cabo. En este ejemplo, el creer o no creer que tenemos la posibilidad de elegir el curso de la historia puede marcar la diferencia entre continuar 
existiendo o extinguirnos. Y cuando está en juego la vida, se ve claramente la aplicación del criterio pragmático: más allá de las razones, las evidencias y los debates, sencillamente es más fructífero creer que tenemos la posibilidad de elegir, creer que el curso de las cosas depende, en parte, de las decisiones que tomamos.

"No hay voluntad política" es una expresión que utilizamos en situaciones en las que todas las condiciones están dadas para que algo ocurra, para que se realice, están los recursos disponibles, todo en el entorno dispuesto, pero falta la voluntad, la decisión, el querer.

Hace alrededor de 10 mil años nuestros antepasados alrededor del mundo aprovecharon otro tipo de cambio climático. En el clima más templado del intermedio de la era del hielo, ellos inventaron la agricultura. Renunciaron a su deambular incesante, la caza y la recolección, que había sido su forma de vida durante un millón de años más o menos, para asentarse y producir alimentos. Encontraron la forma de aprovechar entre 10 y 100 veces más energía solar de la que el medio ambiente proveía naturalmente a sus ancestros. Personas de todo el mundo llevaron a cabo la difícil transición de una cultura nómada a una cultura agrícola, que usaba la energía solar más eficientemente. De aquí surgió la civilización. Estamos parados sobre los hombros de aquellos quienes hicieron el trabajo difícil que requería una transformación tan trascendental. Ahora es nuestro turno.

Una vez existió un mundo. Si alguna vez existió vida en Venus, no habría tenido oportunidad de evitar el destino infernal de este planeta. Este efecto invernadero galopante era imparable. Una vez existió un mundo, el nuestro, y ese mundo es ahora. No hay obstáculos científicos ni tecnológicos que nos impidan proteger nuestro mundo y la preciada vida que alberga, todo depende de lo que valoremos realmente y de si podemos reunir la voluntad para actuar (Hanich \& Holtzman, 2014, Temporada 1, Episodio 12: El mundo liberado).

El jugador existencial se asume parte de Dios, que para él no está personalizado, no es un ser omnipotente que tiene el control de todo; es el Nosotros, el Cosmos en evolución, el deseo y la voluntad colectiva; por eso no reza (dice) "hágase tu voluntad" sino "hágase nuestra voluntad", aceptando que tiene una responsabilidad espiritual por el destino común, que somos parte -a veces pequeña, pero siempre determinante - de ese Destino universal (Ramírez, 2012b, p. 253).

No te arredres. La ergástula es oscura,

La firme trama es de incesante hierro,

Pero en algún recodo de tu encierro

Puede haber una luz, una hendidura.

El camino es fatal como la flecha,

Pero en las grietas está Dios, que acecha.

(Borges, 1977, p. 7). 


\section{Consideraciones Finales}

A lo largo de este trabajo de investigación se transitaron todos los niveles de la realidad (físico, biológico, psíquico y social) indagando la incidencia del azar en cada uno de esos dominios.

En la ciencia moderna estaba prácticamente excluido el concepto de azar, pues la incontestable eficacia de la ciencia al formular leyes y predecir fenómenos enardeció el optimismo por el determinismo: que era posible llegar a conocer todas las causas, las determinaciones y predecir el curso de la naturaleza con la misma precisión que la astronomía predecía el movimiento de los astros. Se olvidaba que suponer que una causa conlleva unívocamente a un efecto era tan solo eso, un supuesto... muy fecundo por cierto.

Entre filósofos y teólogos el azar ha sido una cuestión debatida continuamente, pero fueron las teorías que se empezaron a plantear desde comienzos del siglo xx en el campo de la física cuántica, la termodinámica y la matemática las que renovaron el interés de los científicos por este concepto $y$, a diferencia de la ciencia moderna, con una aceptación cada vez más generalizada de que en el mundo no sólo hay azar, sino que existe y evoluciona gracias a él. Este creciente interés por el concepto de azar es también un efecto de la teoría de la evolución de Darwin, pues con el avance del siglo xx se empezaron a captar sus implicaciones, el antes y el después que marcaba en la cosmovisión de la ciencia.

El científico, nobel de química, Ilya Prigogine, fue uno de los primeros en dilucidar las consecuencias de la teoría evolucionista en el campo de la termodinámica. La evolución hizo evidentes dos procesos intrínsecos de la realidad: las fluctuaciones espontáneas o azarosas y su irreversibilidad. La combinación de estos dos elementos es lo que genera "una evolución que corresponde a una complejidad creciente y a la autoorganización" (Prigogine, 1993, p. 18). En la teoría de Darwin evolución y azar están estrechamente relacionados.

A la luz de estas nuevas teorías y modelos de la realidad se empezó a evidenciar lo estática y simplificada que es la visión moderna de la realidad, sin desconocer su importancia y eficacia. Con la visión moderna sólo se lograban enfocar los aspectos 
mecánicos y estáticos, pero no las características dinámicas y evolutivas de la realidad, ya no estática sino en proceso. Esto se hizo evidente incluso en la matemática por el trabajo de Benoît Mandelbrot: como la geometría euclidiana no logra dar cuenta de fenómenos irregulares (caóticos, aleatorios), por ejemplo las fluctuaciones económicas, la estructura de la costa de Gran Bretaña, las crecidas del Río Nilo, la evolución natural, fue preciso concebir la realidad desde nuevos modelos que contemplaran las características de estos fenómenos: que no se ubican en una dimensión entera, sino fraccionaria; son autosimilares (hay una repetición de patrones) y porosas, permeables.

A modo de síntesis podemos establecer un paralelo entre la visión moderna del mundo y la contemporánea. La visión clásica es lineal (una causa conduce unívocamente a un efecto) y, por ende, es determinista. En la visión contemporánea, dadas unas condiciones, se plantean diversas posibilidades de evolución de los sistemas; es, por tanto, probabilista. La ciencia moderna se ocupa de fenómenos estables (un sistema físico que cuando es perturbado responde reestableciendo su condición inicial). Los fenómenos de los que se ocupa la ciencia contemporánea son sistemas dinámicos, en evolución, es decir, que se transforman con el tiempo, lo que los hace altamente inestables, o sea, sensibles: modificaciones mínimas en las condiciones iniciales vuelve impredecible su evolución. En la descripción clásica de la naturaleza los procesos que implican azar o irreversibilidad eran considerados excepcionales, en cambio, hoy vemos por todas partes el papel de los procesos irreversibles y de las fluctuaciones. Los modelos de la física clásica se ajustan únicamente a situaciones límite $y$, además, aisladas, protegidas de las perturbaciones en condiciones experimentales, es decir, artificiales.

Lo artificial es determinista y reversible. Lo natural contiene elementos esenciales de azar e irreversibilidad. Esto llama a una nueva visión de la materia en la que ésta ya no sea pasiva como la descrita en el mundo del concepto mecánico, sino asociada a actividad espontánea. Este cambio es tan profundo que creo que podemos hablar con justicia de un nuevo diálogo del hombre con la naturaleza (Prigogine, 1993, p. 22).

Haciendo eco de estas transformaciones en la cosmovisión de la ciencia, Edgar Morin enuncia la emergencia de un nuevo paradigma, el de la complejidad. Estas teorías elaboradas en el campo de las ciencias naturales, también han tenido repercusiones en las ciencias sociales, tanto teóricas como prácticas. Teóricamente ha resultado fecundo pensar los problemas de investigación de las ciencias sociales con los modelos teóricos de los sistemas complejos. Distinto a lo que ocurrió en la modernidad, que en el intento de encajar en los modelos positivistas de la ciencia moderna, las ciencias sociales quisieron excluir de su campo de investigación aquellos aspectos de la realidad que, por su naturaleza compleja, no podían ser abordados experimental y matemáticamente. Lo que ocurre ahora es lo inverso, en lugar de empobrecer nuestras teorías, los modelos de la complejidad nos brindan herramientas para abordar y comprender el ser humano y sus relaciones sociales, políticas, económicas, culturales. 
Por eso no es extraño que esta indagación sobre el azar en las ciencias naturales, tenga también repercusiones prácticas y derive en una propuesta ética. Este es el recorrido que ha realizado Ramírez en su obra (teórica y existencial): desde lo físico y lo biológico se eleva a lo espiritual. Retomemos un bello pasaje donde Ilya Prigogine muestra esa repercusión de los planteamientos científicos en la ética:

En un universo en el que el mañana no está contenido en el hoy, el tiempo tiene que construirse. La frase de Valéry expresa nuestra responsabilidad en esta construcción del futuro, no solo de nuestro futuro, sino del futuro de la humanidad. Con esta conclusión, el problema de los valores humanos, de la ética, del arte incluso, cobra nueva dimensión. Podemos considerar la música, con sus elementos de expectación, con su flecha temporal, como una alegoría del devenir, de la física en su significado etimológico griego (Prigogine, 1993, secs. 37-38).

La ciencia mira el mundo con otros ojos, por eso es auténtico e incluso necesario hacer una mirada retrospectiva sobre el psicoanálisis y la psicología, para indagar las implicaciones que tiene concebir el azar en disciplinas que surgieron en medio de la visión moderna del mundo. Esto es evidente en Freud por las imágenes a las que recurre para describir lo psíquico: como "aparato" y sus "mecanismos". Al decir esto no estamos haciendo una crítica al proyecto freudiano; la fecundidad de este modelo para comprender el acontecer psíquico es indudable.

Sin embargo, a medida que avanza en sus investigaciones Freud se percata del papel tan importante que juega el azar, al punto de considerarlo uno de los factores determinantes de la neurosis y, más aún, de la estructura psíquica. Sin embargo, lo mostramos en esta investigación, es un azar filosófico, más precisamente aristotélico, entendido como contingencia, como accidente, que no riñe con el determinismo. Es distinto del azar que plantea la ciencia contemporánea, entendido como ausencia de determinaciones.

El gran descubrimiento de Freud consistió, justamente, en mostrar el poder determinante que tiene lo inconsciente sobre nuestra vida consciente, de hecho, lo que experimentamos como destino, dice Freud, es la expresión de las aspiraciones (deseo) inconscientes. No obstante, con frecuencia Freud expresa, en medio de las restrictivas determinaciones inconscientes, de la fuerza avasalladora de la pulsión y la repetición, su fe en Logos que abre la posibilidad de simbolizar, verbalizar, reelaborar, resignificar y reconducir el devenir. Podríamos decir, más precisamente, que lo inconsciente es para cada sujeto una parte de las condiciones en medio de las cuales debe efectuar sus elecciones, por eso las determinaciones inconscientes no hacen a ningún sujeto irresponsable. En ese sentido consideramos conclusiva la afirmación de Silvia Bleichmar: el hecho de que los elementos de base que componen lo inconsciente sean indestructibles no significa que sean inmodificables, y Ariel Viguera encuentra en los procesos histórico vivenciales esa posibilidad de transformar el modo como las representaciones se han articulado. Lo que coincide plenamente con la visión de 
Ramírez cuando afirma que no podemos olvidar que la Tyché también puede ocasionarnos accidentes y encuentros afortunados, no solamente traumáticos, a partir de los cuales podamos resignificar y ampliar nuestra comprensión de experiencias del pasado, o incluso trascenderlas.

Ramírez define lo psíquico (el alma) como cultura encarnada, es decir, como la incorporación de la cultura por un organismo humano. El alma no sería entonces una entidad metafísica, separada de la materia, sino que se concibe como una realidad que emerge en el proceso de crianza, educación, formación; cuando gradualmente la cría humana incorpora el lenguaje y con él la cultura. Y con base en la propuesta freudiana, Ramírez formaliza los ejes causales de lo psíquico, donde reúne las tres condiciones que inciden en la configuración psíquica: 1 . Lo biológico, que en su vertiente singular son las disposiciones genéticamente heredadas, el organismo, y en su vertiente colectiva es lo ecológico, el entorno físico que rodea al sujeto, el clima, la alimentación, el espacio geográfico. 2. Lo discursivo, que en su vertiente colectiva es la cultura, las normas, los valores, las costumbres del grupo social cercano al sujeto, quienes le transmiten el universo simbólico a partir del cual puede representarse y representar el mundo; en su vertiente singular es el discurso personal, los significantes que el sujeto retoma del universo simbólico ofrecido por quienes para él representan la cultura, es la forma singular de encarnar y expresar el discurso colectivo. 3. Lo contingente $\mathrm{u}$ ocasional, que en su vertiente colectiva son las circunstancias con las que se encuentra el sujeto y que escapan de su control, y en su vertiente singular son los accidentes, los encuentros inesperados que le acontecen. Podríamos decir que estos factores los concibe Freud en su obra. De hecho, el deseo en Freud es la confluencia de todos estos factores, dicho de otro modo, el deseo es la mezcla, siempre singular, de todos estos factores. Pero Ramírez agrega un factor que es transversal a todos los demás, la elección subjetiva que, como efecto del azar (lo indeterminado), puede realizar el sujeto. Es gracias al azar que el sujeto no está a merced de las determinaciones.

Ramírez recupera el concepto de alma y deliberadamente quiere enfatizar las resonancias espirituales - mas no religiosas - que tiene esta palabra, puesto que, así entendida, como la confluencia del lenguaje (Logos, Espíritu) y el organismo, es abordada por las diferentes escuelas psicológicas con dos propósitos distintos. Un propósito epistémico que consiste en abordar el alma con el fin de construir un conocimiento sistemático y en la medida de lo posible formalizado, objetivo, generalizable, al modo de leyes universales tal como procede la ciencia, construyendo teorías válidas sobre esa realidad que se investiga. Este es el propósito que privilegian escuelas como el conductismo, la neuropsicología y la psicología cognitiva de primera y segunda generación. Pero el alma también es posible abordarla con un propósito ascético, es decir, con el fin de llevar a cabo una transformación subjetiva, la búsqueda o, más precisamente, la construcción de una verdad sobre sí mismo que tiene efectos transformadores. Este es el propósito que privilegia el psicoanálisis, la psicología humanista y la transpersonal En Freud, sin embargo, estaban presentes estos dos 
propósitos, y a veces entraban en conflicto el propósito de conducir la cura y sus intereses como investigador. Y si bien es cierto que el psicoanálisis fue propuesto en principio como un procedimiento para el tratamiento de las neurosis, es decir, surge con un propósito ascético, también fue un interés de Freud formalizar hasta donde fuera posible los saberes que iban surgiendo de esa práctica clínica, es decir, construir una episteme (teorías sistemáticas y generales sobre el aparato psíquico, una metapsicología). En Freud puede reconocerse una dialéctica entre esos dos propósitos, un ir y venir del uno al otro.

Con esta definición de alma se trascienden las divisiones al interior de la psicología, pues las diferencias no radican en el objeto del cual se ocupan; todas se ocupan del alma, sino en el propósito con el que abordan dicho objeto. Este campo de estudio común permite emprender un diálogo fructífero entre las distintas escuelas y modelos teóricos, pues se reconoce que todos aportan un saber sobre el psiquismo humano.

La Tyché abre entonces un resquicio, una fisura, quizá apenas una grieta para las posibilidades de transformación contando con las determinaciones, incluso una tan fuerte como la del goce. Pero además las contingencias y los accidentes, está la elección subjetiva como uno de los factores determinantes de lo psíquico y del destino. Desde esta matriz de ejes causales el análisis de un síntoma consistiría justamente en examinar todas las determinaciones en juego, todos los factores que han intervenido y su grado de incidencia, de tal modo que en ese entramado de determinaciones el sujeto pueda vislumbrar también el aspecto que, sin estar determinado, fue una elección subjetiva. Por pequeño sea, este aspecto es el que depende del sujeto, del que se puede hacer cargo, el que está en sus manos modificar y el que le devuelve el poder y la responsabilidad sobre su destino.

$\mathrm{Ni}$ el individuo ni la sociedad podrían funcionar sin hábitos y costumbres, ambos regulados por la mente inconsciente. Nuestro objetivo no es vencer al inconsciente sino crear una nueva armonía entre su modo automático de actuar y la actuación innovadora de la mente consciente, a fin de que podamos ser dueños de nuestro destino en lugar de esclavos del pasado (Markert, 1994).

La propuesta de los ejes causales de lo psíquico en Ramírez puede operar, al mismo tiempo, como una matriz de investigación (abordaje epistémico) y de intervención (abordaje ascético), permite un abordaje desde la ciencia y desde la hermenéutica. En esta matriz ya se ha basado el trabajo en organizaciones; cuando una organización solicita una consultoría, intentando solucionar un problema de gobernabilidad, de clima laboral, de productividad, el análisis se centra en dilucidar los factores que no se pueden modificar, que son determinaciones, y las variables libres, sobre las que hay libertad de elección y, por tanto, que se pueden modificar. Es en esas variables que se concentran todos los esfuerzos. Reconocer que sobre algunos aspectos de la vida nada podemos hacer, pero que hay otros que, al depender de nuestro esfuerzo, requieren toda nuestra atención, produce un efecto nada despreciable: el paso de la queja a la responsabilización. 
La propuesta ética del jugador existencial es un modo de vivir profundamente consciente del evolucionismo, pues al concebir esta perspectiva el ser humano puede dimensionar su lugar en el mundo como lugarteniente de Logos, como la vanguardia del cosmos que por medio de los seres conscientes puede decidir qué orientación darle a sus tendencias, un proceso que ya se efectuaba desde antes de la emergencia de seres conscientes, pero por tanteo.

El curso de la evolución ha favorecido la emergencia de seres con capacidad de agencia, con mayor grado de indeterminación $\mathrm{y}$, en esa medida, más flexibles. Esa indeterminación biológica puede representar incluso desventajas, un prolongado estado de vulnerabilidad y dependencia, pero está en las potencialidades humanas compensarlas con las posibilidades que surgen del lenguaje, el conocimiento y uno de sus derivados, la tecnología. Muchas de las tensiones o problemas que surgen en la interacción del individuo con el entorno, el ser humano los resuelve con la creación de tecnología. En un hombre primitivo que fabrica una herramienta, que afila una piedra, Luria ve a un ser que piensa, que planea, que anticipa y diseña estrategias.

En esa relación del ser humano con el entorno surge la conciencia, el conocimiento, la tecnología y la técnica. Aunque para nosotros es muy visible el abismo al que puede aprontarnos la tecnología, no dejemos de transitar sus otros caminos, no abismales, sino encumbrados. Ese lado es el que nos invita a recorrer Gilbert Simondon. La tecnicidad es la manera como el ser humano logra resolver una tensión con el mundo natural, por tanto, la tecnicidad comunica dos órdenes distintos, el del individuo y el del entorno. Por medio de la tecnicidad se humanizan fuerzas que antes estaban por fuera del alcance humano, por ejemplo, fuerzas que antes de ser humanizadas tenían, literalmente, una dimensión divina, mítica, sobrehumana: el rayo, el viento, el fuego y el agua, por medio del conocimiento y la tecnicidad toman una dimensión humana. Es eso lo que logra un pararrayos, un molino de viento, un encendedor. Hay entonces, para Simondon, una parte divina en la invención, cuando se logra el encuentro de lo sagrado y lo técnico.

Simondon confía en que la cultura técnica, la creación, en lugar de oponerse al proceso de individuación, lo promueva, es decir, favorezca el despliegue de las potencialidades humanas. La apuesta, en los términos del jugador existencial, es que la resolución de tensiones entre el individuo y el entorno conduzca a la armonía, es decir, a una correspondencia, a un despliegue proporcionado de ambos.

Y es aquí donde radica la pertinencia de una propuesta ética como la del jugador existencial, porque a ella subyace una propuesta de armonización de las tendencias cósmicas, ese es su propósito, y busca llevarlo a cabo por medio del método analítico como camino de evolución espiritual, que conduce a la armonía y la alegría cósmica. Una propuesta ética, un modo de vivir, un discurso, un método, una propuesta para 
resolver un problema político, social, histórico, es también una invención, una creación técnica, un descubrimiento.

Se puede pensar que esta es una confianza ingenua en el ser humano, aunque es más una esperanza razonable como dicen los matemáticos, es decir, una opción muy probable. Recordemos aquí la complejización en la frontera del caos: cuando los sistemas llegan a un punto de tensión crítico puede surgir una forma de trascender el conflicto, un nuevo recurso tecnológico para reestablecer el equilibrio.

Con su propuesta ética el jugador existencial quiere aprovechar la pluralidad de tendencias en el cosmos y su ductilidad para encausarlas en función de su proyecto existencial, que también tiene una dimensión política. El hecho de concebir un margen de indeterminación ya lo ubica en una dimensión no sólo ética sino política, desde la cual se puede transformar el ser, el entorno más inmediato (la familia, la comuna, el barrio) y los sistemas sociales. La propuesta del jugador existencial es potencialmente política; aunque no es esa la dimensión que más se enfatiza en este trabajo de investigación es una de las vías que se dejan señaladas para ser posteriormente transitadas.

Me disculpo por su extensión, pero quiero cerrar estas consideraciones con un fragmento literario, que deja abiertas las posibilidades:

Pero había un pasaje que me preocupó mucho. La versión del rey Jacobo dice así..., es cuando Jehová le pregunta a Caín por qué está irritado. Jehová dice: "Si obraras bien ino serías aceptado? Y si obraras mal, iestará el pecado a la puerta? Y él siente apego por ti, y tú le dominarás a él". Fue ese "tú le dominarás" lo que me sorprendió, porque parecía una promesa de que Caín podía dominar el pecado. [...] Luego cayó en mis manos un ejemplar de la edición popular americana de la Biblia. Entonces era muy reciente. Y era muy diferente en este pasaje. Decía: "Gobiérnale a él", lo cual es muy distinto. No es ya una promesa, sino una orden. Empecé a dar vuelta a esto, preguntándome cuál debería ser la palabra original. [...] Y he aqui el oro extraido como resultado de nuestras excavaciones: "tú podrás dominarlo". "Tú podrás dominar el pecado".

¿No comprende usted? -gritó-. La traducción popular americana ordena a los hombres triunfar sobre el pecado, y llamáis al pecado ignorancia. La versión del rey Jacobo contiene una promesa en "tú le dominarás a él", queriendo significar que los hombres triunfarán seguramente del pecado. Pero la palabra hebrea, es decir, timshel, o sea "tú podrás", permite escoger. Acaso sea la palabra más importante del mundo, pues da a entender que el camino está abierto y plantea este acuciante problema: si dice 'tú podrás", también es cierto que podría decir "tú no podrás". ¿No comprende usted?

En la actualidad, hay millones de seres en las sectas y las iglesias que sienten más la orden "gobiérnale a él", y ponen todo su peso en esta parte y en la obediencia a ella. Y hay otros 
millones que intuyen la predestinación del "tú lo dominarás". Nada de lo que pueden hacer puede impedir lo que será. Pero el "tú podrás" hace al hombre grande, esto lo pone al lado de los dioses, porque a pesar de su debilidad le queda la gran libertad de escoger. Puede escoger su camino, luchar para seguirlo y vencer.

Es muy fácil salir de la pereza y de la ociosidad y arrojarse en el regazo de la divinidad, diciendo: "No puedo evitarlo; el camino estaba predestinado". ¡Pero imaginad la gloria que representa la facultad de escoger! Gracias a ella un hombre es un hombre. Un gato no tiene la posibilidad de escoger, una abeja está obligada a hacer miel. Aqui no hay ninguna clase de piedad.

[...] "Tú podrás gobernar el pecado". Eso es. Ya no creo que todos los hombres sean aniquilados. Puedo nombrarle una docena de ellos que ya no existen, pero gracias a los cuales el mundo vive. Es tan cierto con el espíritu como con las batallas: sólo los vencedores son recordados. Es cierto que la mayor parte de los hombres son aniquilados, pero hay otros que, parecidos a columnas de fuego, guian a la humanidad aterrorizada a través de las tinieblas. "iTú podrás, tú podrás!” iQué gloria! Es cierto que somos débiles, dolientes y pendencieros, pero si sólo hubiésemos sido eso, hubiéramos desaparecido de la faz de la tierra hace milenios. Sólo quedarían algunas mandibulas fosilizadas, algunos dientes rotos entre las capas de caliza... Ésas serian las únicas señales que el hombre habría dejado como recuerdo de su paso por este mundo. ¡Pero la facultad de escoger, Lee, y la facultad de vencer! Yo jamás lo había entendido ni aceptado antes de ahora. (John Steinberg. Al este del Eden). 


\section{Referencias Bibliográficas}

Abbagnano, N. (1974). Diccionario de Filosofía (2a ed.). México: Fondo de Cultura Económica.

Adorno, T., Popper, K., Dahrendorf, R., Habermas, J., Albert, H., \& Pilot, H. (1973). La disputa del positivismo en la sociología alemana. Madrid: Ediciones Grijalbo.

Aguilera, A. (2003). La causalidad psíquica: una explicación psicoanalítica del acto criminal. Temas Socio-Jurídicos, 21(45), 99-113.

Agustí, J., Alberch, P., Goodwin, B., HUll, D., Margalef, R., McKinney, M., ... Wagensberg, J. (1998). El progreso ¿un concepto acabado o emergente? (Jordi Agustí y Jorge Wagensberg, Ed.). Barcelona: Tusquets Editores.

Andreas Salomé, L. (1984). Aprendiendo con Freud. Barcelona: Laertes S.A.

Aquino, T. de. (1977). Suma contra los gentiles. México: Porrúa.

Aristóteles. (1983). Acerca del alma. Madrid: Gredos.

Aristóteles. (1995). Física. (G. R. de Echandia, Ed.). Madrid: Editorial Gredos.

Balandier, G. (1998). El desorden: la teoría del caos y las ciencias sociales. Barcelona: Gedisa.

Barthelemy, M. (1974). La ideología del azar y de la necesidad. Barcelona: Barral Editores.

Bauman, Z. (1992). Libertad. Madrid: Alianza.

Bilbao, A. (2006). Lacan lector de Hume: "En torno al problema de la causalidad y la libertad en psicoanálisis". Philosophica (Valparaíso-Chile), 29, 125-159.

Blas Lahitte, H., Azcona, M., \& Ortiz Oria, V. (2013). La noción de causalidad en 
Sigmund Freud. Límite. Revista de Filosofía y Psicología, 8, 59-74.

Bleichmar, S. (1994). Repetición y temporalidad: una historia bifronte. En S. Bleichmar (Ed.), Temporalidad, determinación y azar. Lo reversible y lo irreversible1 (pp. 4575). Buenos Aires: Paidós.

Bleichmar, S. (2005). Del polimorfismo perverso al sujeto de la ética. Actualidad Psicológica, (335).

Bleichmar, S. (2011). La construcción del sujeto ético. Buenos Aires: Paidós.

Bleichmar, S., Bernardi, R., Ford, A., Hornstein, L., Kornblihtt, A., Naishtat, F., ... Ulloa, F. (1994). Temporalidad, determinación y azar. Lo reversible y lo irreversible. (S. Bleichmar, Ed.). Buenos Aires: Paidós.

Borges, J. L. (1977). Para una versión del “I King”. En R. Wilhem (Ed.), I Ching. El libro de las mutaciones. Barcelona: Edhasa.

Borges, J. L. (1983). Historia universal de la infamia. Barcelona: Alianza Editorial.

Bruckner, G. (2003). La miseria del mercado y la prosperidad. La religión y sus enemigos. Barcelona: Tusquets.

Bruner, J. (1998). Los fundamentos de las primeras acciones humanas: los inicios. Discurso emitido en el acto de su investidura como Doctor Honoris Causa por la Universidad de Girona. Infancia y aprendizaje, (82), 119-127.

Canguilhem, G. (1984). Lo normal y lo patológico. México: Siglo XXI.

Capra, F. (1992). El tao de la física (3a). Barcelona: Humánitas.

Capra, F. (1998). La trama de la vida. Barcelona: Anagrama.

Cox, B., \& Forshaw, J. (2015). El universo cuántico. Bogotá: Debate.

Damasio, A. (2001). El error de Descartes: la emoción, la razón y el cerebro humano. Barcelona: Editorial Crítica.

Damasio, A. (2010). Y el cerebro creó al hombre. Barcelona: Planeta.

Degrande, F. (2014). Azar y psicoanálisis: una interpretación del sueño en Nadie nada nunca de Juan José Saer. Revista Chilena de Literatura (Santiago de Chile), (87), 47-68. 
Dennett, D. (1995). La conciencia explicada. Barcelona: Paidós.

Dennett, D. (2005). Dulces sueños: Obstáculos filosóficos para una ciencia de la conciencia. Madrid: Katz Editores.

Duque Martínez, J. D., Lasso Toro, P., \& Orejuela Gómez, J. J. (2011). Fundamentos epistemológicos de las psicologías. Cali: Editorial Bonaventuriana.

Elias, N. (1990a). La sociedad de los individuos. Barcelona: Ediciones Península.

Elias, N. (1990b). Problemas de la autoconciencia y de la concepción del ser humano (1940-1950). Barcelona: Ediciones Península.

Ferrater Mora, J. (1965). Diccionario de Filosofía (5a ed.). Buenos Aires: Editorial Sudamericana.

Feyerabend, P. (1974). Contra el método. España: Orbis.

Foucault, M. (2000). La ética del cuidado de sí como práctica de la libertad. Nombres, Revista de filosofía, 10(15), 257-280.

Foucault, M. (2006). Hermeneutica del sujeto. México: Fondo de Cultura Económica.

Freud, S. (1892). Carta 125. Fragmentos de la correspondencia con Fliess (1950 [1892-99]). En Obras completas. Tomo I (p. 322). Buenos Aires: Amorrortu Editores.

Freud, S. (1894). Obsesiones y fobias. Su mecanismo psíquico y su etiología (1895 [1894]). En Obras completas. Tomo III (pp. 69-84). Buenos Aires: Amorrortu Editores.

Freud, S. (1895). Proyecto de psicología para neurólogos (1950 [1895]). En Obras completas. Tomo I (pp. 323-392). Buenos Aires: Amorrortu Editores.

Freud, S. (1896a). La etiología de la histeria (1896). En Obras completas. Tomo III (pp. 185-218). Buenos Aires: Amorrortu Editores.

Freud, S. (1896b). La herencia y la etiología de las neurosis (1896). En Obras completas. Tomo III (pp. 139-156). Buenos Aires: Amorrortu Editores.

Freud, S. (1901). Psicopatología de la vida cotidiana (1901). En Obras completas. Tomo VI. Buenos Aires: Amorrortu Editores.

Freud, S. (1910a). Puntualizaciones psicoanalíticas sobre un caso de paranoia 
(Dementia paranoides) descrito autobiográficamente (1911 [1910]). En Obras completas. Tomo XII (pp. 1-76). Buenos Aires: Amorrortu Editores.

Freud, S. (1910b). Un recuerdo infantil de Leonardo da Vinci (1910). En Obras completas. Tomo XI (pp. 54-127). Buenos Aires: Amorrortu Editores.

Freud, S. (1912). Sobre la dinámica de la transferencia (1912). En Obras completas. Tomo XII (pp. 94-105). Buenos Aires: Amorrortu Editores.

Freud, S. (1913a). El motivo de la elección del cofre (1913). En Obras completas. Tomo XII. Buenos Aires: Amorrortu Editores.

Freud, S. (1913b). La predisposición a la neurosis obsesiva. Contribución al problema de la elección de neurosis (1913). En Obras completas. Tomo XII. Buenos Aires: Amorrortu Editores.

Freud, S. (1916a). 23 conferencia. Los caminos de la formación de síntoma (19161917). En Obras completas. Tomo XVI (pp. 326-343). Barcelona: Amorrortu Editores.

Freud, S. (1916b). Conferencias de introducción al psicoanálisis (1915-1916). En Obras completas. Tomo XV (p. 219). Buenos Aires: Amorrortu Editores.

Freud, S. (1920). Más allá del principio de placer (1920). En Obras completas. Tomo XVIII (pp. 1-62). Buenos Aires: Amorrortu Editores.

Freud, S. (1923a). Breve informe sobre el psicoanálisis (1924 [1923]). En Obras completas. Tomo XIX (pp. 199-221). Buenos Aires: Amorrortu Editores.

Freud, S. (1923b). Dos artículos de enciclopedia: «Psicoanálisis» y «Teoría de la libido» (1923 [1922]). En Obras completas. Tomo XVIII (pp. 228-354). Buenos Aires: Amorrortu Editores.

Freud, S. (1924a). El problema económico del masoquismo (1924). En Obras completas. Tomo XIX (pp. 161-176). Buenos Aires: Amorrortu Editores.

Freud, S. (1924b). Presentación autobiográfica (1925 [1924]). En Obras completas. Tomo XX (pp. 1-70). Buenos Aires: Amorrortu Editores.

Freud, S. (1927a). Dostoievski y el parricidio (1928 [1927]). En Obras completas. Tomo XXI (pp. 171-194). Buenos Aires: Amorrortu Editores.

Freud, S. (1927b). El porvenir de una ilusión (1927). En Obras completas. Tomo XXI (pp. 1-55). Buenos Aires: Amorrortu Editores. 
Freud, S. (1929). El malestar en la cultura (1930 [1929]). En Obras completas. Tomo XXI (pp. 57-140). Buenos Aires: Amorrortu Editores.

Freud, S. (1932). 32 conferencia. Angustia y vida pulsional (1933 [1932]). En Obras completas. Tomo XXII (pp. 75-103). Buenos Aires: Amorrortu Editores.

Fromm, E. (1985). El arte de amar. Bogotá: Círculo de lectores.

Gadenne, V. (2006). Filosofía de la psicología. Barcelona: Herder.

Galeano, M. E. (2011). Diseño de proyectos en la investigación cualitativa. Medellín: Fondo Editorial Universidad EAFIT.

Gell-Mann, M. (1995). El quark y el jaguar: aventuras en lo simple y lo complejo. Barcelona: Tusquets Editores.

Gibbons, M., Limoges, C., Nowotny, H., Schwartzman, S., Scott, P., \& Trow, M. (1997). La nueva producción del conocimiento: la dinámica de la ciencia y la investigación en las sociedades contemporaneas. Barcelona: Pomares Corredor.

Gil, L. M. (2015). El trabajo como entorno de individuación psíquica transindividual. Universidad EAFIT.

Gil, L. M., \& Manrique, H. (2013). Azar, libertad y responsabilidad: aportes para una práctica psicológica. Pensamiento Psicológico, 11(2), 2143-155.

Gloy, K. (1993). Imágen del mundo holístico-ecológico contra imagen del mundo mecanicista. Estudios de Filosofía (Medellín), (7), 89-107.

Grabmann, M. (1928). Filosofía medieval. Barcelona: Labor.

Guerrero, J. A. (2009). Determinismo versus libertad en Freud. Pensamiento: Revista de Investigación e Información Filosófica (Madrid), 65(243), 117-142.

Habermas, J. (1982). Conocimiento e interés. Madrid: Taurus.

Habermas, J. (1992). Ciencia y Técnica como ideología. Madrid: Tecnos.

Habermas, J. (2015). La lógica de las ciencias sociales (4ª). Madrid: Tecnos.

Hacking, I. (1995). La domesticación del azar. La erosión del determinismo y el nacimiento de las ciencias del caos. Barcelona: Gedisa. 
Hadot, P. (2010). No te olvides de vivir. Madrid: Ediciones Siruela.

Halbwachs, F. (1977). Reflexiones sobre la causalidad física. En Las teorías de la causalidad (pp. 25-45). Salamanca: Ediciones Sígueme.

Han, B.-C. (2012). La sociedad del cansancio. Barcelona: Herder.

Han, B.-C. (2014). Psicopolítica. Barcelona: Herder.

Hanich, L., \& Holtzman, S. (2014). Cosmos: A Spacetime Odyssey. Estados Unidos.

Hansberg, O., \& Platts, M. (Compiladores). (2002). Responsabilidad y libertad. México: Fondo de Cultura Económica.

Hanson, N.-R. (1997). Observación y explicación: guía de la filosofía de la ciencia. Patrones de descubrimiento. Investigación de las bases conceptuales de la ciencia. Madrid: Alianza.

Hawking, S. (2001). Historia del tiempo. Barcelona: Crítica.

Hofstadter, D. (1987). Gödel, Escher, Bach un eterno y grácil bucle. Barcelona: Tusquets Editores.

Hornstein, L. (1994). Determinismo, temporalidad y devenir. En S. Bleichmar (Ed.), Temporalidad, determinación y azar. Lo reversible y lo irreversible (pp. 97-124). Buenos Aires: Paidós.

Hoyos, C. (2000). Un modelo para investigación documental. Guía teórico-práctica sobre construcción de estados del arte. Medellín: Señal Editora.

Johnson, S. (2004). Sistemas emergentes: o qué tienen en común hormigas, neuronas, ciudades y software. México: Fondo de Cultura Económica.

Kimura, M. (1986). The neutral theory of molecular evolution. University of Cambridge.

Kuhn, T. (1982). La tensión esencial: estudios selectos sobre la tradición y el cambio en el ámbito de la ciencia. Y EL CAMBIO EN EL AMBITO DE LA CIENCIA. México: Fondo de Cultura Económica.

Kuhn, T. (1992). La estructura de las revoluciones científicas. México: Fondo de Cultura Económica.

Lacan, J. (1959). El seminario de Jacques Lacan. Libro 6: El deseo y su interpretación. Buenos Aires: Paidós. 
Lacan, J. (1982). El seminario de Jacques Lacan. Libro 20: Aún. Buenos Aires: Paidós.

Lacan, J. (1987). Tyche y Automaton. En El seminario de Jacques Lacan. Libro 11: los cuatro conceptos fundamentales del psicoanálisis 1964 (pp. 61-72). Buenos Aires: Paidós.

Lacan, J. (1999). El seminario de Jacques Lacan. Libro 5: Las Formaciones del Inconsciente. Buenos Aires: Paidós.

Lacan, J. (2009). Escritos (3a ed.). México: Siglo XXI.

Landsberg, P., Ludwig, G., Thom, R., Schatzman, E., Margalef, R., \& Prigogine, I. (1986). Proceso al azar. (J. Wagensberg, Ed.). Barcelona: Tusquets Editores.

Laplace, P. S. De. (1985). Ensayo filosófico sobre las probabilidades. Madrid: Alianza.

Laplanche, J. (1987). Nuevos fundamentos para el psicoanálisis. La seducción originaria. Buenos Aires: Amorrortu Editores.

Llamazares, A. M. (2011). Del reloj a la flor de loto. Crisis contemporánea y cambio de paradigma. Buenos Aires: Editorial del nuevo extremo.

Llamazares, A. M. (2013). Los tiempos de crisis. Paradigmas en transición, ampliación de la consciencia y transformación personal.

Llinás, R. (2003). El cerebro y el mito del yo. Bogotá: Grupo Editorial Norma.

Lopera, J. D. (2006). Psicología ascética y psicología epistémica. Acta Colombiana De Psicologia, 9, 75-86.

Lopera, J. D. (2007). La consciencia: ¿una realidad no algorítmica? Acta Colombiana de Psicología, 10(2), 153-167.

Lopera, J. D. (2016). Sabiduría práctica y salud psíquica. Bogotá: San Pablo.

Lopera, J. D., Manrique, H., Zuluaga, M., \& Ortiz, J. (2010). El objeto de la psicología: el alma como cultura encarnada. Medellín: Editorial Universidad de Antioquia.

Lopera, J. D., Ramírez, C. A., Zuluaga, M., \& Ortiz, J. (2017). El método analítico (2a ed.). Medellín: San Pablo.

López, H. (2006). Cognitivismo y psicoanálisis. Ensayo sobre sus relaciones ocultas. Segunda parte. El debate en torno a la causalidad psíquica. Perspectivas en 
Psicología: Revista de Psicología y Ciencias Afines (Buenos Aires), 3(1), 11-19.

Lorenz, K. (1993). La ciencia natural del hombre. Barcelona: Tusquets.

Luria, A. (1982). Introducción evolucionista a la psicología. Barcelona: Fontanela.

Mandelbrot, B. (1996). Del azar benigno al azar salvaje. Investigación y ciencia, (243), $14-20$.

Manrique, H. (2008). Saber y conocimiento: una aproximación plural. Acta Colombiana de Psicología, 11(2), 89-100.

Manrique, H., \& De Castro, A. (2016). Realidad, teoría y conmensurabilidad: Reflexiones en torno a las modas intelectuales en psicología. Revista CES Psicología, 9, 65-88.

Manrique, H., Lopera, I. C., Pérez, J. D., Ramírez, V. E., \& Henao, C. M. (2016). Clínica analítica de las organizaciones. Bogotá: San Pablo.

Marco Aurelio. (2001). Meditaciones. Madrid: Gredos.

Markert, C. (1994). I Ching: la fórmula número uno para el éxito. Apóstrofe.

Martínez-Freire, P. (1995). La nueva filosofía de la mente. Barcelona: Gedisa.

Monod, J. (1993). El azar y la necesidad: ensayo sobre la filosofía natural de la biología moderna. Barcelona: Tusquets Editores.

Morin, E. (1984). Ciencia con consciencia. Barcelona: Anthropos Editorial.

Morin, E. (2005). Introducción al pensamiento complejo (3a). España: Gedisa.

Morizot, B. (2012). Le hasard contraint comme modalité de l'individuation. En J.-H. Barthelemy (Ed.), Cahiers Simondon 4 (pp. 9-32). Paris: Edition L'Harmattan.

Muñoz, J. M. (2012). Hacia una sistematización de la relación entre determinismo y libertad. Daímon: Revista de Filosofía (Murcia), (56), 5-19.

Pagels, H. (1991). Los sueños de la razón: el ordenador y los nuevos horizontes de las ciencias de la complejidad. Barcelona: Gedisa.

Pasternac, M. (1979). El método experimental y el método clínico en psicología. En Psicología: ideología y ciencia (6a ed.). México: Siglo XXI. 
Patarroyo Gutierrez, C. (2009). Libertad, determinismo y responsabilidad moral. Ideas y Valores (Bogotá), 58(141), 5-9.

Peirce, C. (1893). Réplica a los partidarios de la necesidad. En The monist, 3.

Penrose, R. (1999). Lo grande, lo pequeño y la mente humana. Madrid: Cambridge University.

Penrose, R. (2007). El camino a la realidad: una guía completa de las leyes del universo. México: Random House Mondadori.

Penrose, R. (2011). La nueva mente del emperador. Barcelona: Debolsillo.

Penrose, R. (2012). Las sombras de la mente: hacia una comprensión científica de la consciencia. Barcelona: Crítica.

Polanyi, M. (1962). Personal knowledge towards a post critical philosophy. Chicago: University of Chicago Press.

Polanyi, M. (1967). The tacit dimension. Garden City: Anchor Books.

Popper, K. (1972). Conjeturas y refutaciones: el desarrollo del conocimiento científico. Barcelona: Paidós.

Popper, K. (1973). La lógica de las ciencias sociales. En La disputa del positivismo en la sociología alemana. Barcelona: Ediciones Grijalbo.

Popper, K. (1974). Conocimiento objetivo: un enfoque evolucionista. Madrid: Tecnos.

Popper, K. (1985). El universo abierto: un argumento en favor del indeterminismo. Madrid: Tecnos.

Popper, K. (1997). El mito del marco común: en defensa de la ciencia y la racionalidad. Barcelona: Paidós.

Popper, K. (2003). La lógica de la investigación científica. Madrid: Tecnos.

Porras, M. A. (2007). Azar y destino en psicoanalisis. Documenta Laboris: Serie de Trabajos y Estudios de la Escuela de Graduados (Buenos Aires), (12), 237-246.

Prigogine, I. (1993). ¿Tan solo una ilusión? Una exploración del caos al orden (3a ed.). Barcelona: Tusquets Editores.

Prigogine, I., \& Stengers, I. (1990). La nueva alianza: metamorfosis de la ciencia. 
Madrid: Alianza Universidad.

Ramírez, C. A. (1985). El deseo en Freud. Suplemento Correo de los Carteles, (4).

Ramírez, C. A. (1991). El método científico en el psicoanálisis. Revista Universidad de Antioquia, 60(224), 35-41.

Ramírez, C. A. (1994). El psicoanálisis: una ética. Psiqué. Revista de Psicología. Departamento de Psicología de la Universidad de Antioquia, (5).

Ramírez, C. A. (1996). El espíritu científico. Memorias del Foro Relaciones entre el psicoanálisis y la ciencia.

Ramírez, C. A. (1999). Fabulaciones. Medellín: Policopiado por el Grupo de Investigación El método analítico y sus aplicaciones en las ciencias sociales y humanas.

Ramírez, C. A. (2007). Divagaciones. Medellín: Policopiado por el Grupo de Investigación El método analítico y sus aplicaciones en las ciencias sociales y humanas.

Ramírez, C. A. (2008). Transficciones. Medellín: Policopiado por el Grupo de Investigación El método analítico y sus aplicaciones en las ciencias sociales y humanas.

Ramírez, C. A. (2009). Cavilaciones. Medellín: Policopiado por el Grupo de Investigación El método analítico y sus aplicaciones en las ciencias sociales y humanas.

Ramírez, C. A. (2010). Ocurrencias. Medellín: Policopiado por el Grupo de Investigación El método analítico y sus aplicaciones en las ciencias sociales y humanas.

Ramírez, C. A. (2011a). Apuntes. Medellín: Policopiado por el Grupo de Investigación El método analítico.

Ramírez, C. A. (2011b). Fragmentos. Medellín: Policopiado por el Grupo de Investigación El método analítico y sus aplicaciones en las ciencias sociales y humanas.

Ramírez, C. A. (2012a). Errancias. Medellín: Policopiado por el Grupo de Investigación El método analítico y sus aplicaciones en las ciencias sociales y humanas.

Ramírez, C. A. (2012b). La vida como un juego existencial: Ensayitos. Medellín: Fondo 


\section{Editorial Universidad EAFIT.}

Ramírez, C. A. (2014). Escorsos. Medellín: Policopiado por el Grupo de Investigación El método analítico y sus aplicaciones en las ciencias sociales y humanas.

Ramírez, C. A., Lopera, J. D., Zuluaga, M., Ramírez, V. E., Henao, C. M., \& Carmona, D. M. (2014). Relaciones psicología-psicoanálisis (2a ed.). Bogotá: San Pablo.

Ramírez, C. A., \& Saavedra, C. (1981). El sentido de la vida. Una aproximación axiológica. Universidad de Antioquia.

Ramírez, C. A., \& Vargas, G. (comps). (2013). Ensayitos, en debate: alcances y límites del método analítico. Bogotá: Fondo Editorial Universidad Pedagógica Nacional.

Simondon, G. (2007). El modo de existencia de los objetos técnicos. Buenos Aires: Prometeo.

Simondon, G. (2009). La Individuación. A la luz de las nociones de forma y de información. Buenos Aires: La Cebra Ediciones y Editorial Cactus.

Simondon, G. (2012). Curso sobre la percepción. 1964-1965. Buenos Aires: Editorial Cactus.

Simondon, G. (2013). Imaginación e invención. Buenos Aires: Editorial Cactus.

Skinner, B. F. (1987). Más allá de la libertad y la dignidad: un profundo estudio del hombre y la sociedad. Barcelona: Salvat.

Solé, R. V., Bascompte, J., Delgado, J., Luque, B., \& Manrubia, S. C. (1996). Complejidad en la frontera del caos. Investigación y Ciencia, 14-21.

Todorov, T. (2009). Nosotros y los otros. México: Siglo XXI.

Tomasello, M. (1999). The cultural origins of human cognition. Cambridge: Harvard University Press.

Vargas, G. (1988). Algunas características epistemológicas de la investigación documental. Revista de ASCOLBI, 1(3).

Viguera, A. (2013). Justificación del concepto signos de percepción para una metapsicología de lo originario. Universidad Nacional de la Plata, La Plata.

Vygotsky, L. (1966). El desarrollo de los procesos psicológicos superiores. Barcelona: Crítica. 
Wagensberg, J. (1994). Ideas sobre la complejidad del mundo. Barcelona: Tusquets Editores.

Wagensberg, J. (2007). La rebelión de las formas: o cómo perseverar cuando la incertidumbre aprieta. Barcelona: Tusquets Editores.

Wells, B. (1973). Los niveles y las entidades integradas. En Lancelot Law Whyte; Albert G. Wilson; Donna Wilson (Ed.), Las estructuras jerárquicas. Madrid: Alianza Editorial.

Wilber, K. (2005). Sexo, ecología y espiritualidad: el alma de la evolución. Madrid: Gaia.

Wilhelm, R. (2008). I ching: el libro de las mutaciones. Barcelona: Edhasa.

Yutang, L. (1961). La importancia de comprender. Buenos Aires: Suramericana.

Zapata, L. (2010). Causalidad psíquica y lazo social contemporáneo. Revista de psicología: Universidad de Antioquia, 2(4), 77-86.

Zemelman, H. (2007). El ángel de la historia: determinación y autonomía de la condición humana. Barcelona: Anthropos Editorial.

Zizek, S. (2005). La suspensión política de la ética. Buenos Aires: Fondo de Cultura Económica.

Zuleta, E. (2004). Psicoanálisis y criminología (3a ed.). Medellín: Hombre nuevo.

Zuluaga, M. (2014). Identidad y devenir. Bogotá: San Pablo. 